\title{
Active Flow Control for Maximizing Performance of Spark Ignited Stratified Charge Engines
}

\author{
Final Report
}

\author{
Submitted to: \\ United States Department of Energy
}

By:

Andrew Fedewa. Tom Stuecken. Edward Tögm, Harold Schock, Tom Shih. Manooch Koochesfahani go of ofestoreton

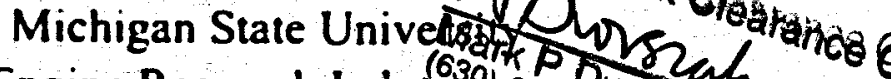
Engine Research Laborifo Pro

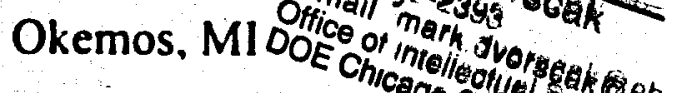

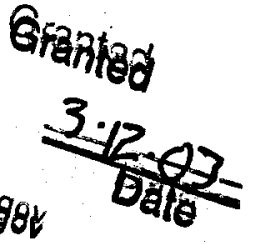

October 15, 2002 


\section{DISCLAIMER}

This report was prepared as an account of work sponsored by an agency of the United States Government. Neither the United States Government nor any agency thereof, nor any of their employees, makes any warranty, express or implied, or assumes any legal liability or responsibility for the accuracy, completeness, or usefulness of any information, apparatus, product, or process disclosed, or represents that its use would not infringe privately owned rights. Reference herein to any specific commercial product, process, or service by trade name, trademark, manufacturer, or otherwise does not necessarily constitute or imply its endorsement, recommendation, or favoring by the United States Government or any agency thereof. The views and opinions of authors expressed herein do not necessarily state or reflect those of the United States Government or any agency thereof. 


\section{DISCLAIMER}

Portions of this document may be illegible in electronic image products. Images are produced from the best avallable original document. 


\section{ABSTRACT \\ THE EFFECT OF ACTIVE FLOW CONTROL ON IN CYLINDER FLOW AND ENGINE PERFORMANCE}

Reducing the cycle-to-cycle variability present in stratified charge engines is an important step in the process of increasing their efficiency. As a result of this cycle-to-cycle variability, fuel injection systems are calibrated to inject more fuel than necessary, in an attempt to ensure the engine fires on every cycle. When the cycle-to-cycle variability is lowered, the variation of work per cycle is reduced and the lean operating limit decreases, resulting in increased fuel economy.

In this study an active flow control device is used to excite the intake flow of an engine at various frequencies. The goal of this excitation is to control the way in which vortices shed off of the intake valve, thus lowering the cycle-to-cycle variability in the flow field. This method of controlling flow is investigated through the use of three engines. First, a single cylinder optically accessible engine is used to measure the in cylinder flow field. Next, a single cylinder firing engine with identical geometry to the optical engine is used to measure how the flow field changes affect the engine performance. Finally, a four cylinder production engine is used to determine whether applying the flow control device improves the work output of a production engine.

The results of this study show that the active flow control device did help to lower the cycle-to-cycle variability of the in cylinder flow field; however, the reduction did not translate directly into improved engine performance. Exciting the intake flow of the optically accessible engine 
resulted in a reduction of velocity rms for many of the excitation frequencies with a maximum reduction of approximately $25 \%$. Applying the same active flow control to both the single cylinder firing engine and the four cylinder firing engine resulted in no measurable increase in work output and no reduction in the variability of the work output. 


\section{TABLE OF CONTENTS}

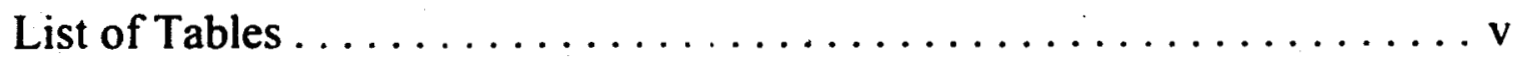

List of Figures $\ldots \ldots \ldots \ldots \ldots \ldots \ldots \ldots \ldots \ldots \ldots \ldots \ldots \ldots \ldots \ldots \ldots$

List of Symbols and Abbreviations $\ldots \ldots \ldots \ldots \ldots \ldots \ldots \ldots \ldots \ldots$

CHAPTER 1

INTRODUCTION $\ldots \ldots \ldots \ldots \ldots \ldots \ldots \ldots \ldots \ldots \ldots \ldots \ldots \ldots$

1.1 Motivation $\ldots \ldots \ldots \ldots \ldots \ldots \ldots \ldots \ldots \ldots \ldots \ldots \ldots$

1.2 Previous Work . .......................... 3

1.3 Introduction to Molecular Tagging Velocimetry ......... 4

\section{CHAPTER 2}

Experimental Equipment ......................... 7

2.1 Active flow control device $\ldots \ldots \ldots \ldots \ldots \ldots \ldots \ldots 7$

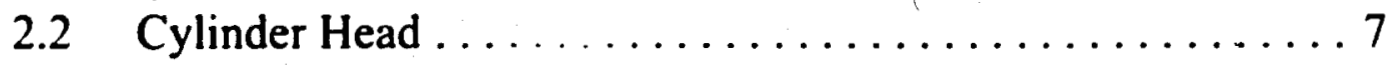

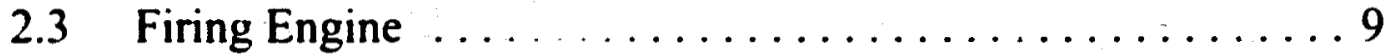

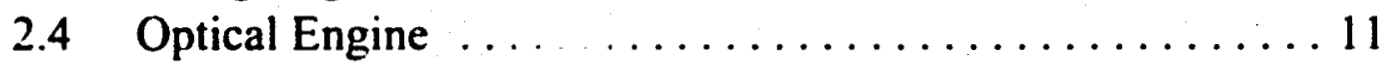

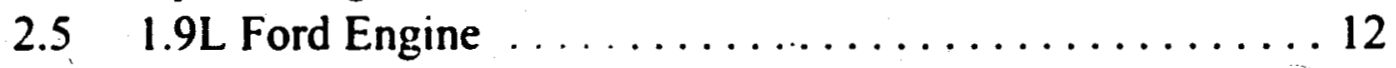

2.6 MTV Data Acquisition ..................... 13

2.7 Firing Engine Data Acquisition and Control . . . . . . . 15

2.7.1 Cosworth .......................... 15

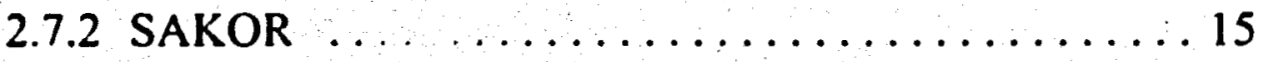

2.7 .3 RTCAM .......................... 16

2.7.4 ECM AFRecorder $\ldots \ldots \ldots \ldots \ldots \ldots \ldots \ldots$

\section{CHAPTER 3}

Experimental Procedure ............................ 17

3.1 Optical Engine Assembly . ................... 17

3.2 Molecular Tagging Velocimetry $\ldots \ldots \ldots \ldots \ldots \ldots \ldots 24$

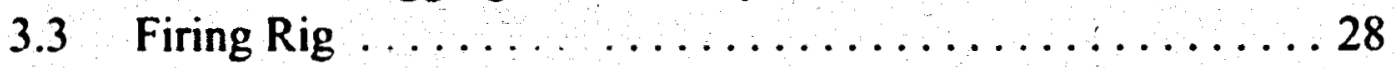

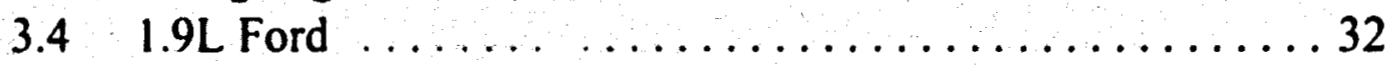




\section{CHAPTER 4}

Results and Discussion ....................... 34

4.1 . Molecular Tagging Velocimetry $\ldots \ldots \ldots \ldots \ldots \ldots \ldots$

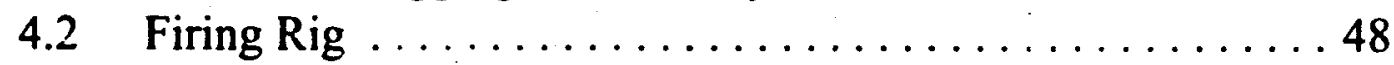

$4.3 \quad 1.9 \mathrm{~L}$ Ford $\ldots \ldots \ldots \ldots \ldots \ldots \ldots \ldots \ldots \ldots \ldots \ldots \ldots \ldots \ldots \ldots \ldots \ldots \ldots$.

\section{CHAPTER 5}

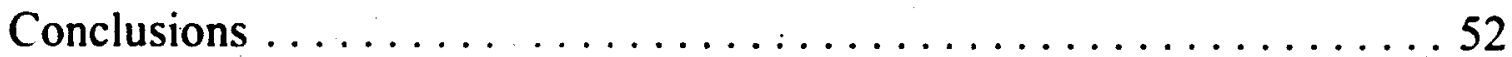

\section{CHAPTER 6}

Recommendations .......................... 54

\section{Appendices}

Appendix A

Average Flowfields for Various Crank Angles $\ldots \ldots \ldots \ldots . \ldots 56$

Appendix B

Disassembly of Firing Rig $\ldots \ldots \ldots \ldots \ldots \ldots \ldots$

Appendix C

Discussion of Indicated Mean Effective Pressure $\ldots \ldots \ldots \ldots 6$

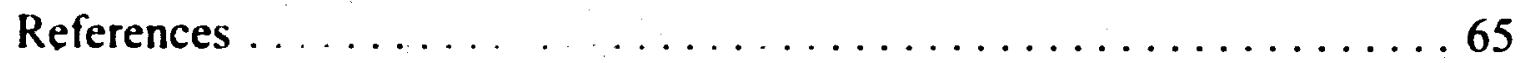




\section{List of Tables}

Table 1: Valvetrain specifications $\ldots \ldots \ldots \ldots \ldots \ldots \ldots \ldots$

Table 2: Single cylinder firing engine specifications. $\ldots \ldots \ldots \ldots \ldots 10$

Table 3: Single cylinder optical engine specifications. $\ldots \ldots \ldots \ldots 12$

Table 4: Ford Engine Specifications $\ldots \ldots \ldots \ldots \ldots \ldots \ldots \ldots \ldots$ 


\section{List of Figures}

Figure 1: Instantaneous flow fields at $270 \mathrm{CAD}$ for three consecutive cycles at 1500 RPM. Cylinder head located at $y=0$, cylinder walls

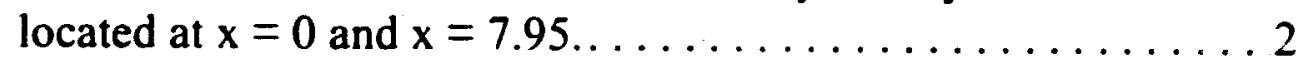

Figure 2: The natural flow (left) and excited flow (right) from a circular jet.

Figure 3: Undelayed Image of laser induced grid pattern. . . . . . . 5

Figure 4: Delayed image of phosphorescing grid pattern. $\ldots \ldots \ldots \ldots 6$

Figure $5:$ Speaker and amplifier. $\ldots \ldots \ldots \ldots \ldots \ldots \ldots \ldots$

Figure $6:$ Cylinder head and cam carrier. $\ldots \ldots \ldots \ldots \ldots \ldots$

Figure 7: Cylinder head and flat insert with centrally located spark plug hole. $\ldots \ldots \ldots \ldots \ldots \ldots \ldots \ldots \ldots \ldots \ldots$

Figure $8:$ Single cylinder firing engine. $\ldots \ldots \ldots \ldots \ldots \ldots \ldots \ldots$

Figure 9: Single cylinder optical test rig. $\ldots \ldots \ldots \ldots \ldots \ldots \ldots$

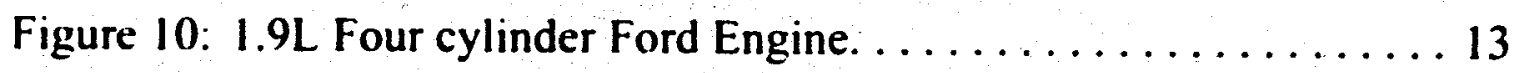

Figure 11: Xybion intensified CCD video camera and control box. . . 14

Figure 12: Data recording and control equipment, from left: data storage computer, volt meter (top), camera monitor, encoder box (top), camera controller (middle), delay generator (bottom) and computer monitor. ..................... 15

Figure 13: Lower End for Optical Engine with adaptor plates installed. . 17

Figure 14: Recıprocating engine parts $\ldots \ldots \ldots \ldots \ldots \ldots \ldots$ 
Figure 15: Schematic of counterbalancing shaft and bob weight. $\ldots \ldots 19$

Figure 16: Counterbalance shaft and bob weight on balancing stand. . . 20

Figure 17: Crankshaft with flywheelandbobweightattachedonbalancingstand.

Figure 18: Top half of optical engine. $\ldots \ldots \ldots \ldots \ldots \ldots \ldots \ldots 22$

Figure 19: Intake manifold (left) and exhaust manifold. $\ldots \ldots \ldots \ldots 23$

Figure 20: Closed loop nitrogen/biacetyl flow system. . . . . . . 24

Figure 21: Original laser beam configuration. $\ldots \ldots \ldots \ldots \ldots \ldots$

Figure 22: Modified laser beam configuration $\ldots \ldots \ldots \ldots \ldots \ldots \ldots$

Figure 23: IMEP for the Firing Engine at $1500 \mathrm{RPM}$ and 0 in. $\mathrm{Hg} . \quad \ldots .29$

Figure 24: IMEP for the Firing Engine at $1500 \mathrm{RPM}$ and $14.5 \mathrm{in} . \mathrm{Hg} \ldots 29$

Figure 25: Average IMEP for the Firing Engine At 1500 RPM and $14.5 \mathrm{in} . \mathrm{Hg}$

Figure 26: IMEP for the Firing Engine At $1500 \mathrm{RPM}$ and $14.5 \mathrm{in} . \mathrm{Hg}$, alternating between $1800 \mathrm{~Hz}$ excitation, and no force. . . . . 31

Figure 27: IMEP for 4000 cycles of the Firing Engine at 1500 RPM and 14.5

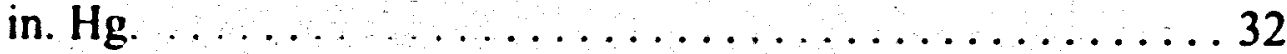

Figure 28: IMEP for 2000 Cycles of the 1.9L Ford Engine at 1500 RPM and

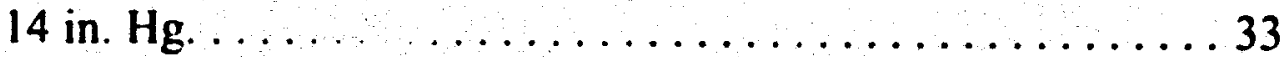

Figure 29: Average Velocity/u'/ ${ }^{\circ}$ Fields for the crank angle of 270 at 1500 RPM, 0 in. Hg and no excitation. (Day 1) .............. 36

Figure 30: Average Velocity/ $\mathbf{u}^{\prime} / \mathrm{v}^{\prime}$ Fields for the crank angle of 270 at 1500 RPM, $\mathrm{O}$ in. $\mathrm{Hg}$ and excited at $1500 \mathrm{~Hz} \ldots \ldots \ldots \ldots . \ldots 37$ 
Figure 31: Average Velocity/u'/v' Fields for the crank angle of 270 at 1500 $\mathrm{RPM}, 0$ in. $\mathrm{Hg}$ and excited at $1600 \mathrm{~Hz} . \ldots \ldots \ldots \ldots . \ldots 38$

Figure 32: Average Velocity/u'/v' Fields for the crank angle of 270 at 1500 $\mathrm{RPM}, 0$ in. $\mathrm{Hg}$ and excited at $1700 \mathrm{~Hz}$.

Figure 33: Average Velocity/u'/v' Fields for the crank angle of 270 at 1500 RPM, 0 in. $\mathrm{Hg}$ and excited at $1800 \mathrm{~Hz}$. (Day 2) ....... 40

Figure 34: Average Velocity/u'/v' Fields for the crank angle of 270 at 1500 $\mathrm{RPM}, 0$ in. $\mathrm{Hg}$ and excited at $1900 \mathrm{~Hz}$.

Figure 35: Average Velocity/u'/v' Fields for the crank angle of 270 at 1500 RPM, 0 in. $\mathrm{Hg}$ and excited at $2000 \mathrm{~Hz} . \ldots \ldots \ldots \ldots . \ldots 42$

Figure 36: Average Velocity/u'/ ${ }^{\prime}$ ' Fields for the crank angle of 270 at 1500 RPM, 0 in. $\mathrm{Hg}$ and excited at $2100 \mathrm{~Hz} . \ldots \ldots \ldots \ldots \ldots 43$

Figure 37: Average Velocity/u'/v' Fields for the crank angle of 270 at 1500 RPM, 0 in. $\mathrm{Hg}$ and excited at $2200 \mathrm{~Hz} . \ldots \ldots \ldots \ldots . \ldots 44$

Figure 38: Average Velocity $/ \mathrm{u}^{\circ} / \mathrm{v}^{\wedge}$ Fields for the crank angle of 270 at 1500 RPM, 0 in. $\mathrm{Hg}$ and excited at $2300 \mathrm{~Hz} . \ldots \ldots \ldots \ldots 45$

Figure 39: Average Velocity/u'/ $v^{\prime}$ Fields for the crank angle of 270 at 1500 RPM, 0 in. $\mathrm{Hg}$ and excited at $2400 \mathrm{~Hz} . \ldots \ldots \ldots \ldots . \ldots 46$

Figure 40: Average Velocity/u'/v' Fields for the crank angle of 270 at 1500 $\mathrm{RPM}, \mathrm{O}$ in. $\mathrm{Hg}$ and excited at $2500 \mathrm{~Hz} \ldots \ldots \ldots \ldots \ldots 47$

Figure 41: Average $u$ and $v$ RMS Velocities of Each Test Condition. . . 48

Figure 42: Average IMEP Calculated From Three Wavelengths of Cycles For the Firing Engine at 1500 RPM and 14 in. $\mathrm{Hg} . \ldots . \ldots . . .49$

Figure 43: Standard Deviation Calculated From Three Wavelengths of Cycles For the Firing Engine at $1500 \mathrm{RPM}$ and 14 in. $\mathrm{Hg} \ldots \ldots . .49$ 
Figure 44: Average IMEP for the 1.9L 4 Cylinder Ford Engine at 1500 RPM and 14 in. Hg. . . . . . . . . . . . 50

Figure 45: Standard Deviation of IMEP for the 1.9L 4 Cylinder Ford Engine at $1500 \mathrm{RPM}$ and $14 \mathrm{in.} \mathrm{Hg} . \ldots \ldots \ldots \ldots \ldots \ldots \ldots \ldots \ldots$

Figure 46: 2000 cycle Average IMEP for the 1.9L Ford Engine at 1500 RPM

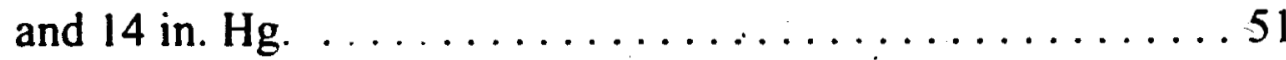

Figure 47: Average velocity field for the crank angle of 90 degrees, 1500

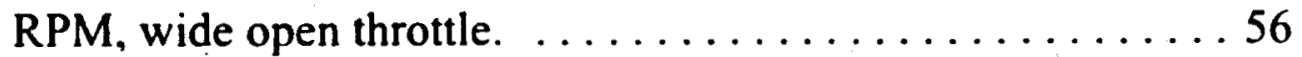

Figure 48: Average velocity field for the crank angle of 136 degrees, 1500 RPM, wide open throttle................ 56

Figure 49: Average velocity field for the crank angle of 180 degrees, 1500 RPM, wide open throttle ................ 57

Figure 50: Average velocity field for the crank angle of 226 degrees, 1500 RPM, wide open throttle ................. 57

Figure 51: Average velocity field for the crank angle of 270 degrees, 1500 RPM, wide open throttle ................ 58

Figure 52: Single cylinder firing rig with head removed after testing. $\ldots 60$

Figure 53: Cylinder head from single cylinder firing rig after testing. . . 60

Figure 54: Piston from single cylinder firing rig after testing. .......61

Figure 55: Typical Pressure vs. Volume diagram for a four cycle spark ignition engine. 


\section{List of Symbols and Abbreviations}

\begin{tabular}{ll} 
Symbol & Description \\
ATDC & After Top Dead Center \\
BBDC & Before Bottom Dead Center \\
BDC & Bottom Dead Center \\
BTDC & Before Top Dead Center \\
BWOD & Bob Weight Offset Distance \\
CAD & Crank Angle Degrees \\
DC & Direct Current \\
Hg & Mercury \\
Hz & Hertz \\
IMEP & Indicated Mean Effective Pressure \\
L & Lieter \\
MBWOD & Measured Bob Weight Offset Distance \\
MTV & Molecular Tagging Velocimetry \\
PMEP & Pumping Mean Effective Pressure \\
RMS & Root Mean Square \\
RPM & Revolutions Per Minute \\
TDC & Top Dead Center \\
UV & Ultra Vilot \\
cm & Centimeters \\
in & Inches \\
mm & Millimeters \\
$\lambda$ & Wavelength \\
\hline &
\end{tabular}




\section{CHAPTER 1}

\section{INTRODUCTION}

\subsection{Motivation}

The existence of cycle-to-cycle variations in automotive engines is a concern of engine designers. These variations result in a cyclic variation of the in cylinder air and fuel flows. Figure 1 gives an example of the pheasured differences in the flow field for three consecutive cycles. These variations compromise the tuned power output of engines operating at stoichiometric conditions and place an undesirably high lean limit on fuel-lean stratified charge engines. If this cycle-to-cycle variability could be reduced, the variation in the air/fuel ratio at the location of the spark plug could be decreased resulting in more consistent initial conditions for the combustion process. With such control, the variation of work per engine cycle would be reduced and engines could be calibrated more accurately, thus lowering the lean operating limit. 


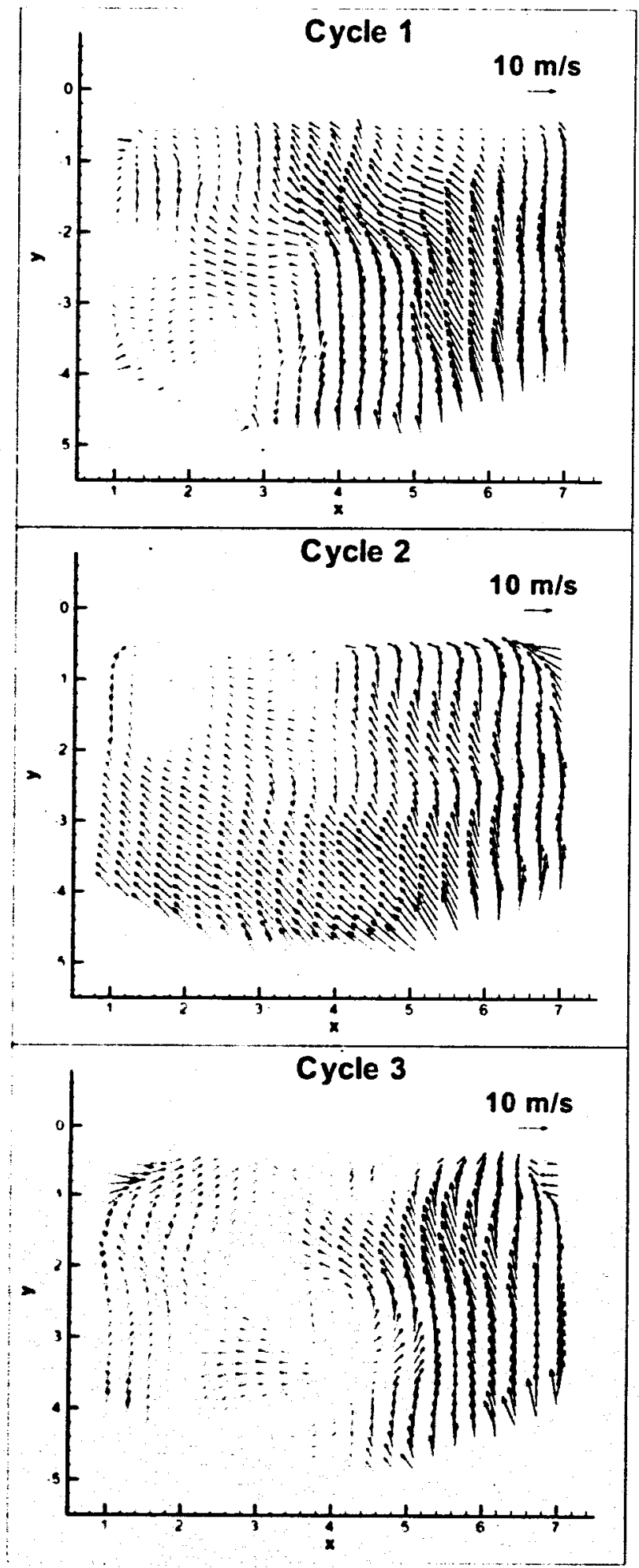

Figure 1: Instantaneous flow fields at $270 \mathrm{CAD}$ for three consecutive cycles at 1500 RPM. Cylinder head located at $y=0$, cylinder walls located at $x=0$ and $x=7.95$. 


\subsection{Previous Work}

Before attempting to control the complicated flow inside an engine cylinder, an understanding of how to control the flow in more simple geometries must be reached. Several studies have been performed which show that the natural flow from round jets and two stream mixing layers can be altered by exciting the flow at the correct frequency[8][9][14]. Results from such a study by Koochesfahani and Stier [10] can be seen in Figure 2. This figure illustrated the way in which exciting the flow can alter the location of vortex roll-up as well as the size of the vortices. Modifying these properties of the vortices provides a means for controlling the amount of turbulence and mixing downstream of the jet. When applied to an engine, this provides a means for controlling the mixing of the fuel and air charge in the engine cylinder.
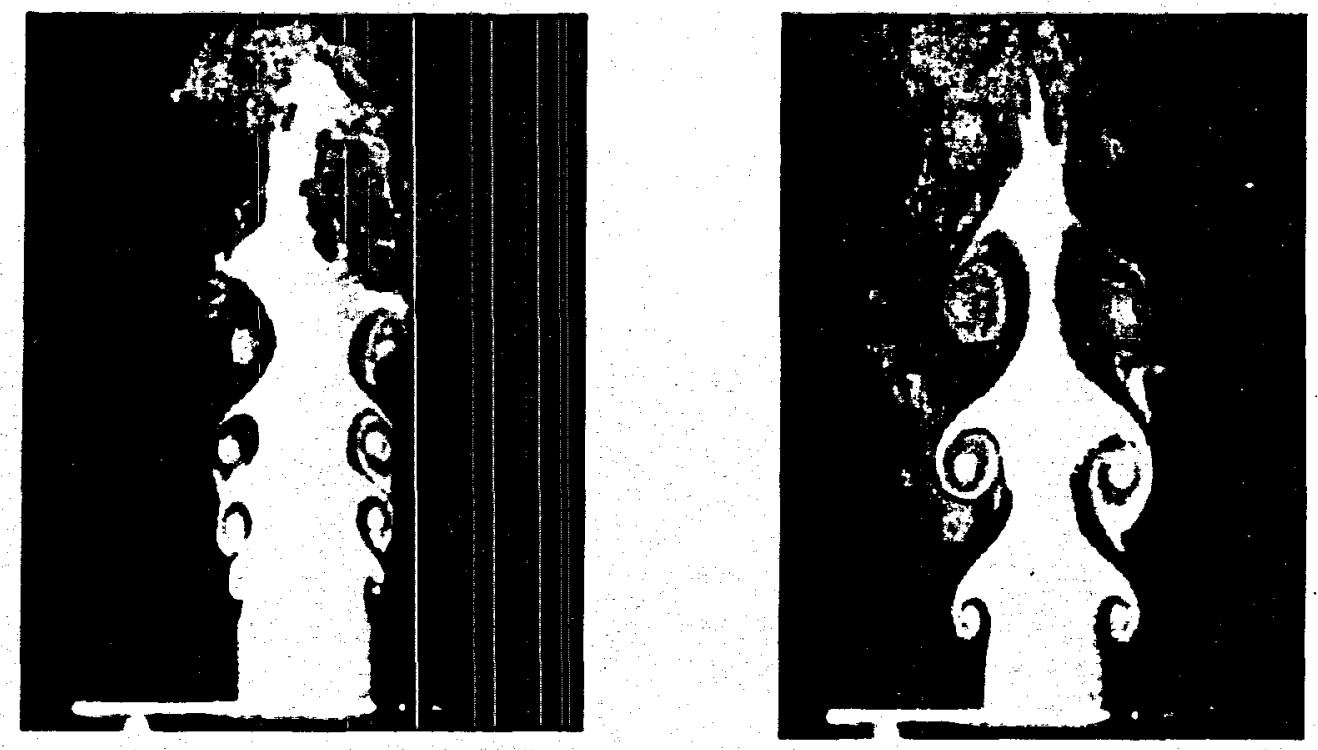

Figure 2: The natural flow (left) and excited flow (right) from a circular jet.

Studies have also been done on the effect of exciting the intake flow on an engine model by Ambrose [1.]. This study used a water analog model 
of an internal combustion engine, which limited the data to the intake stroke only, but promising results were obtained. Ambrose found that exciting the flow at certain frequencies resulted in significant changes in the large scale flow features, including a maximum increase in circulation of $40 \%$ and a maximum increase in kinetic energy of $30 \%$. These values suggest that the excitation could result in better mixing of the air/fuel charge in the cylinder. They do not, however, reveal the effect of the forcing on the flow patterns late in the compression stroke, which is of particular interest since that is when the onset of combustion occurs.

The effect of exciting the intake flow of an engine on the compression stroke was performed by Goh[6]. This work is of particular interest since the measurements were made in a gas phase flow as opposed to the prior work on the water flow model, allowing a view of late in the compression stroke. This study showed that at 270 CAD the velocity rms was reduced by $20 \%-30 \%$ at engine speeds of both 600 RPM and 1200 RPM when the correct excitation frequency was used. With such encouraging results, the next step is to determine how the reduction in velocity rms effects combustion in a running engine.

\subsection{Introduction to Molecular Tagging Velocimetry}

The in cylinder flow measurements for this study were performed using Molecular Tagging Velocimetry (MTV). MTV is a non-intrusive optical technique for measuring the flow in a plane. The tracer (in this case Biacetyl) is "tagged" by the pulse of a UV laser $(\lambda=308)$ by way of two sets of intersecting lines forming a grid and an image (see Figure 3 ) is taken of the fluorescing biacetyl with an intensified CCD camera. This is done several 
times and the images are averaged to obtain an undelayed image. To obtain the delayed images, the process is repeated, but this time the image is recorded after the laser pulse, but still within the phosphorescence lifetime of the molecules (see Figure 4). The time between images is known and the distance each line intersection has traveled can be measured giving a velocity vector for each intersection point. This type of measurement technique has been used successfully by many authors, including Stier and Koochesfahani [11][12], Hill and Klewicki [7], Gendrich and Koochesfahani [3], and Gendrich, Koochesfahani, and Nocera [4]. With this technique, many quantities including vorticity can be determined; however, for this study the quantity examined is the velocity field, and the rms of the velocity.

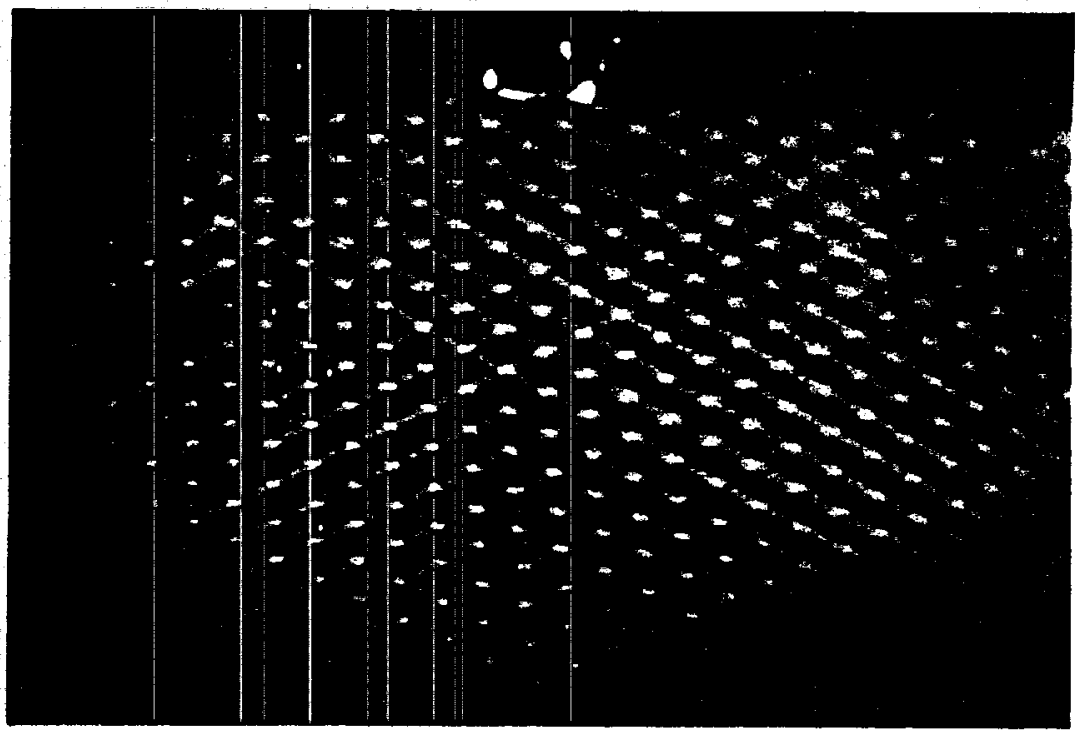

Figure 3: Undelayed Image of laser induced grid pattern. 


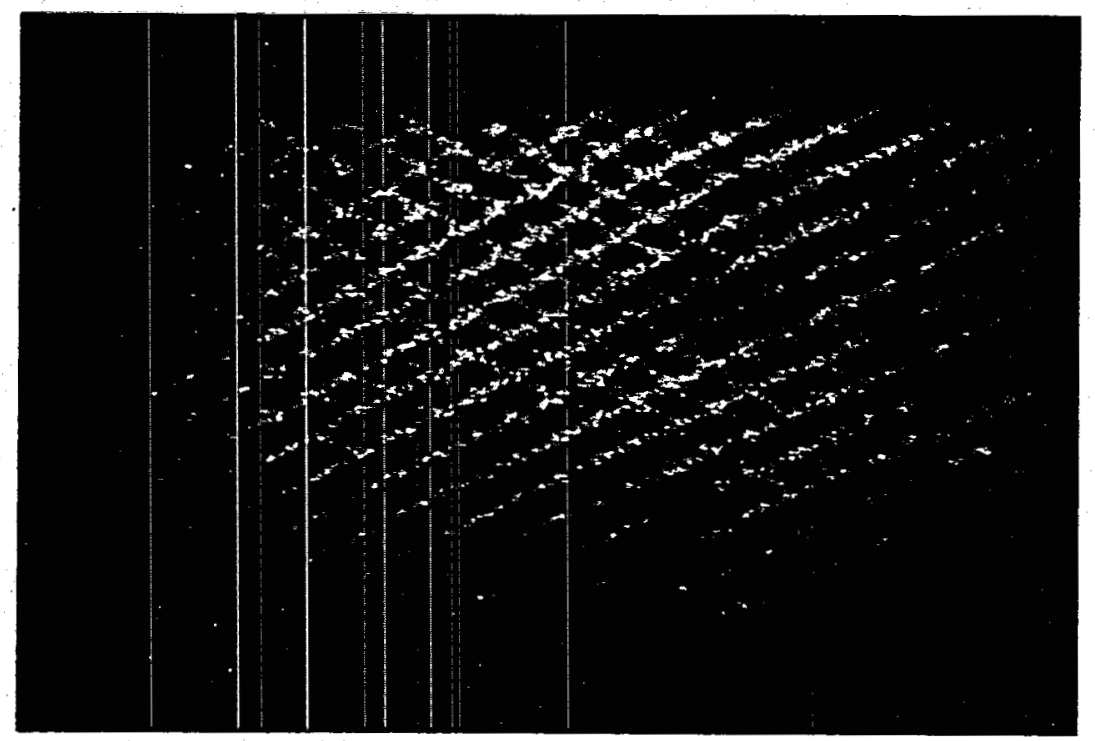

Figure 4: Delayed image of phosphorescing grid pattern. 


\section{CHAPTER 2}

\section{Experimental Equipment}

\subsection{Active flow control device}

For this experiment, the active flow control device used was a Speco model SRD-100 horn driver. It is a 16 ohm speaker rated at 100 Watts RMS, with a frequency response of $250-8,000 \mathrm{~Hz}$. This type of speaker was chosen over a standard audio speaker based on its robust design. The only modification made to the speaker was the addition of a $.040 "$ hole in the center of the diaphragm: this was done to allow the pressure behind the diaphragm to be equal to the manifold pressure, thus allowing the speaker to use its full range of motion even under, throttled conditions. To power the speaker, a Hafler model P1000 amplifier was used to amplify the sine wave produced by a Agilent model 33120A function generator.

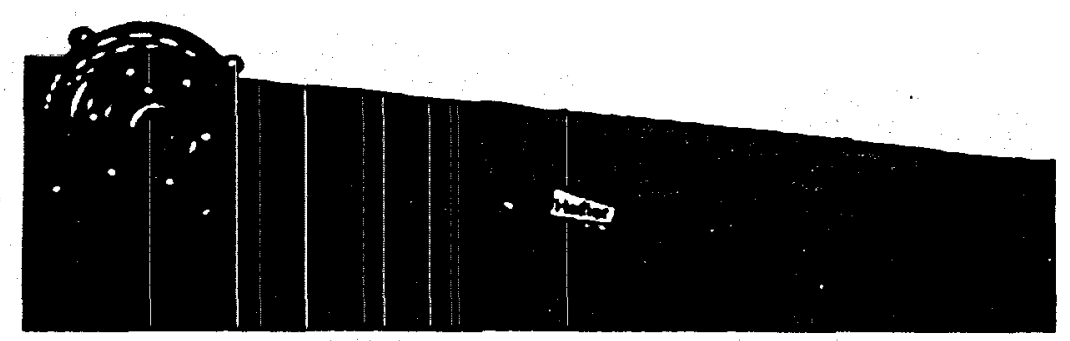

Figure 5: Speaker and amplifier.

\section{$2.2 \quad$ Cylinder Head}

In order to study the flow features as well as the engine's performance. both an optical engine and a firing engine were constructed using the same induction system and cylinder head design. The cylinder head was designed at Michigan State University, and includes a removable 
cam carrier and combustion chamber insert. The goal of this system is to enable the change of combustion chamber geometry and spark plug location without necessitating the construction of entirely new cylinder heads. The cam carrier houses dual overhead cams, which actuate the valves in the four valve head and the insert houses the spark plug and a thermocouple for monitoring head temperature. The specifics of the valvetrain can be found in Table 1. Detailed drawings of the head and cam carrier can be found in George [5].

Since the intent of this study is to determine the effect of the active flow control device and not the combustion chamber geometry, a cylinder head insert was designed to produce a combustion chamber with a flat top and a centrally located spark plug.

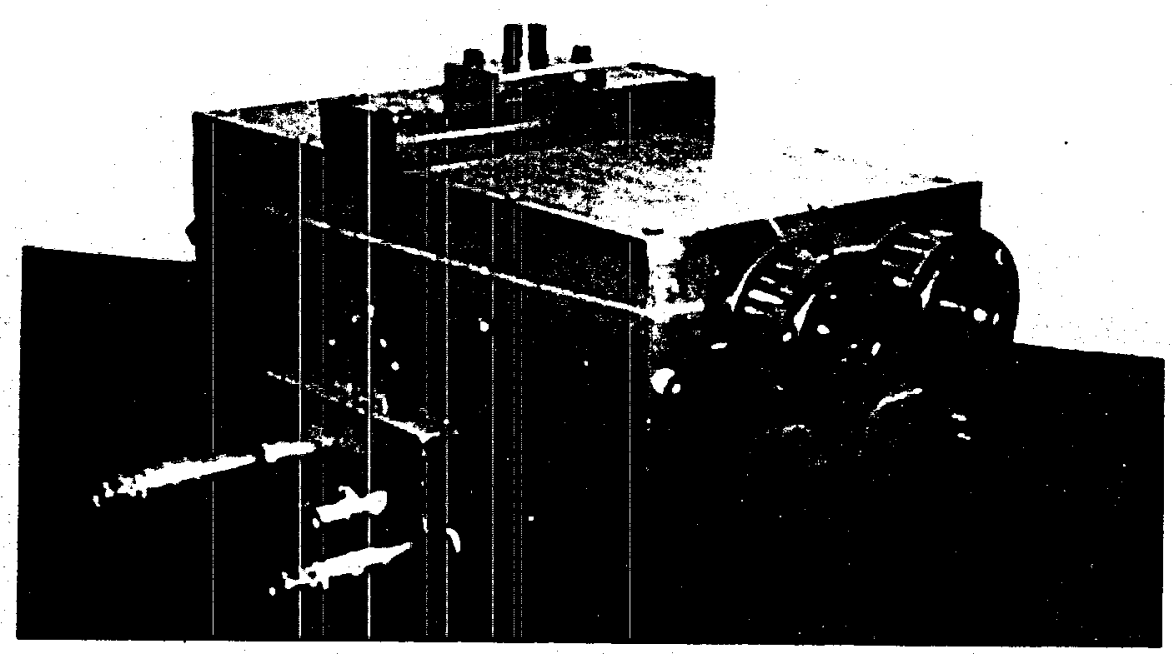

Figure 6: Cylinder head and cam carrier. 


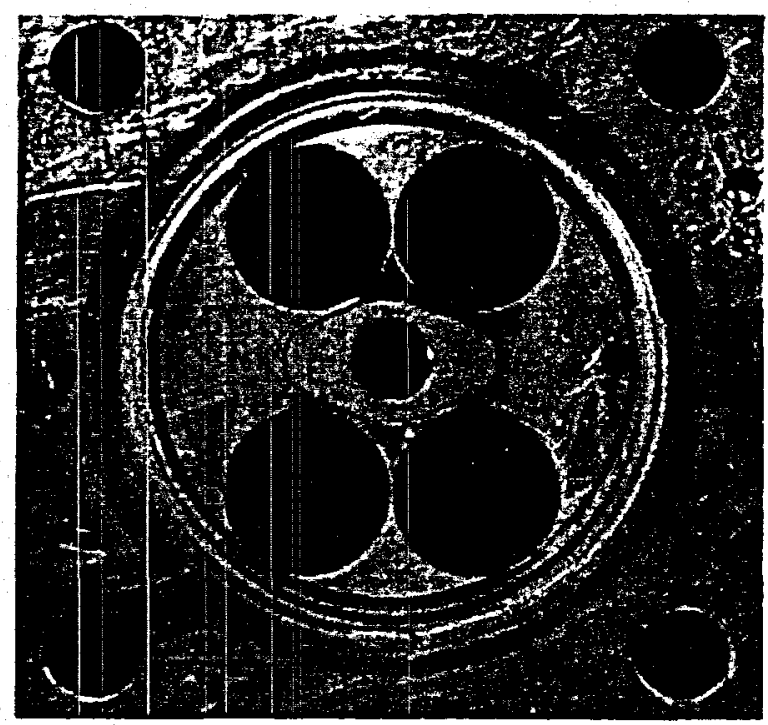

Figure 7: Cylinder head and flat insert with centrally located spark plug hole.

Table 1: Valvetrain specifications

\begin{tabular}{|c|c|c|}
\hline & Intake & Exhaust \\
\hline Open & 12 BTDC & 38 BBDC \\
\hline Close & 8 ATDC & ATDC \\
\hline Maximum Lift & $8.7 \mathrm{~mm}$ & $8.9 \mathrm{~mm}$ \\
\hline
\end{tabular}

\subsection{Firing Engine}

The base for the firing engine is a model 503 AVL research engine.

The single cylinder engine block uses a removable cylinder, which enables the compression ratio to be varied by changing the thickness of the spacer between the block and cylinder. Coupled to the AVL flywheel is a $200 \mathrm{hp}$ General Electric DC electric dynamometer. The function of the dynamometer is twofold; it first acts as a power source for motoring and starting the engine, and then as a brake for absorbing the power produced. Attached to the front of the crankshaft is a 360 pulse per revolution shaft 
angle encoder which is used for spark and fuel injector timing as well as data acquisition.

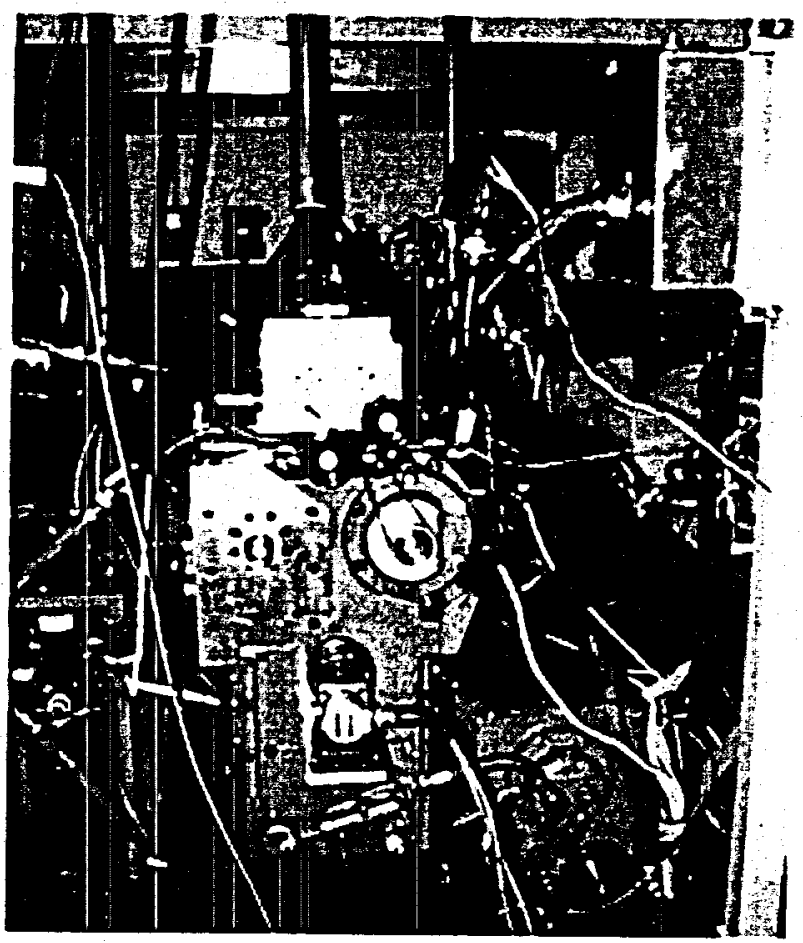

Figure 8: Single cylinder firing engine.

Table 2: Single cylinder firing engine specifications.

\begin{tabular}{|c|c|}
\hline Bore & $79.5 \mathrm{~mm}$ \\
\hline Stroke & $100 \mathrm{~mm}$ \\
\hline Displacement & $496 \mathrm{~cm}^{3}$ \\
\hline Compression Ratio & $9.0: 1$ \\
\hline Connecting Rod Length & $198 \mathrm{~mm}$ \\
\hline
\end{tabular}

The robust design of this engine block is not the only advantage to using it as the base for the firing test rig. It also has an externally accessible oil system enabling the head and cam carrier to be lubricated. Also, the AVL block incorporates an external drive pulley which runs at cam speed, providing a source for powering the dual overhead cams. 


\subsection{Optical Engine}

The base for the optical engine is a Hatz model $1 \mathrm{D} 81 \mathrm{Z}$ single cylinder diesel engine. This engine is chosen based on several of its features. It uses two counterbalancing shafts in conjunction with the crankshaft counterweight to produce a smooth operation. The crankshaft can be stroked and rebalanced allowing for different engine confrgurations to be used. Also, an adjustable oil pick up system allows the engine to be motored in either the clockwise or counterclockwise direction. Finally, the cylinder and head are separate, removable pieces.

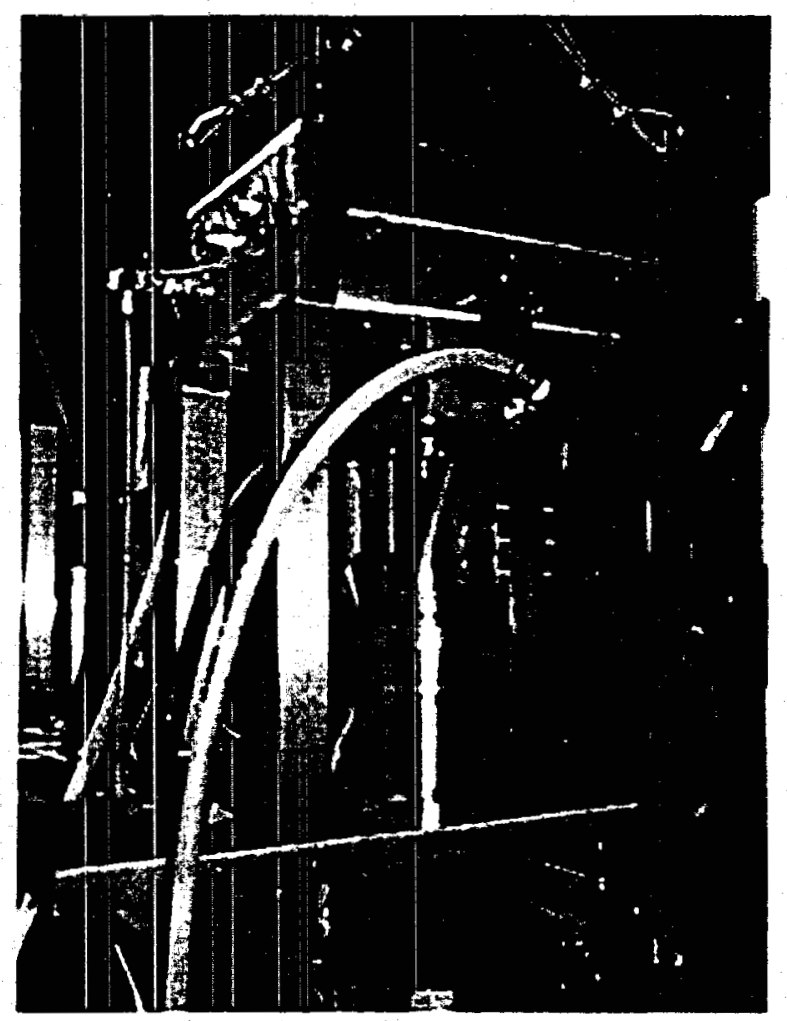

Figure 9: Single cylinder optical test rig. 
Table 3: Single cylinder optical engine specifications.

\begin{tabular}{|c|c|}
\hline Bore & $79.5 \mathrm{~mm}$ \\
\hline Stroke & $100 \mathrm{~mm}$ \\
\hline Displacement & $496 \mathrm{~cm}^{3}$ \\
\hline Compression Ratio & $9.0: 1$ \\
\hline Connecting Rod Length & $151 \mathrm{~mm}$ \\
\hline
\end{tabular}

\subsection{9L Ford Engine}

In addition to the two single cylinder engines, a 1.9L four cylinder Ford engine was also used, see Figure 10. This engine is a 1995 model year and was produced for use in the Ford Escort. Testing was done on this engine in an attempt to determine if any immediate improvements could be made by applying this type of active flow control to a production engine. The engine was coupled to the same dynomometer as the single cylinder firing engine and also used the same style shaft angle encoder. The only modifications made to the engine were the addition of the active flow control device to the number one cylinder runner on the intake manifold, and the insertion of a pressure transducer into cylinder number one. The specifications for this engine can be seen in Table 4. 


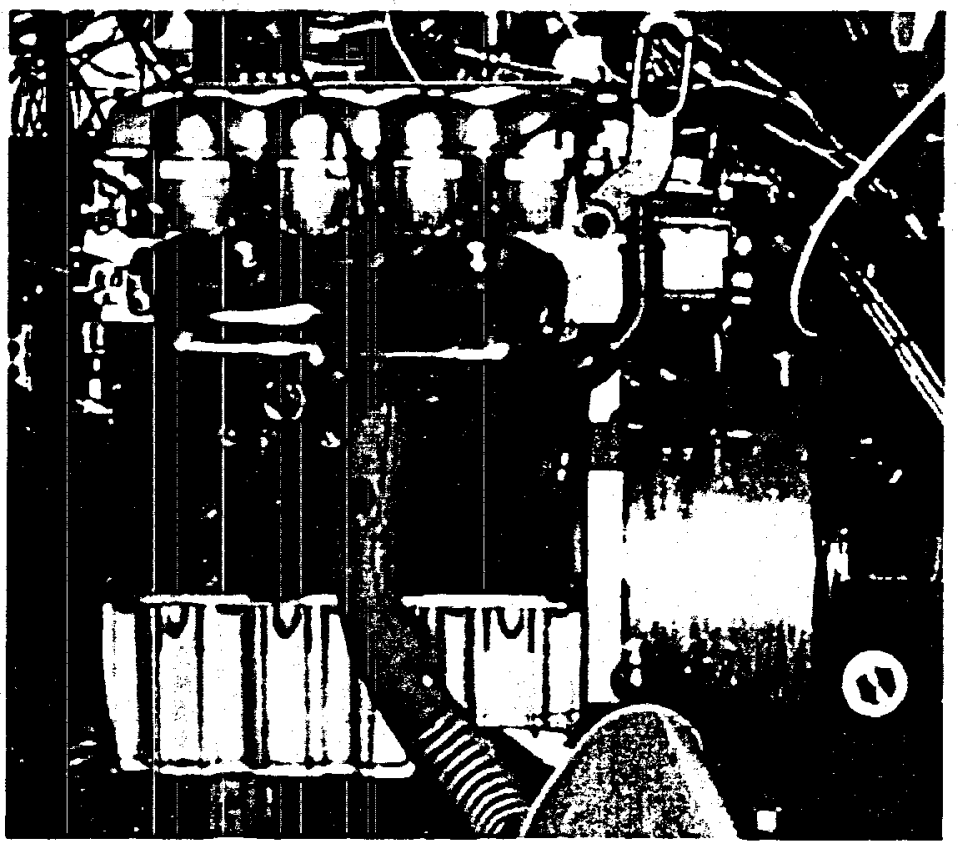

Figure 10: 1.9L Four cylinder Ford Engine.

Table 4: Ford Engine Specifications

\begin{tabular}{|c|c|}
\hline Bore & $82 \mathrm{~mm}$ \\
\hline Stroke & $88 \mathrm{~mm}$ \\
\hline Displacement & $1859 \mathrm{~cm}^{3}$ \\
\hline Compression Ratio & $9.1: 1$ \\
\hline Connecting Rod Length & $13.62 \mathrm{~mm}$ \\
\hline
\end{tabular}

\subsection{MTV Data Acquisition}

To record the images of the MTV grids, a Xybion model ISG-350 intensified CCD video camera. as seen in Figure 11 was used. "MTV", a program developed by Infinite Delta Corporation was used to store the images. Although MV-1000 software has been used successfully in the past 
for the recording of MTV grids, the software from Infinite Delta Corporation was used based on two distinct advantages. First, using "MTV" guarantees that an image will be stored for every consecutive engine cycle, whereas the MV-1000 software does not. Also, using "MTV" enables the entire frame to be stored. In contrast, the MV-1000 software only allows a field, or every other line of the frame, to be stored.

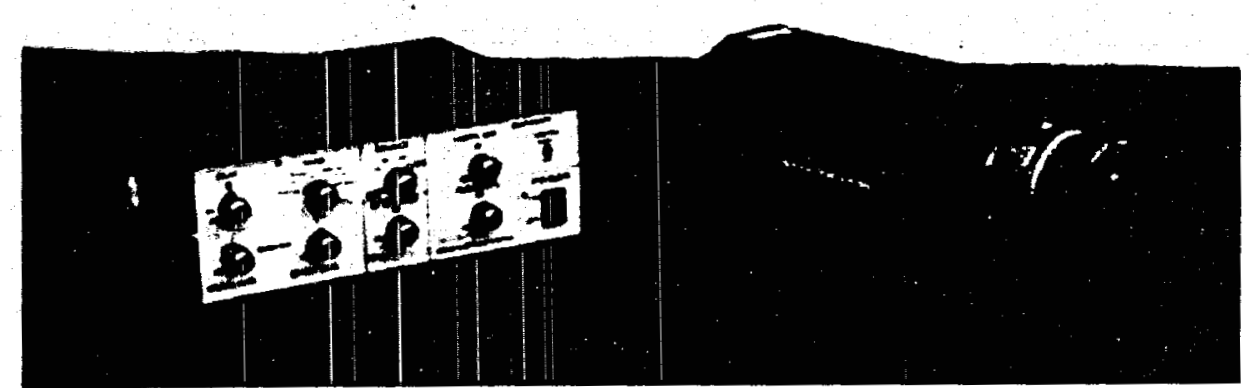

Figure 11: Xybion intensified CCD video camera and control box.

The equipment used to store the images and control the camera can be seen in Figure 12. An Agilent model 34401 A multimeter is used to monitor the camera gain, and act as a reference for image intensity. A JB-100 timing control box is used to control the crank angle at which the images are recorded, and a Stanford Research Systems model DG535 delay generator is responsible for controlling the camera gate, and the time delay between laser firing, and image recording. A Linux based Pentium II computer is used to store the images. 


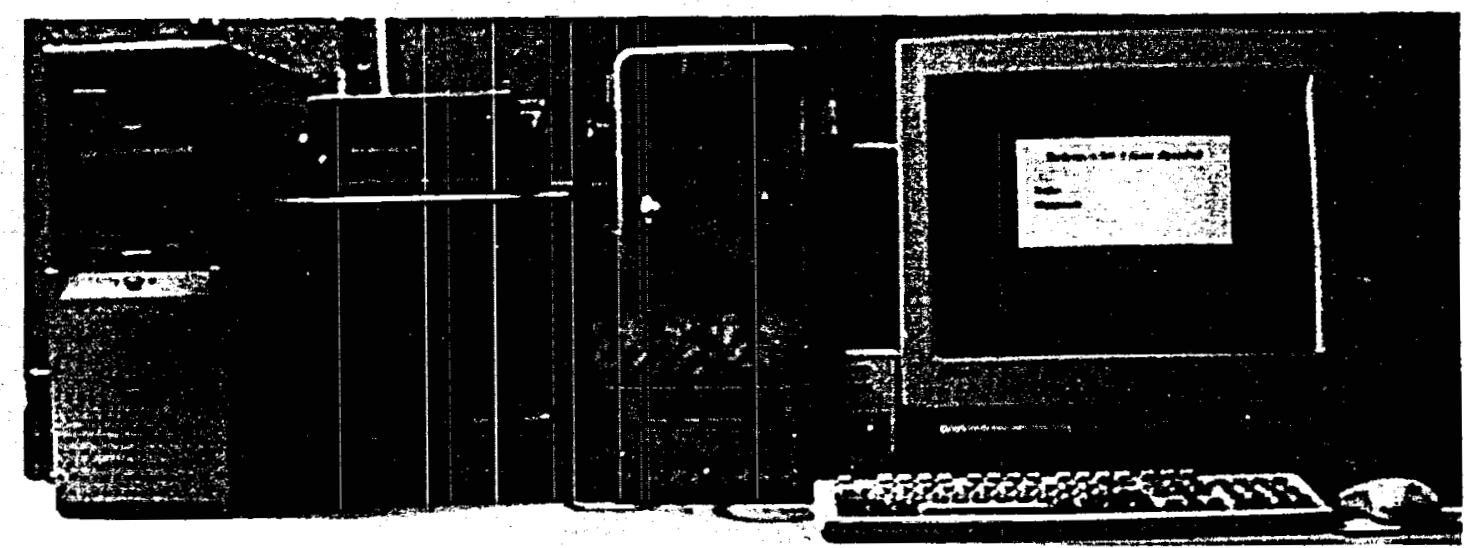

Figure 12: Data recording and control equipment, from left: data storage computer, volt meter (top), camera monitor, encoder box (top), camera controller (middle), delay generator (bottom) and computer monitor.

\subsection{Firing Engine Data Acquisition and Control}

In order to control the firing engines and $\log$ the desired performance data, four separate systems must be used.

\subsubsection{Cosworth}

There are two separate devices which make up the Cosworth control system, the IC 5460 and IC 5580 . The IC 5460 is a microprocessorbased engine control system. Based on the input from the optical shaft encoder, it controls the spark timing, as well as the timing and duration of the fuel injector. The spark signal from the IC 5460 is sent to the IC 5580, a distributorless ignition system, which provides the spark to the engine.

\subsubsection{SAKOR}

The SAKOR system has the capability to function as a data acquisition system, but is used in this test for engine control and monitoring. The primary use is for the control of the engine temperature of the single cylinder firing rig. Based on the input from a thermocouple, located in the 
cylinder head insert, the SAKOR system operates a pneumatic proportional control valve to maintain a constant cylinder head temperature. It also serves as a monitor for the head temperature, oil temperature, horsepower and torque for both the single cylinder firing rig and the 1.9L Ford engine.

\subsubsection{RTCAM}

Produced by Real Time Engineering, the Real Time Combustion Analysis Module (RTCAM) system was used for logging the cylinder. pressure data. RTCAM uses the input from the optical shaft encoder, as well as an Optrand model Q312940-Q optical pressure transducer, located in the cylinder head, to record the cylinder pressure value at each crank angle. This pressure versus crank angle data can be seen in real time as the engine is running. The software is also capable of calculating indicated mean effective pressure, which is the desired performance parameter for the test. This is not done in real time, but is instead calculated and stored by the software at the completion of each test.

\subsubsection{ECM AFRecorder}

The air/fuel ratio was monitored using the AFRecorder 2400G produced by ECM. This system uses a heated sensor to determine the amount of Carbon Monoxide, Hydrogen, and Oxygen present in the exhaust. From this information, the air/fuel ratio is calculated and reported as lambda, which is defined as the inverse of the equivalence ratio, or air/fuel ratio divided by the stoichiometric air/fuel ratio.

$$
\lambda=\frac{\left(\frac{A}{F}\right)}{\left(\frac{A}{F}\right) \text { Stoichiometric }}
$$




\section{CHAPTER 3}

\section{Experimental Procedure}

\subsection{Optical Engine Assembly}

The first step in modifying the Hatz engine was to create a flat surface on which to mount the head and quartz cylinder supports. An adaptor plate was constructed and attached to the front of engine, while a second adaptor plate was welded to the flywheel housing, see Figure 13. With the two adaptor plates attached, the engine block was fixtured in a mill and the plates machined to ensure a flat surface on which to mount the optical engine components.

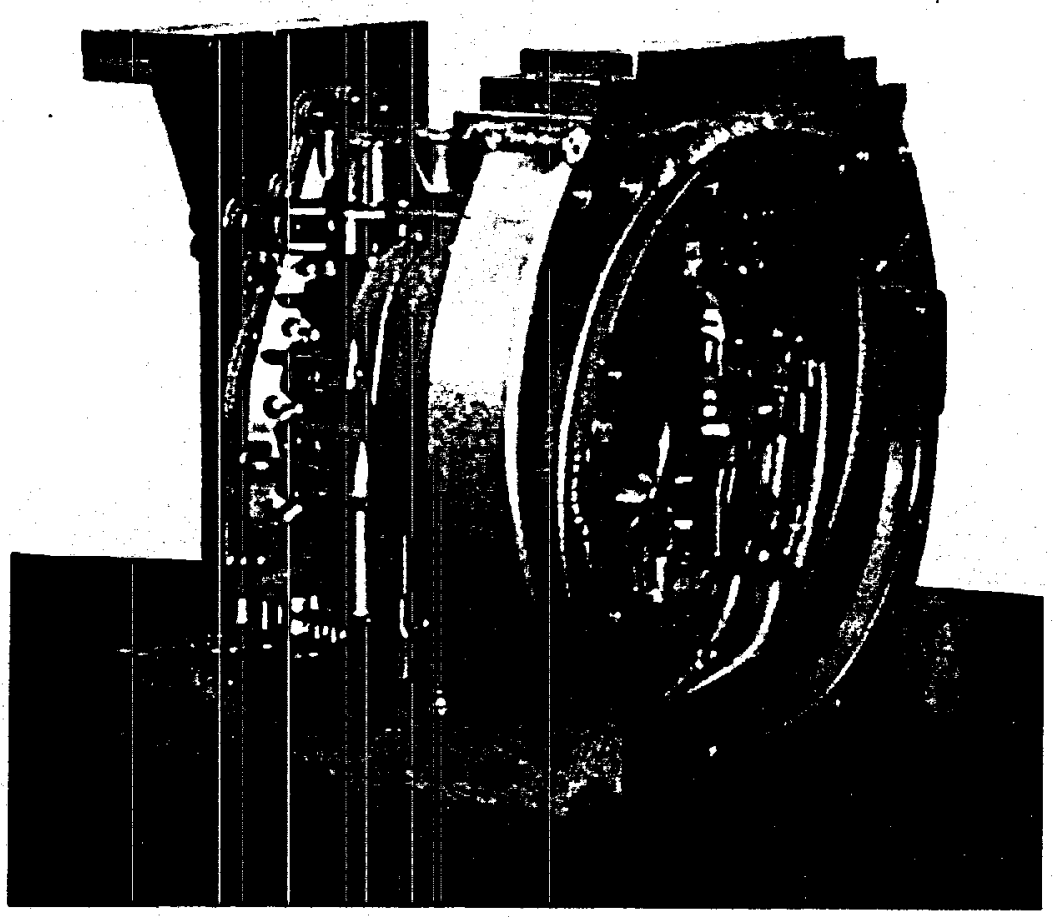

Figure 13: Lower End for Optical Engine with adaptor plates installed.

To provide optical access, a quartz cylinder was mounted above the standard Hatz engine cylinder. This is accomplished using a piston extension 
which is bolted to the top of the Hatz piston. On the top of the extension rides a second piston with the same dimensions as the piston in the engine which is being duplicated. This piston also houses a quartz window to provide optical access into the cylinder from below the piston. Torlon rings provide the sealing between piston and the quartz cylinder.

The addition of the second piston, extension, rings and quartz window add a large amount of mass to the reciprocating assembly of the Hatz engine, which makes rebalancing necessary. The first step is to add up the entire reciprocating mass of the rig. This includes both pistons, all-six rings, quartz piston insert, wrist pin, snap rings, piston extension, screws and light end of the connecting rod See Figure 14.

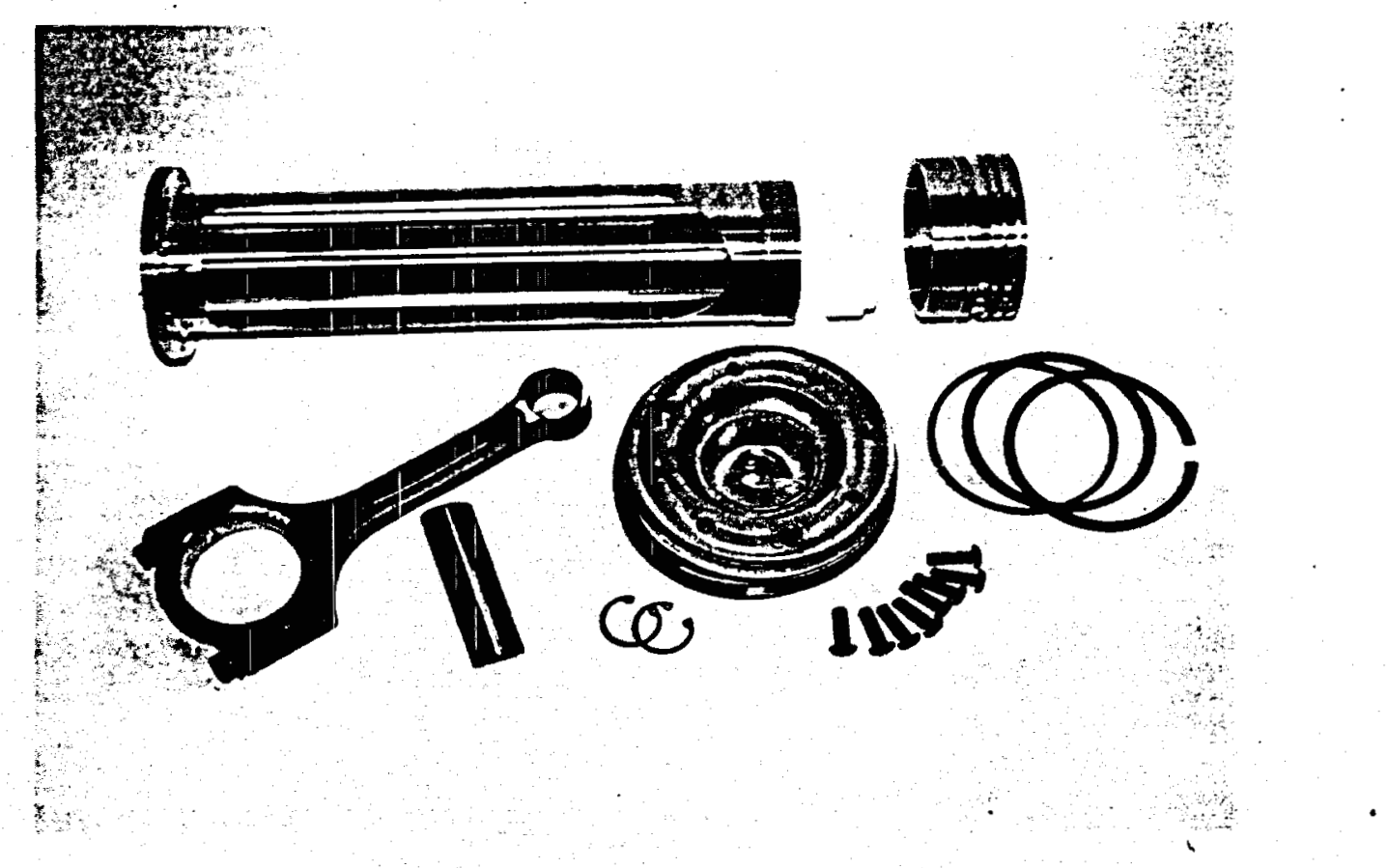

Figure 14: Reciprocating engine parts

With the reciprocating mass known, the next step is to balance the counterbalancing shafts. To do so, a specially made adjustable bob weight is 
used as seen in Figure 15. To determine the location of the bob weight, the following calculation is used.

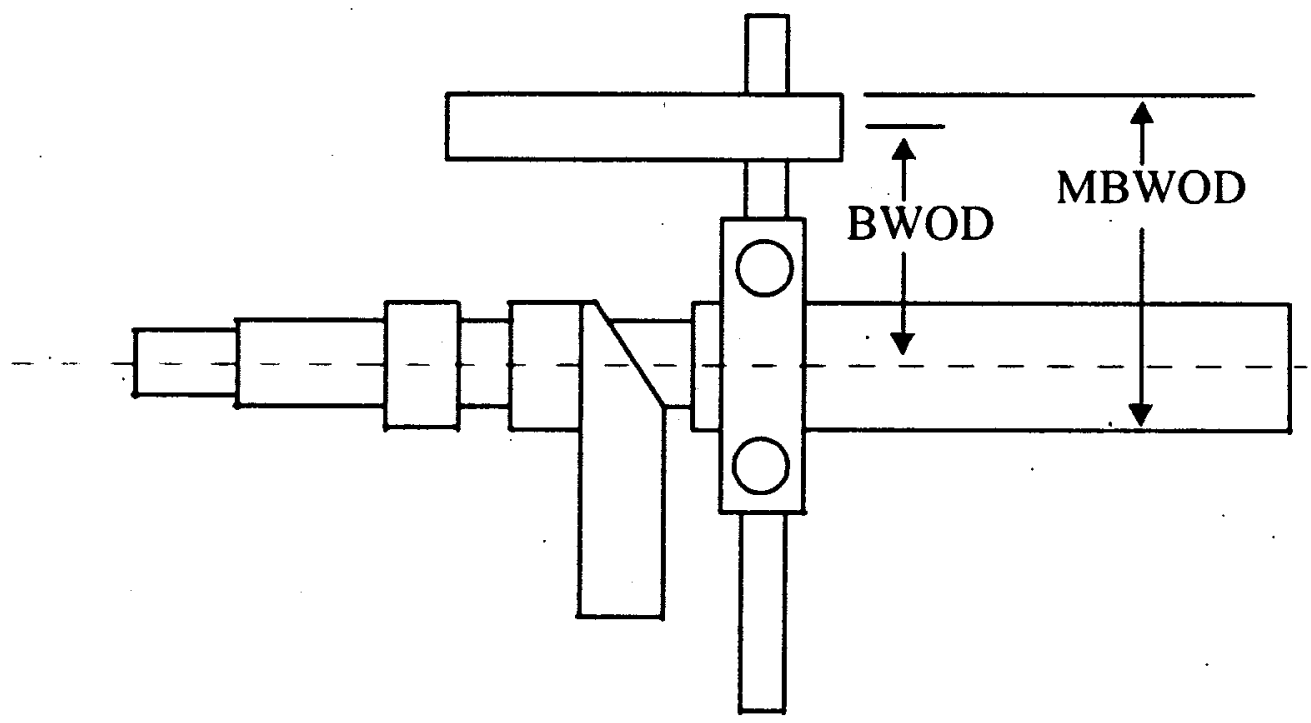

Figure 15: Schematic of counterbalancing shaft and bob weight.

1. Bob weight $(\mathrm{g} \mathrm{mm})=1 / 4$ reciprocating mass $(\mathrm{g}) *$ crank radius $(\mathrm{mm})$

2. Bob weight offset distance (BWOD) $(\mathrm{mm})=$ Bob weight $(\mathrm{g} \mathrm{mm}) /$ $43.48 \mathrm{~g}$

3. Measured bob weight offset distance (MBWOD) $=$ BWOD $(\mathrm{mm})$ $+19.97$

With the bob weight adjusted to the proper location, it is attached to the counter balancing shafts one at a time, and placed in the balancing rig as shown in Figure 16. Mallory metal, which is approximately twice the density of the original counterweight material is then added to the counterweight to 
balance out the weight of the bobweight until the assembly can be rotated in the rig without having a tendency to fall to one side.

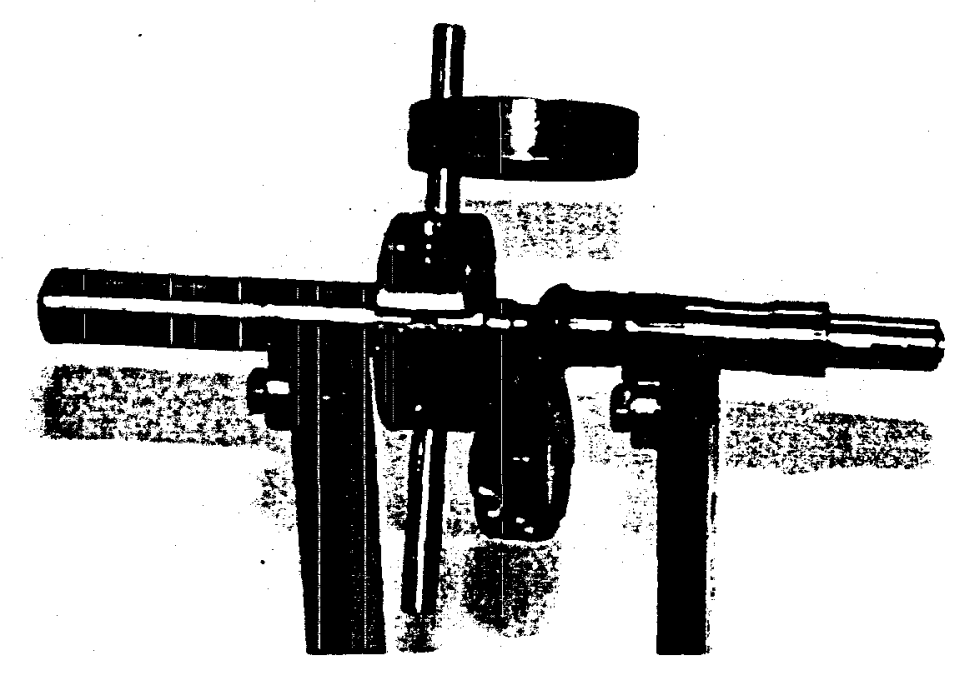

Figure 16: Counterbalance shaft and bob weight on balancing stand.

Next, the crankshaft had to be balanced. To do so, a second bob weight of adjustable mass was used. To determine the proper amount of mass to be added, the following procedure is used.

4. Rotating mass = mass of the large end of the connecting rod

5. Reciprocating mass $=$ same as above

6. Crank shaft bob weight $=1 / 2$ reciprocating mass + rotating mass

7. Mass to be added = crank shaft bob weight $-520 \mathrm{~g}$

The mass is then added to the bob weight and it is attached to the rod journal of the crankshaft. Just as with the counterbalancing shafts, the crankshaft is placed in the balancing rig see Figure 17, and mallory metal is added until it balances out the mass of the bobweight. 


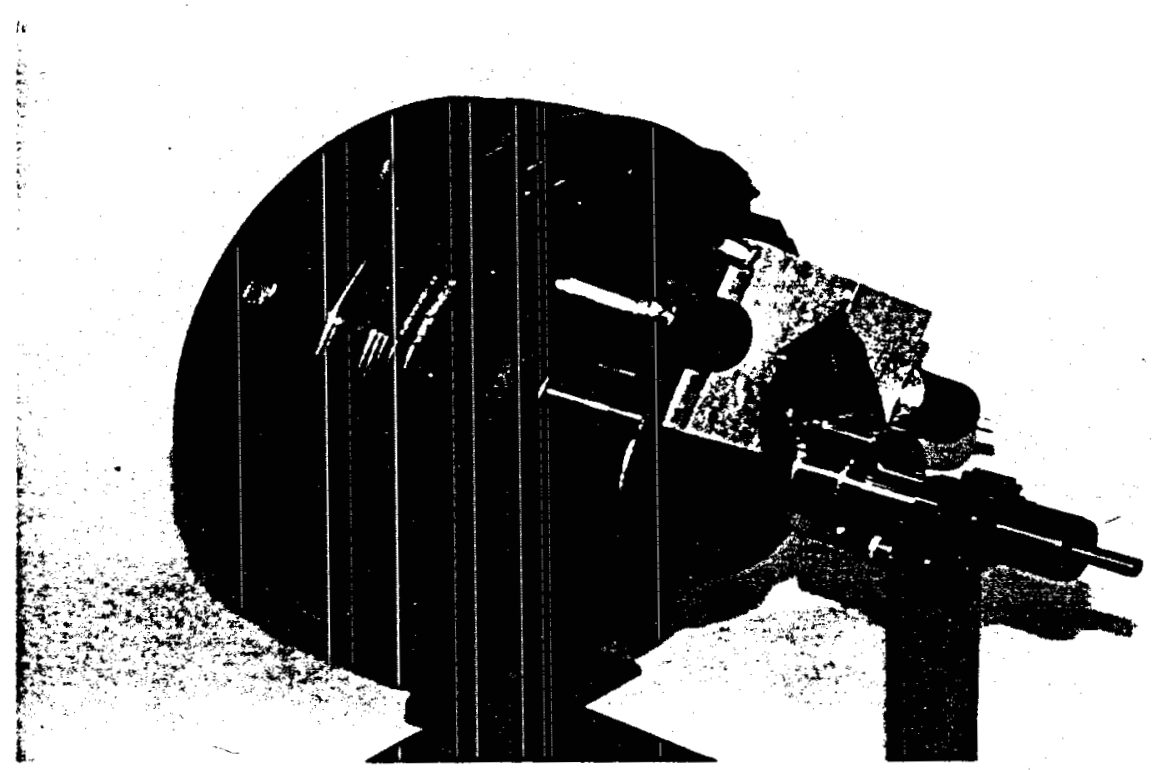

Figure 17: Crank shaft with flywheel and bobweight attached on balancing stand.

The optical engine is topped off with the custom built aluminum cylinder head. Two steel supports were fabricated to hold the head in place atop the quartz cylinder. A belt drive system is used to drive the dual over head cams. This is accomplished by running a belt to a jack shaft with a pulley twice the size of the crankshaft pulley to make the reduction from engine speed to cam speed. Then. a second belt is used to drive the camshafts at a one to one ratio with the jack shaft. Not only does it serve the purpose of reducing the rotational speed, but the jack shaft also routs the belts to the side of the engine, allowing for better optical access to the cylinder. 


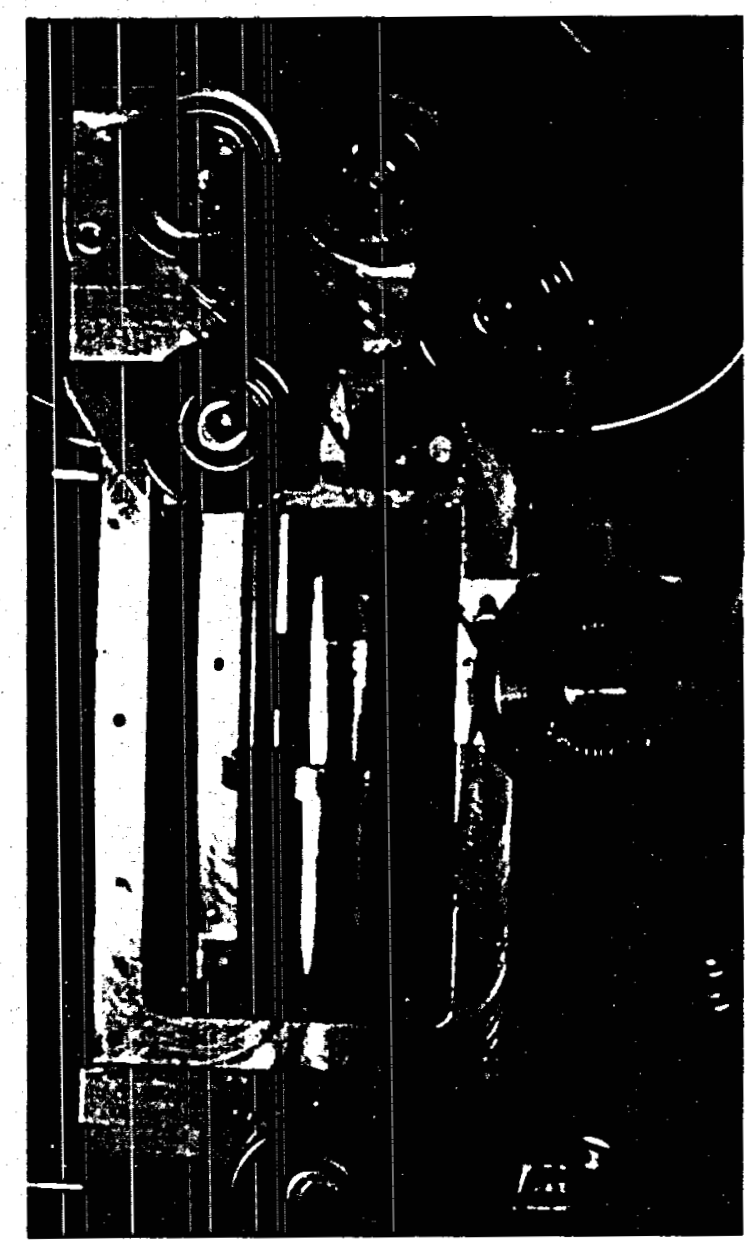

Figure 18: Top half of optical engine.

Custom intake and exhaust manifolds were built for use with the MSU cylinder head, see Figure 19. Both manifolds were constructed using one inch steel tubing, and both were designed to angle upward to provide better optical access of the quartz cylinder. The intake manifold did have to incorporate some special additions. First, since the same manifold would be used on the firing engine, fuel injectors needed to be installed to provide fuel. Also, a means for attaching the active flow control device had to be incorporated. This was accomplished by creating a "Y" in the intake and attaching a threaded adaptor for the speaker. 


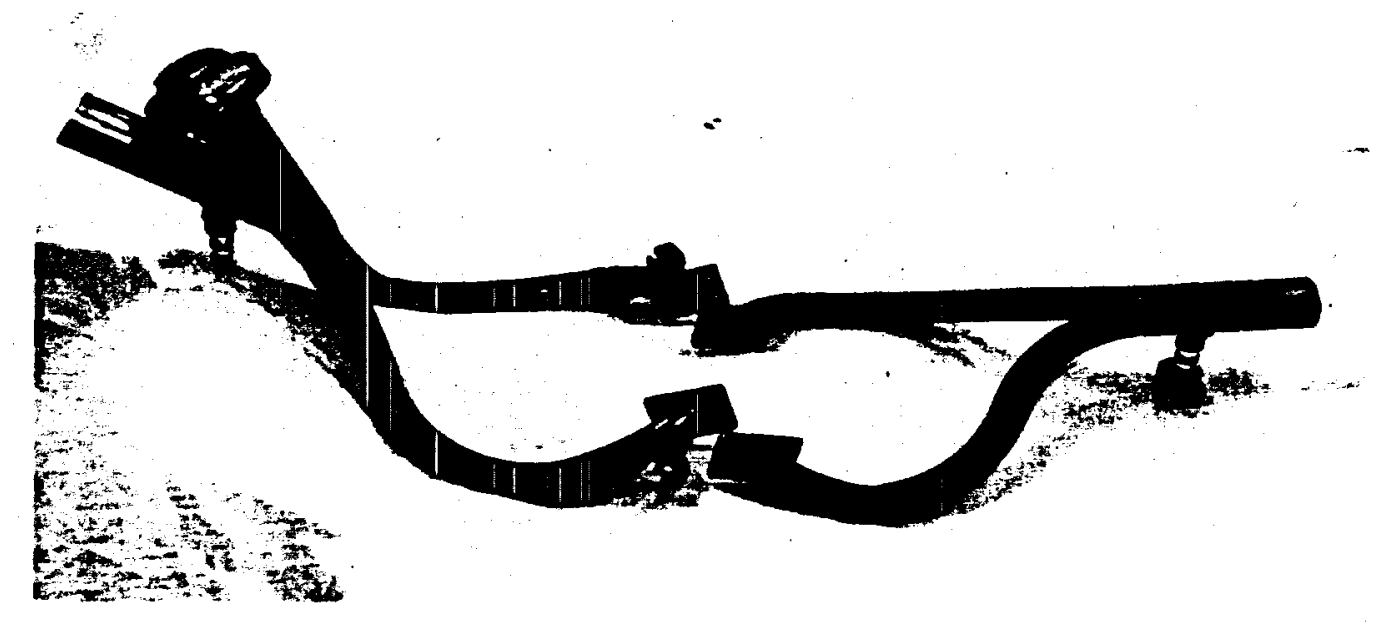

Figure 19: Intake manifold (left) and exhaust manifold.

Since MTV was to be performed on the optical engine, a special closed loop flow system had to be built. (See Figure 20). Since a mixture of Nitrogen and Biacetyl must be supplied to the engine, a system was designed and constructed to rout the exhaust back into the intake of the engine. If the exhaust were to be fed directly into the intake, however, it would cause a pressure pulse at the intake each time the exhaust valves were opened. This is avoided through the use of two plenums. A large rectangular plenum is used on the intake side of the engine to provide a mass of nitrogen at a steady pressure each time the intake valves are opened. This plenum also serves as the mixing chamber for the Biacetyl and nitrogen. By filling the bottom with liquid biacetyl, it provides a large surface area over which the biacetyl can evaporate into the nitrogen. Once the mixture is expelled from the cylinder, it travels to the exhaust plenum. This is a cylindrical plenum with two internal baffles which serve to disperse the mixture throughout the plenum and reduce the exhaust pulsations traveling through the plenum. After 
leaving the exhaust plenum, the mixture travels through a throttle to provide the desired manifold vacuum. From the throttle, the mixture travels back into the intake plenum to start the process again.

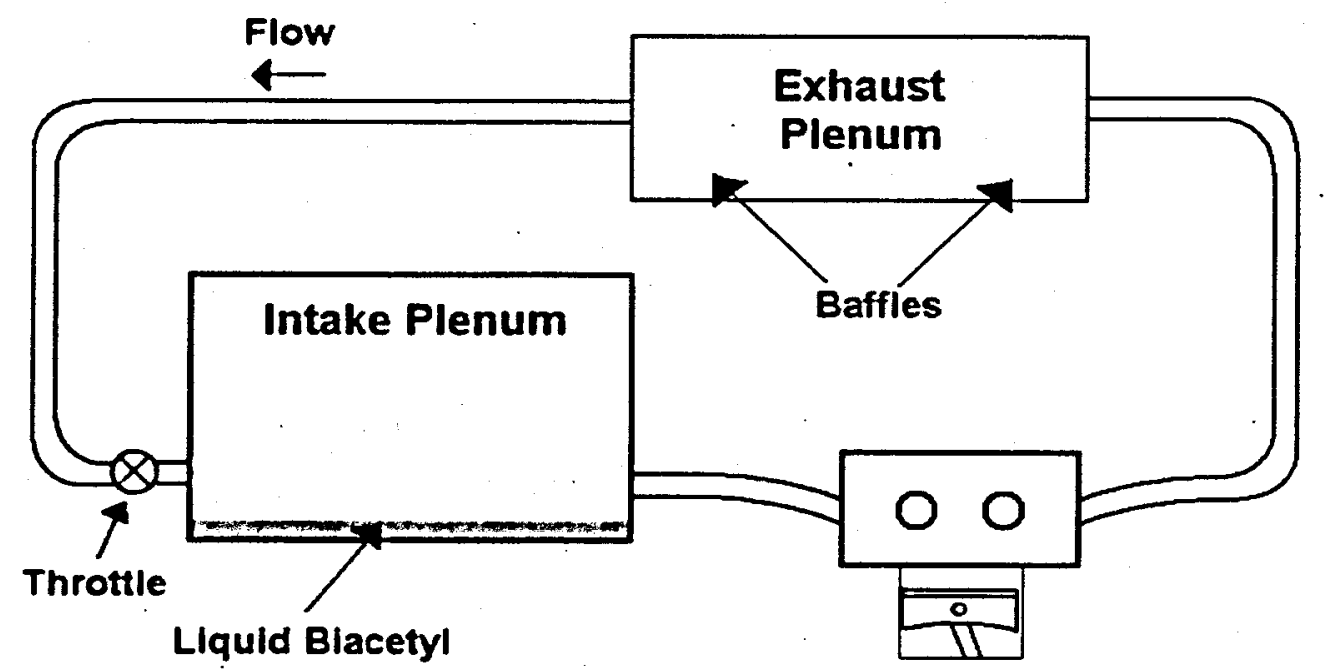

Figure 20: Closed loop nitrogen/biacetyl flow system.

\subsection{Molecular Tagging Velocimetry}

Before firing the engine, work was first done to determine the in cylinder flow features using the optical engine. It was decided that all measurements would be taken at 1500 RPM and wide open throttle. Based on previous work on a similar configuration by Goh [6], it was predicted that active flow control would produce the greatest reduction in cycle to cycle variability between $1800 \mathrm{~Hz}$ and $2200 \mathrm{~Hz}$. Therefore, measurements were to be taken in $100 \mathrm{~Hz}$ increments from $1500 \mathrm{~Hz}$ to $2500 \mathrm{~Hz}$. Also based on previous work at MSU's Engine Research Laboratory, 200 undelayed images were averaged to provide a reference grid and 500 delayed images were needed to provide a repeatable average flow field. 
Experiments began with a laser setup, as shown in Figure 21. Such a setup was used for several previous experiments at MSU and has traditionally worked well; however, this setup would prove troublesome for the current study. The biggest problem was with the Biacetyl film produced by this engine. Although the intake manifold designed for this engine served the purpose of incorporating a speaker, it had the unfortunate side effect of causing the evaporated biacetyl to condense. This liquid biacetyl would eventually make its way into the cylinder, and form a film on the top of the piston. The droplets would act as tiny lenses and cause the incoming laser light to diverge after passing through them. By the time the light had traveled to the top of the cylinder, it was no longer in the form of precise grid lines, but instead. appeared as a haze. With no distinct lines, no intersections were available for meaningful analysis.

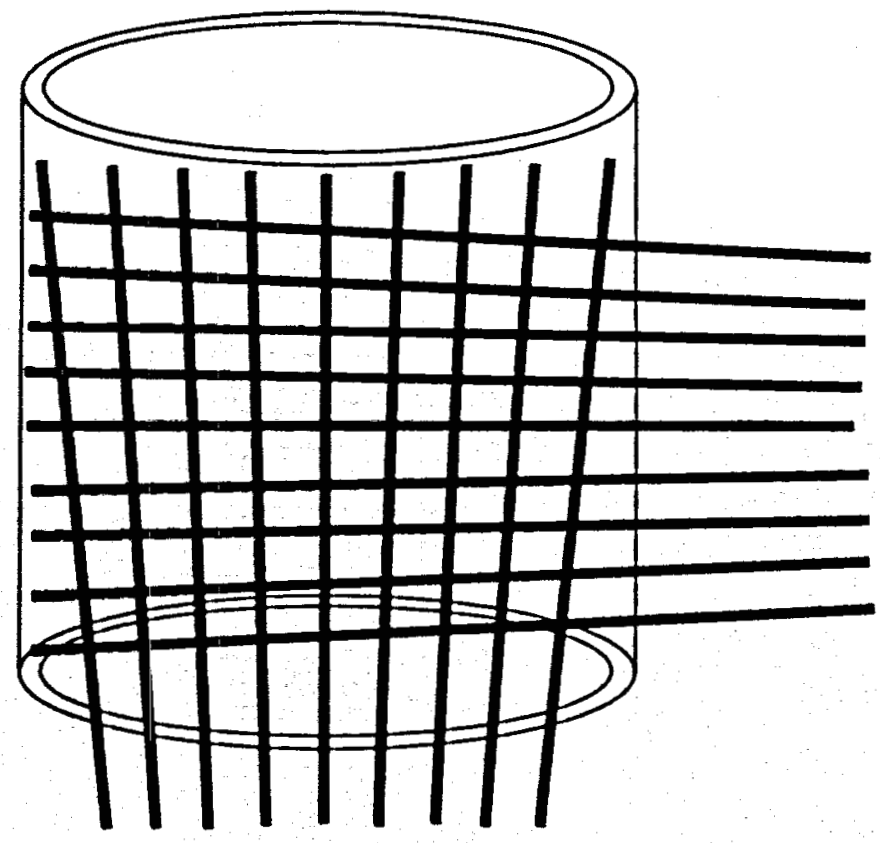

Figure 21: Original laser beam configuration. 
Aside from the downfall of unclear images, there were also other disadvantages associated with the laser beam setup. Bringing lines through the piston meant that only the center of the cylinder could be studied since the piston itself would block beams near the cylinder walls. Also, bringing in beams horizontally makes measurement at the top of the cylinder near the spark plug difficult since parts of the engine outside the cylinder block these beams.

In order to make the desired measurements, a different laser grid had to be designed. The modified laser beam setup can be seen in Figure 22 . Beams enter the cylinder from each side aiming upward on a 30 degree angle. This results in an intersection angle of 120 degrees which still allows the intersection point to be found accurately [3]. Such a setup has multiple advantages; it allows measurements to be taken all the way to the sides as well as to the top of the cylinder. Most importantly, the beam intersections are still distinguishable when the piston becomes coated with biacetyl. Of course, this design is not without flaws. Since the beams are angled upward, the region directly above the piston cannot be measured. Still, the benefits far outweigh the disadvantage. 


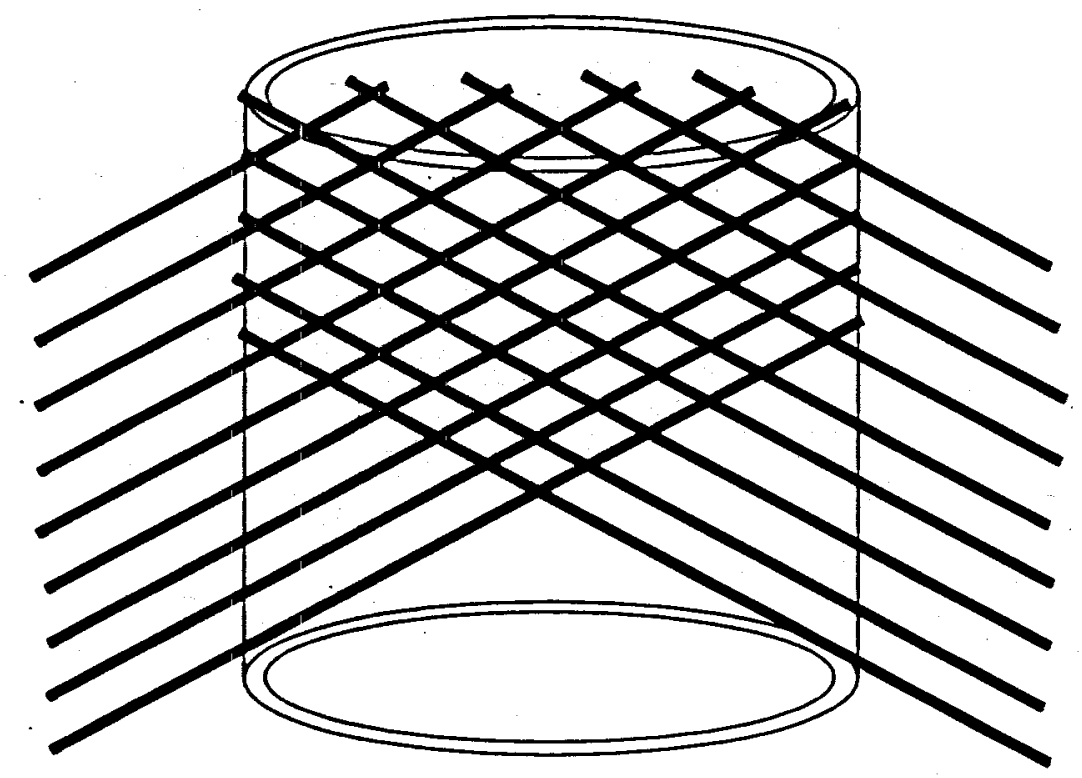

Figure 22: Modified laser beam configuration

Ideally, all of the testing would take place in one session; however, the combination of torlon piston rings, and biacetyl cause the cylinder walls to become too cloudy for accurate data analysis before all 12 conditions could be tested. This means the rig would be run until the images become too cloudy, then the rig would be disassembled and cleaned. In the first run five conditions were completed, which included a no force, and $1500 \mathrm{~Hz}$ through $1800 \mathrm{~Hz}$. After cleaning the rig, the $1800 \mathrm{~Hz}$ through $2500 \mathrm{~Hz}$ conditions as well as another no force condition were run. Although not all of the tests were run consecutively, the no force condition, and $1800 \mathrm{~Hz}$ condition were run in each test providing a way to ensure the repeatability of the experiment.

Once all of the data had been collected, it was then processed using software developed at MSU's Turbulent Mixing and Unsteady Aerodynamics 
Laboratory. The software serves the purpose of finding the grid intersections in the undelayed images, and correlating them with the appropriate intersections in the delayed images. The details of the correlation process can be found in Gendrich and Koochesfahani [3] and a discussion of the accuracy of the plotting process can be found in Cohn and Koochesfahani [2].

\subsection{Firing Rig}

With the flow field data collected, it was time to test the effect of active flow control on the firing engine. The intake plenum, manifold; and speaker from the MTV rig were fitted to the firing rig to ensure the in cylinder flow fields would be the same. The initial test conditions were chosen as $1500 \mathrm{RPM}$, wide open throttle, with forcing from $1500 \mathrm{~Hz}$ to 2500 $\mathrm{Hz}$. The spark timing and injector timing were set to 18 degrees before TDC and 100 degrees before TDC respectively. The injector pulse width was manually adjusted to maintain lambda approximately equal to 1 .

Indicated Mean Effective Pressure (IMEP) was the measurement of performance for the running engines in this study, the definition of which can be found in Appendix C. The IMEP for each of 400 consecutive engine cycles was recorded and averaged to determine the average work output per cycle. However, due to the engine's inability to run smoothly at this condition no meaningful results could be obtained. Figure 23 shows the large fluctuations in IMEP between cycles at the 1500 RPM, wide open throttle condition. Further investigation showed that throttling the engine to $14.5 "$ $\mathrm{Hg}$ produced a much smoother running engine, as seen in Figure 24. Therefore, subsequent testing was performed at $14.5 \mathrm{Hg}$. 


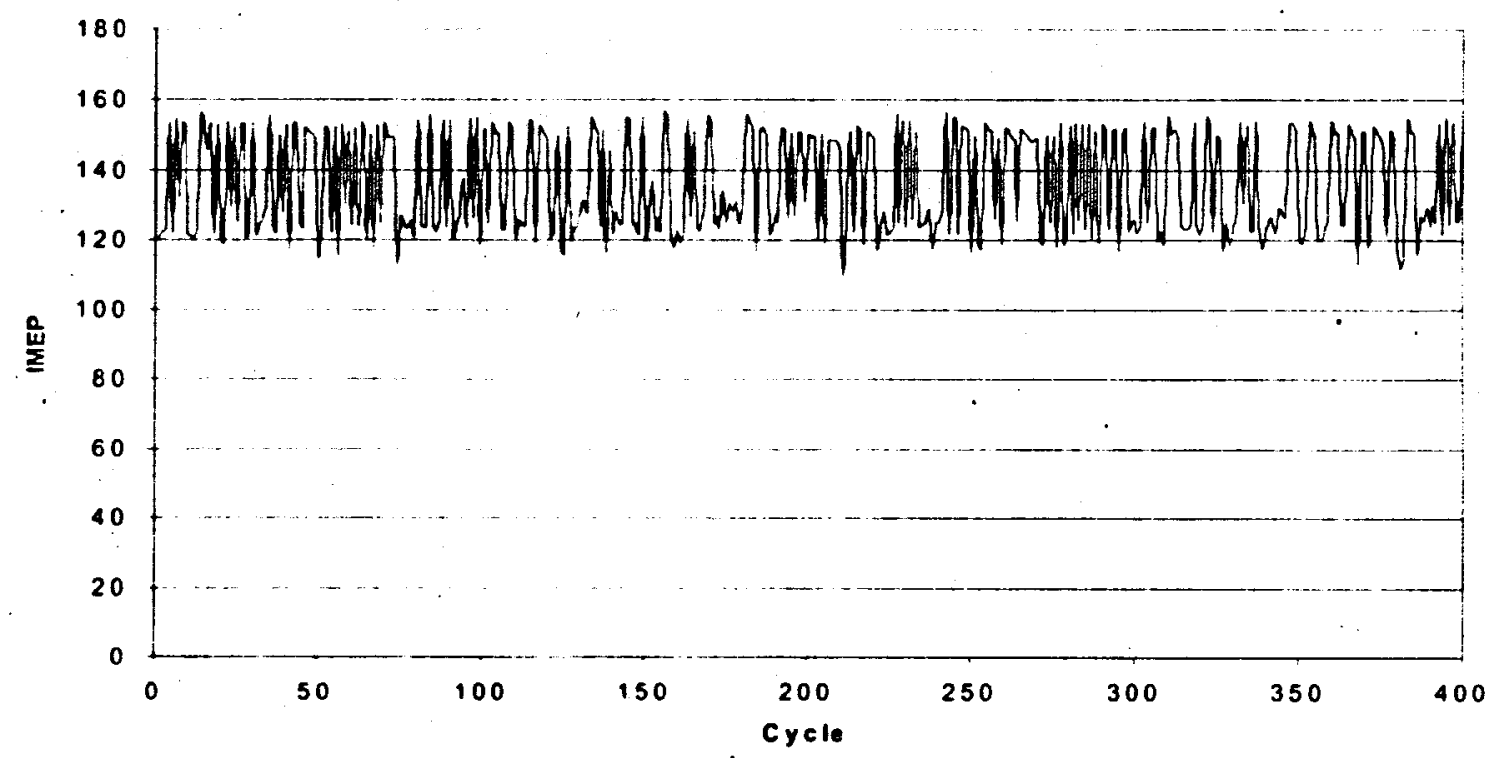

Figure 23: IMEP for the Firing Engine at $1500 \mathrm{RPM}$ and 0 in. $\mathrm{Hg}$.

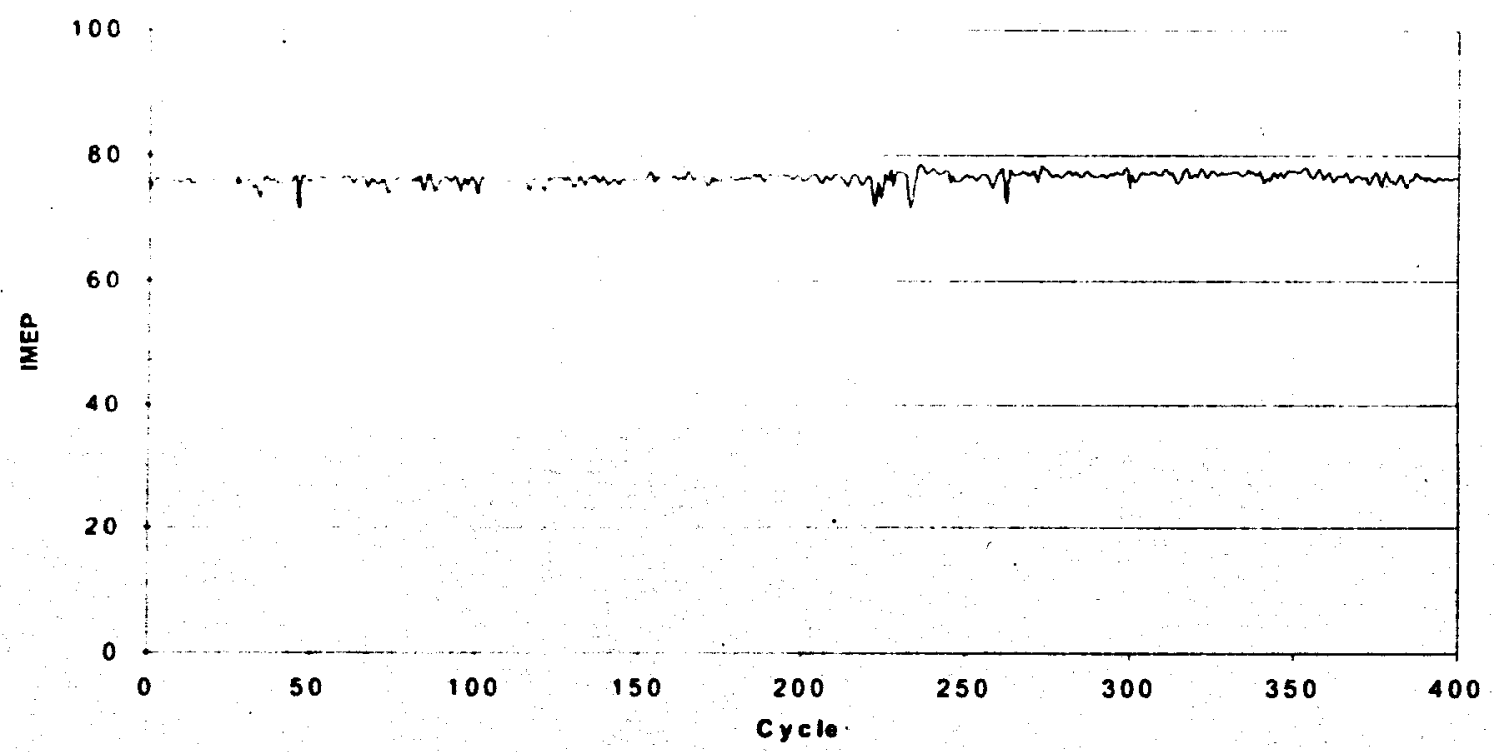

Figure 24: IMEP for the Firing Engine at $1500 \mathrm{RPM}$ and $14.5 \mathrm{in.} \mathrm{Hg}$

Before completing the entire set of test conditions, it was important to first determine whether meaningful data could be gathered at the throttled 
condition. To test this, a simple test sequence was used, 1000 cycles of IMEP would be recorded with $1800 \mathrm{~Hz}$ excitation then 1000 cycles with no excitation force. This sequence was then repeated 2 more times, so as to determine the repeatability of the results. Figure 25 shows that although the runs with active flow control appear to produce a higher IMEP, they are not very consistent. The unaveraged data shown in Figure 26 reveals an interesting trend; it would appear that the data resembles a broken sine wave.

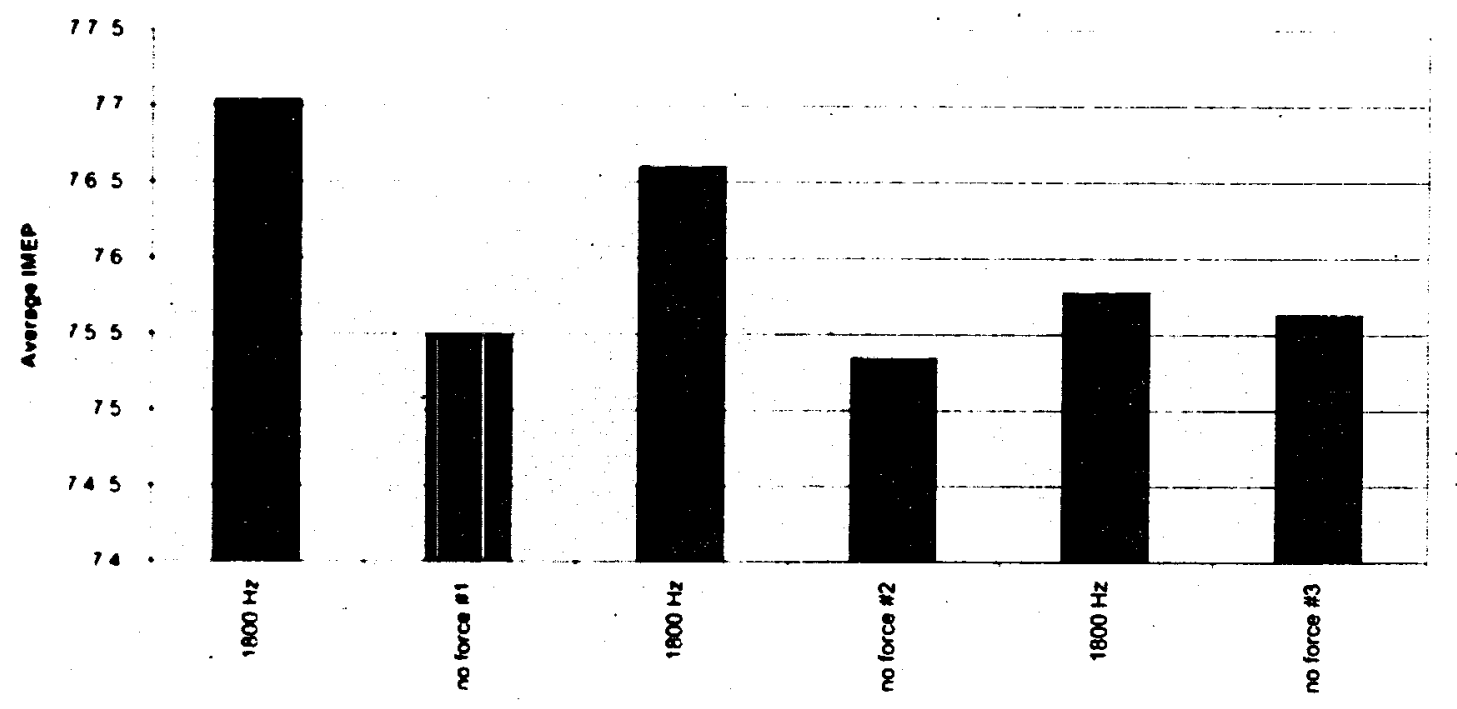

Figure 25: Average IMEP for the Firing Engine At 1500 RPM and 14.5 in. $\mathrm{Hg}$ 


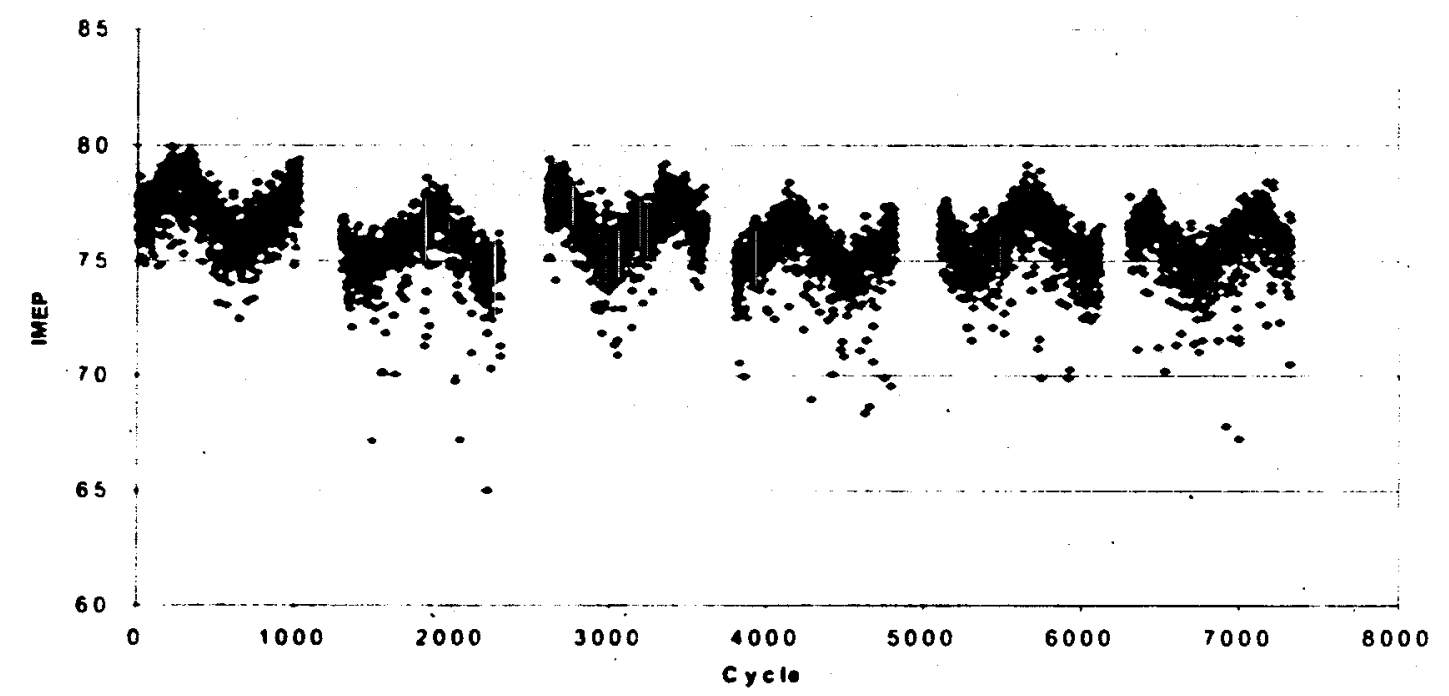

Figure 26: IMEP for the Firing Engine At 1500 RPM and 14.5 in. $\mathrm{Hg}$, alternating between $1800 \mathrm{~Hz}$ excitation, and no force.

To investigate this apparent sine wave, a test run was made with no active flow control. The IMEP of 4000 consecutive cycles was recorded and plotted in Figure 27. It can be seen that the data does in fact take the form of a sine wave. Closer inspection reveals that the wavelength of the sine wave is approximately 750 cycles, or I minute since the engine is running at 1500 RPM. Since the dynamometer controller is an electronic device operating at $60 \mathrm{~Hz}$ it is assumed that the sine wave is somehow linked to the way that the controller is making adjustments to the dynamometer. This discovery accounted for the inconsistency in the 1000 cycle averages since the sampled cycles may contain two peaks and one valley, or two valleys and one peak, depending on when the data logging is initiated. 


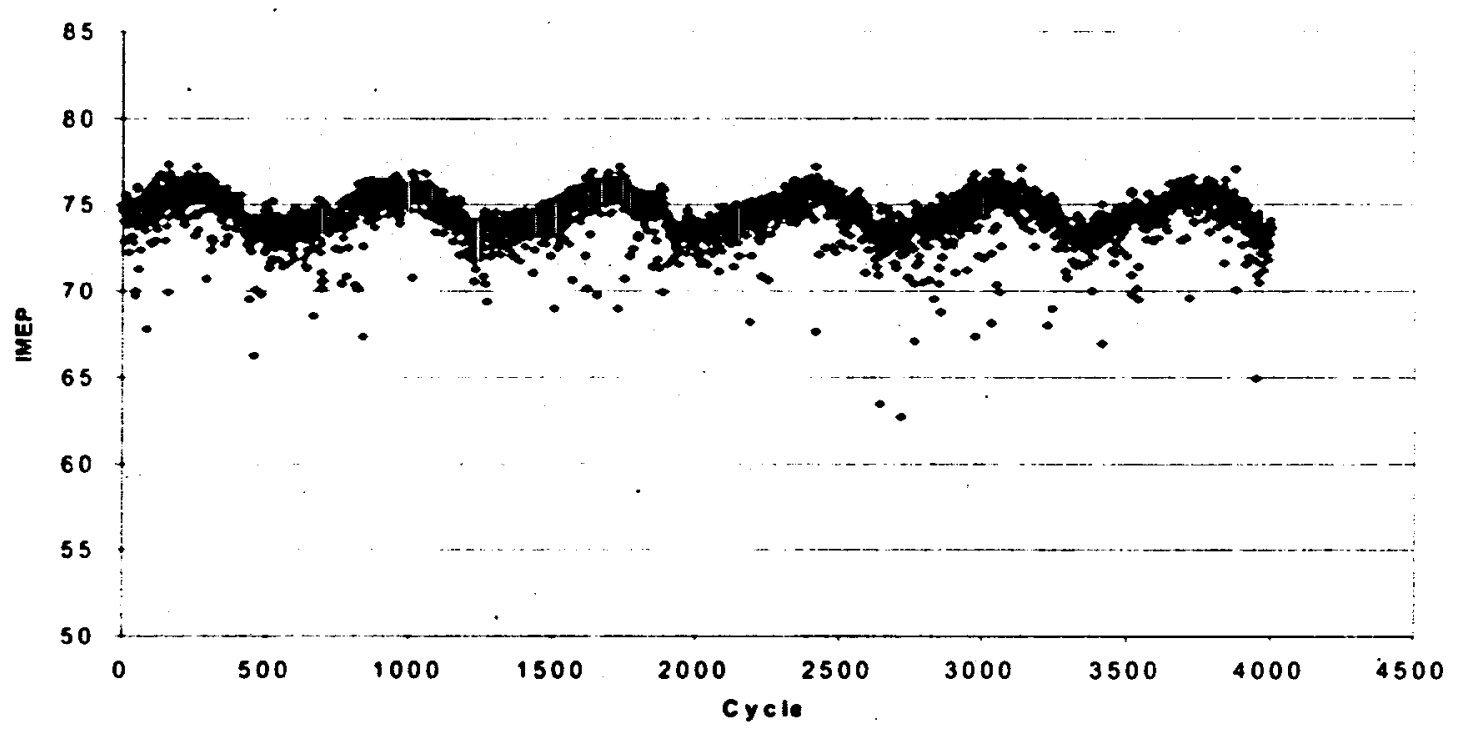

Figure 27: IMEP for 4000 cycles of the Firing Engine at 1500 RPM and 14.5 in. $\mathrm{Hg}$.

Data was then collected for 3000 cycles, and from that data, three wavelengths of data were averaged. This was done for both the non forced and $1800 \mathrm{~Hz}$ excited conditions three times and these results were compared.

Upon completion of the testing, the engine was disassembled and inspected. The findings of this inspection can be found in Appendix B.

\subsection{9L Ford}

Although the single cylinder engine makes for a good way to compare flow field information and corresponding engine performance, it may not show how active flow control would perform in an automotive application. To investigate this, the active flow control device was attached to a $1.9 \mathrm{~L} 4$ cylinder Ford engine. As with the single cylinder firing rig, the parameter of interest was IMEP. 
Step one would be to determine whether the sine wave present in the data from the single cylinder engine would also be present in the data from the four cylinder. IMEP for 2000 consecutive cycles without forcing was recorded and plotted in Figure 28. It can be seen from these plots that the sine wave was no longer present. Although the exact reason is unclear, it is possibly the result of the smoother operation of a four cylinder as opposed to a single cylinder engine.

With the sine wave no longer an issue, the testing proceded. IMEP for 500 consecutive cycles were recorded for the no force condition as well as the $1500 \mathrm{~Hz}$ to $2500 \mathrm{~Hz}$ excitation conditions at $100 \mathrm{~Hz}$ intervals. The results for these tests can be found in chapter 4 .

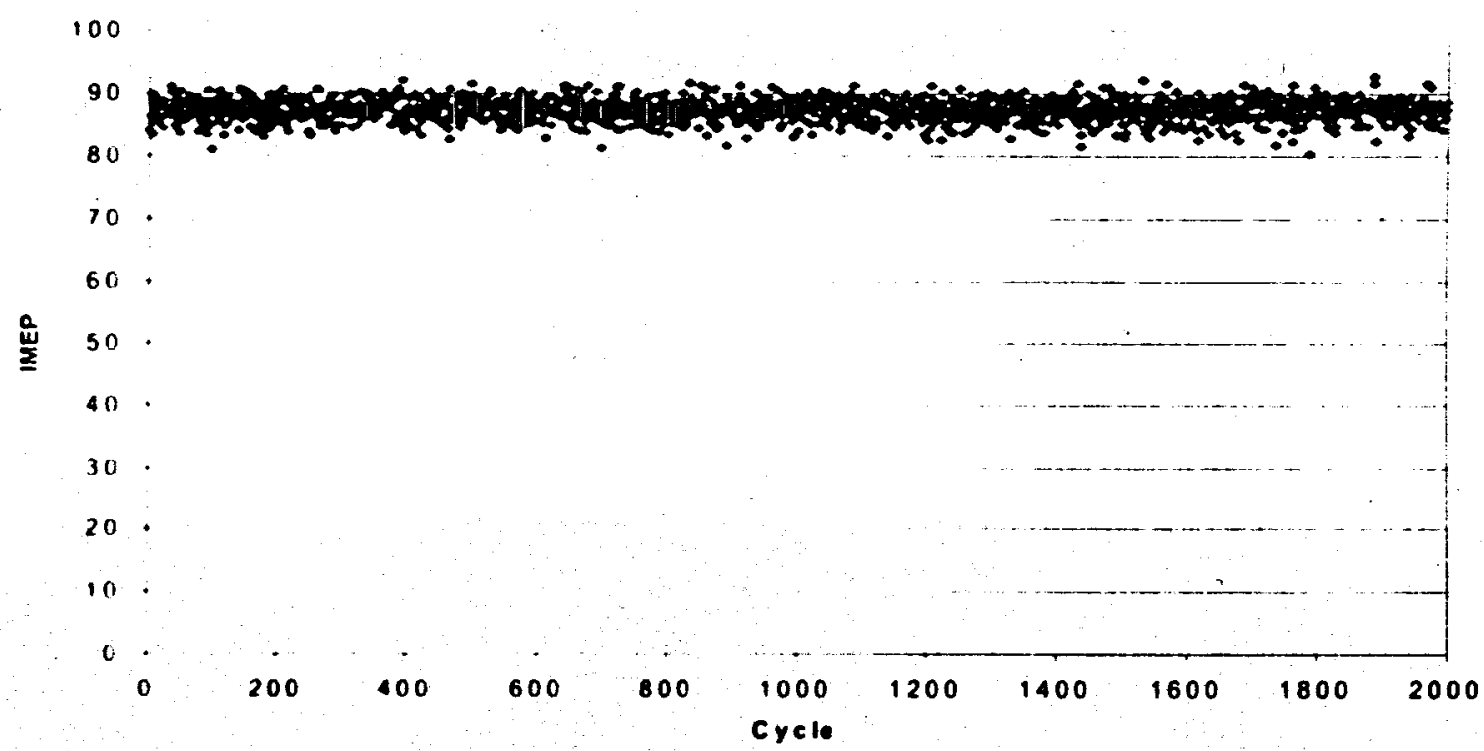

Figure 28: IMEP for 2000 Cycles of the 1.9L Ford Engine at 1500 RPM and 14 in. $\mathrm{Hg}$. 


\section{CHAPTER 4}

\section{Results and Discussion}

\subsection{Molecular Tagging Velocimetry}

The flow fields calculated from the measurements made in the optical engine for the crank angle of 270 degrees can be seen in Figure 29 through Figure 40. In these plots, The axes are in centimeters, cylinder head is located at $\mathrm{Y}=0$ and the cylinder walls are located at $\mathrm{X}=0$ and $\mathrm{X}=7.95$. The intake valves are located on the left side and the exhaust valves on the right. The vectors represent the average velocity and the color represents the rms value of the $u$ and $v$ components of velocity. The unforced flow fields for the intake and compression strokes at various crank angles between 90 and 270 degrees are shown in Appendix A, Figure 47 to Figure 51.

The first parameter of interest is the velocity field. The most notable detail is the strangely out of place vectors found on the lower diagonal lines of the sample area in several of the conditions, namely no force, $1700 \mathrm{~Hz}, 2000 \mathrm{~Hz}, 2200 \mathrm{~Hz}, 2300 \mathrm{~Hz}$ and $2400 \mathrm{~Hz}$. These vectors seem to imply high velocities in directions contradictory to the vectors around them. However, these vectors are more likely a result of errors finding the intersections along the lowest diagonal lines due to the piston partially blocking the beam. Therefore, these vectors will be ignored throughout the rest of the discussion.

With these vectors discarded, one can see that the rest of the flow field is almost identical for each of the conditions. This implies that the active flow control applied to the engine had essentially no effect on the 
average in cylinder flow field. However, it does not mean that the active flow control had no effect on the in cylinder flow.

Looking at the $u$ and $v$ RMS velocities reveals a different trend. One can note that in all of the cases tested with the exception of the $1700 \mathrm{~Hz}$, $2200 \mathrm{~Hz}$, and $2300 \mathrm{~Hz}$ cases, all of the excitation frequencies produce a reduction in RMS velocities, as compared to the non forced condition. In order to see this more clearly, the RMS velocities from each point were averaged over the entire plane and plotted in Figure 41, which clearly shows the difference. The largest improvement can be seen at $1900 \mathrm{~Hz}$ with a reduction of approximately 25 percent from the non forced condition. This implies that the air/fuel ratio and velocities will be more constant in the region surrounding the spark plug, providing a more consistent flame initialization. Also of interest is the fact that both $u$ and $v$ RMS are reduced by approximately the same amount for any given condition. 

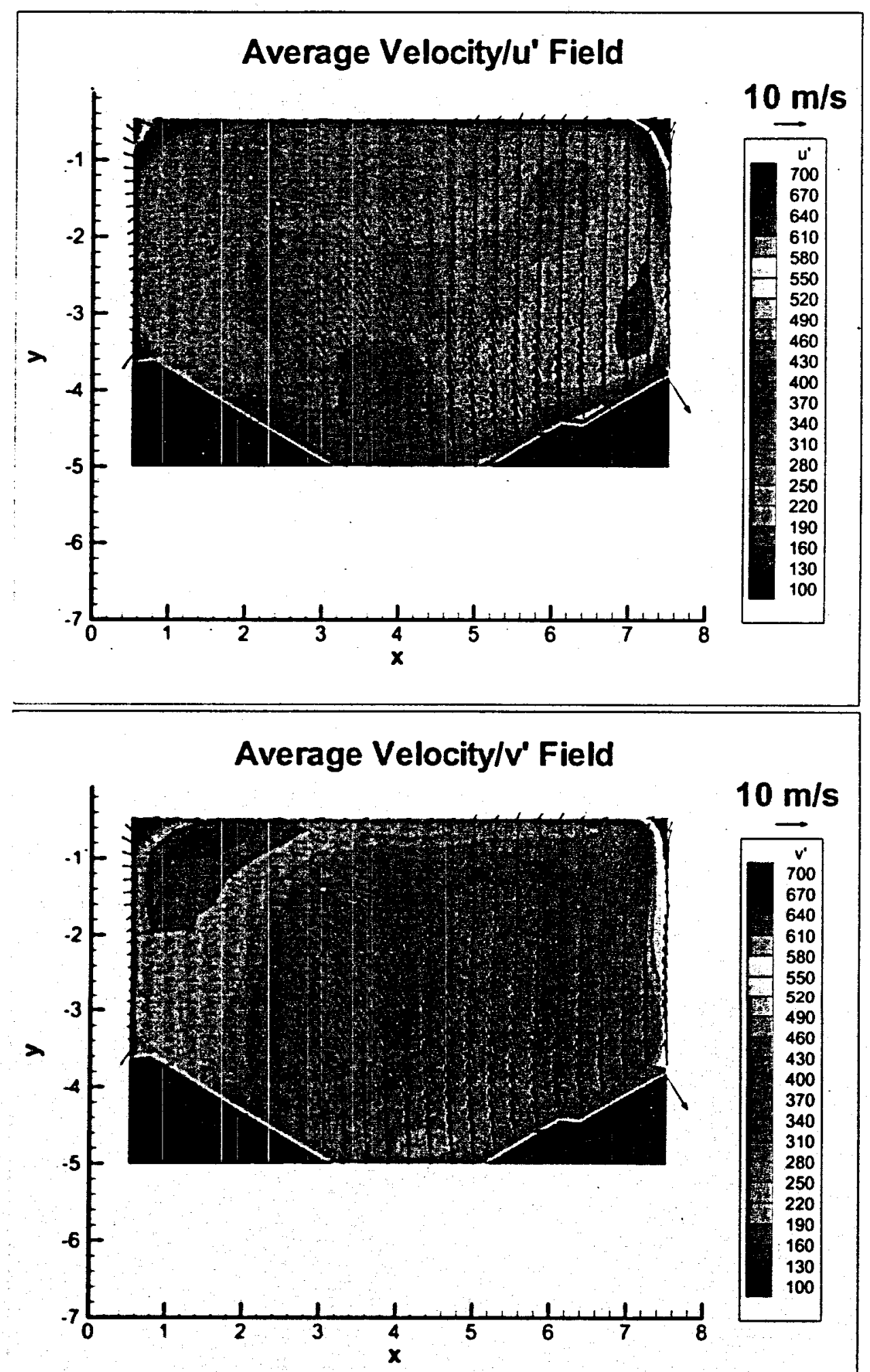

Figure 29: Average Velocity $/ \mathrm{u}^{\prime} / \mathrm{v}^{\prime}$ Fields for the crank angle of 270 at 1500 RPM, 0 in. $\mathrm{Hg}$ and no excitation. (Day 1) 

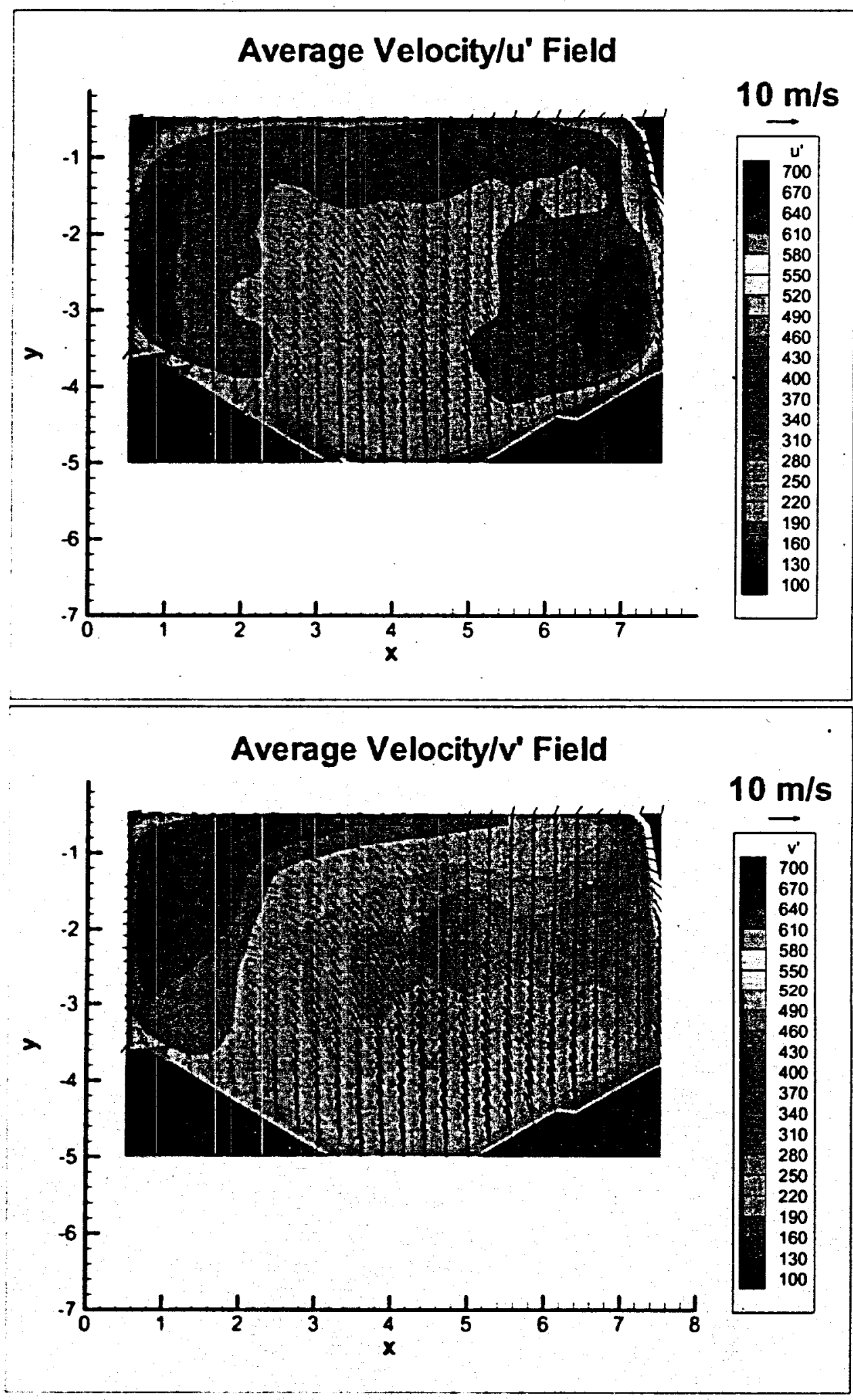

Figure 30: Average Velocity $\mathrm{u}^{\prime} / v^{*}$ Fields for the crank angle of 270 at 1500 RPM, 0 in. $\mathrm{Hg}$ and excited at $1500 \mathrm{~Hz}$. 

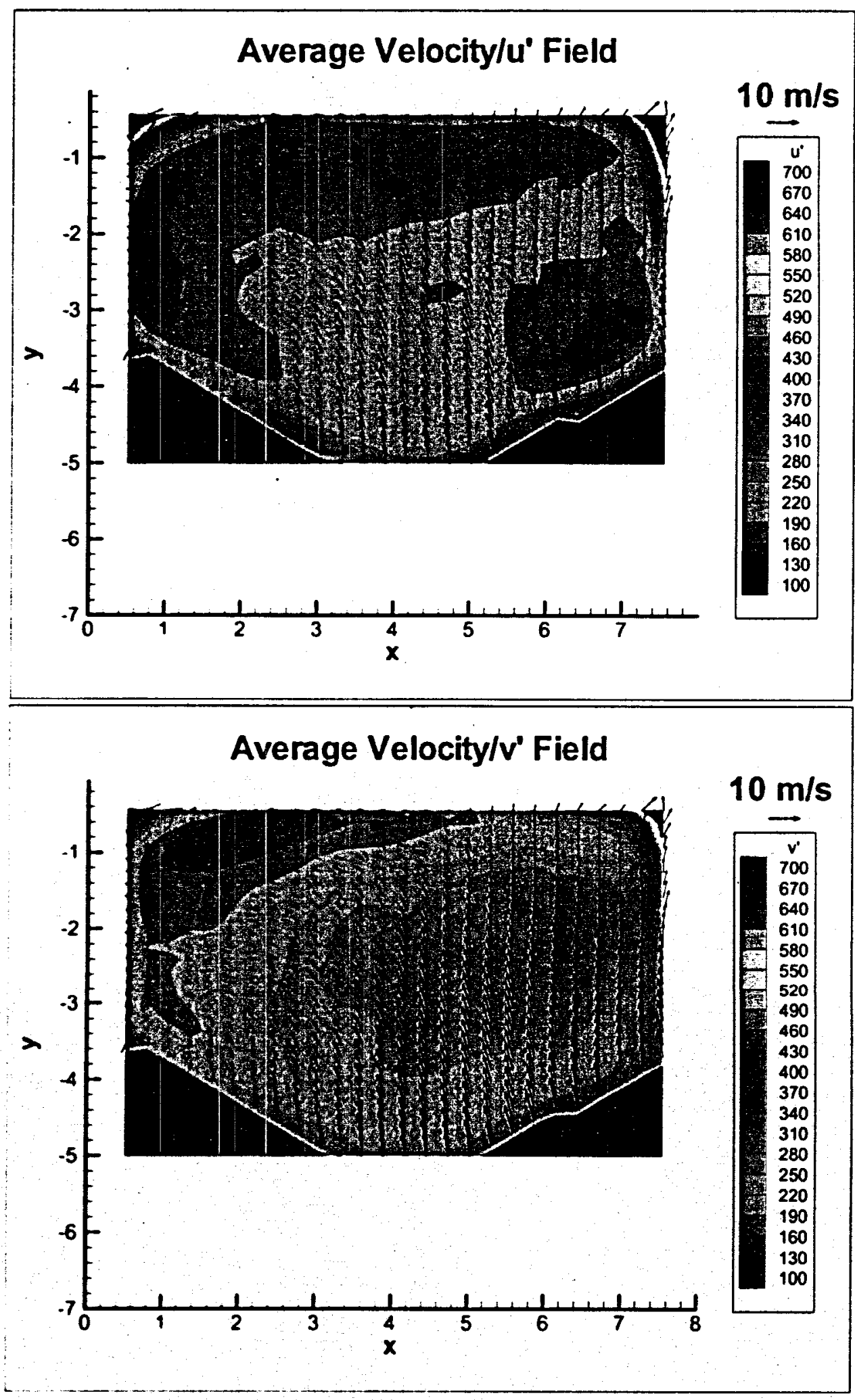

Figure 31: Average Velocity $\mathbf{~}^{\prime} / \mathrm{v}^{\prime}$ Fields for the crank angle of 270 at 1500 RPM, 0 in. $\mathrm{Hg}$ and excited at $1600 \mathrm{~Hz}$. 

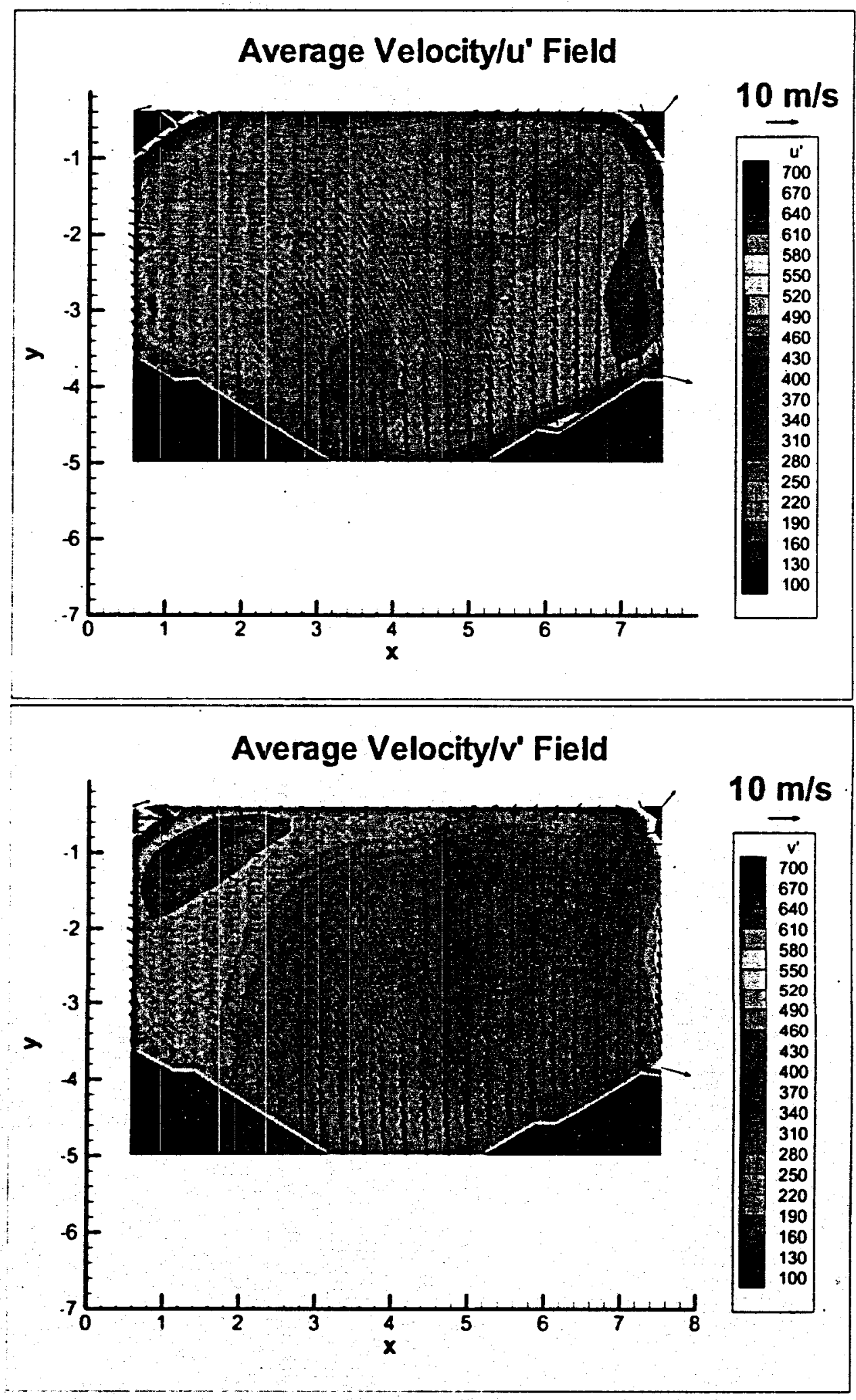

Figure 32: Average Velocity $/ \mathrm{u}^{\prime} / \mathrm{v}^{\prime}$ Fields for the crank angle of 270 at 1500 RPM, 0 in. $\mathrm{Hg}$ and excited at $1700 \mathrm{~Hz}$. 

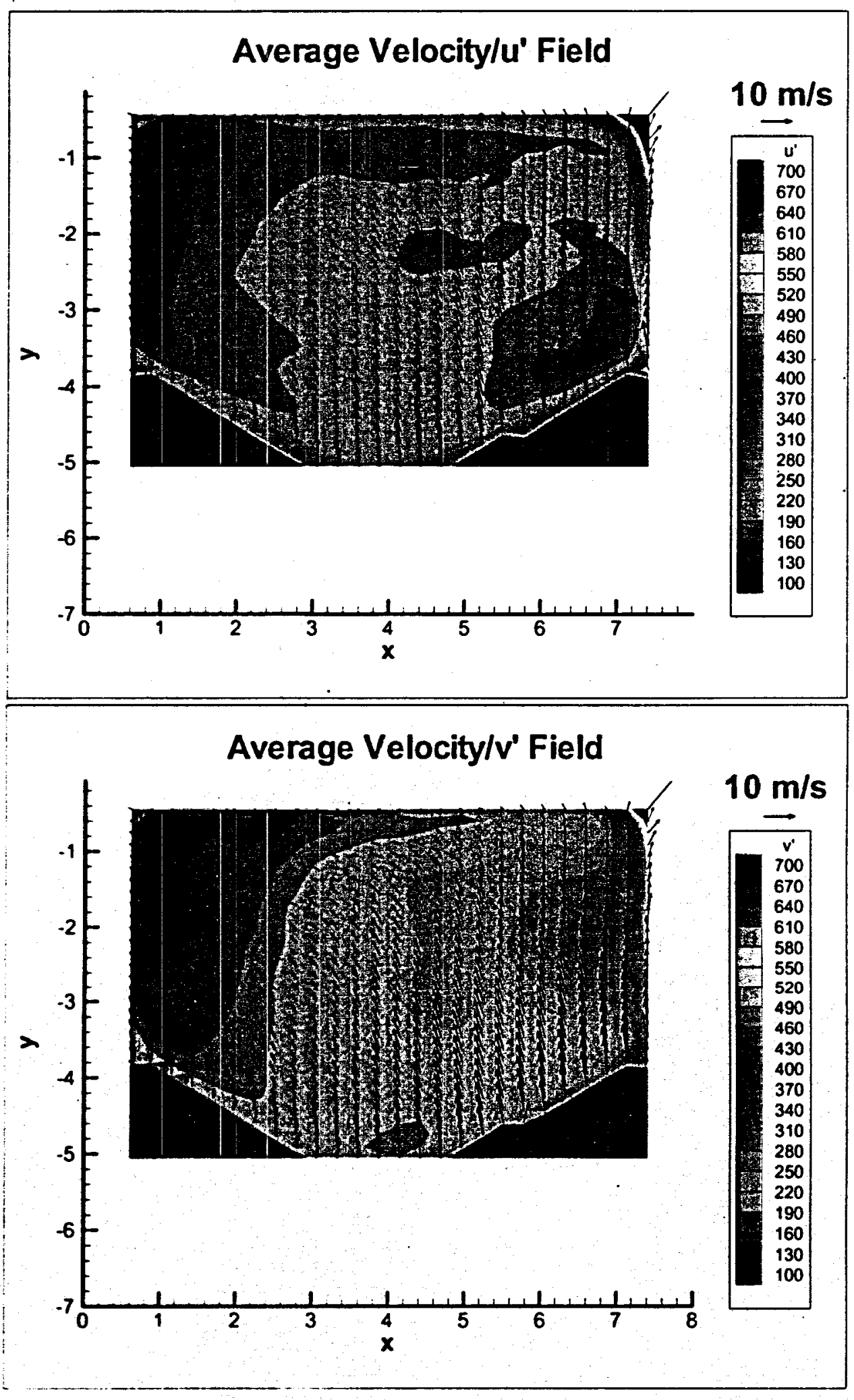

Figure 33: Average Velocity/u'/v' Fields for the crank angle of 270 at 1500 $\mathrm{RPM}, 0$ in. $\mathrm{Hg}$ and excited at $1800 \mathrm{~Hz}$. (Day 2) 

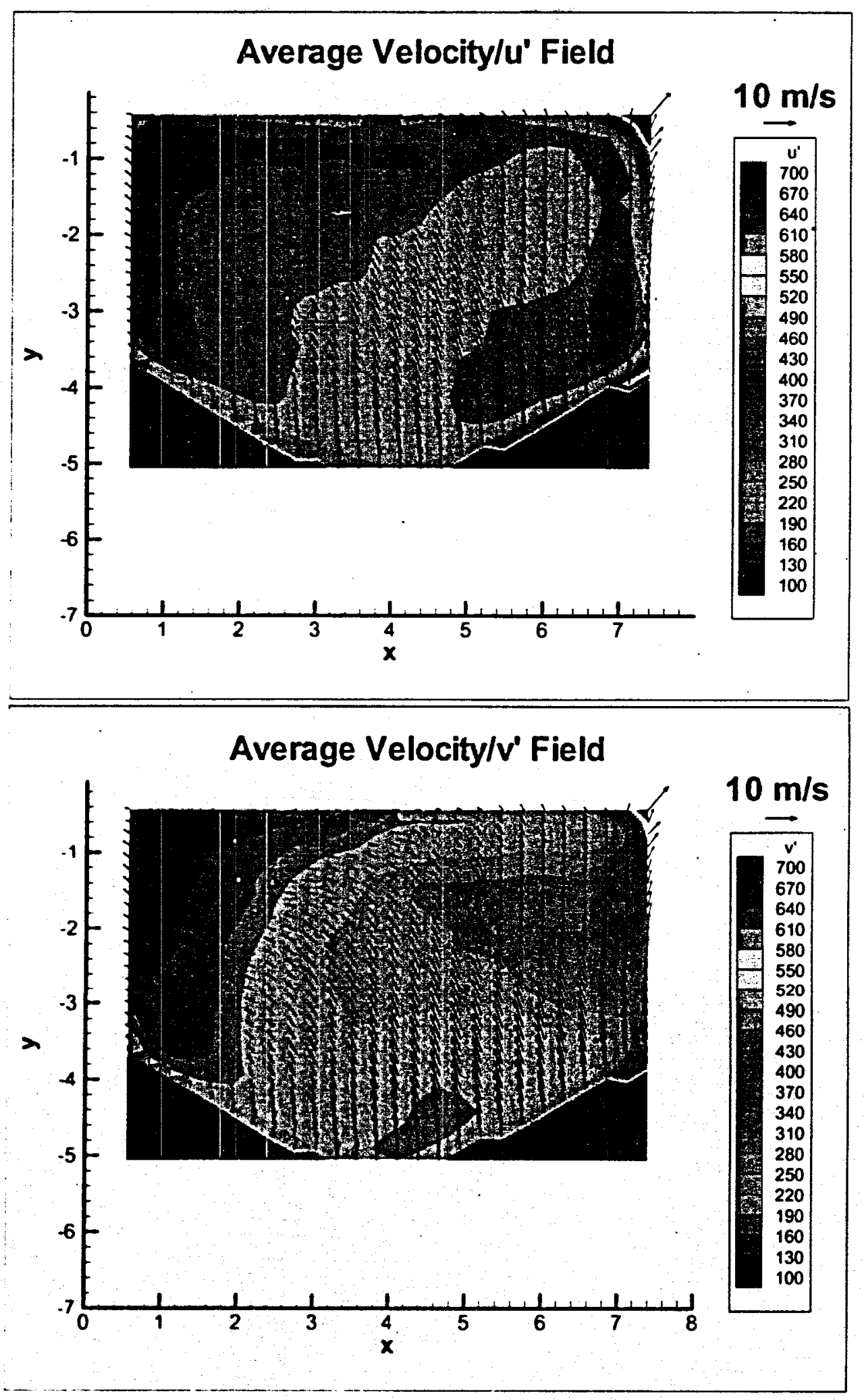

Figure 34: Average Velocity $\mathbf{u}^{\prime} / \mathrm{v}^{\circ}$ Fields for the crank angle of 270 at 1500 RPM, 0 in. $\mathrm{Hg}$ and excited at $1900 \mathrm{~Hz}$. 

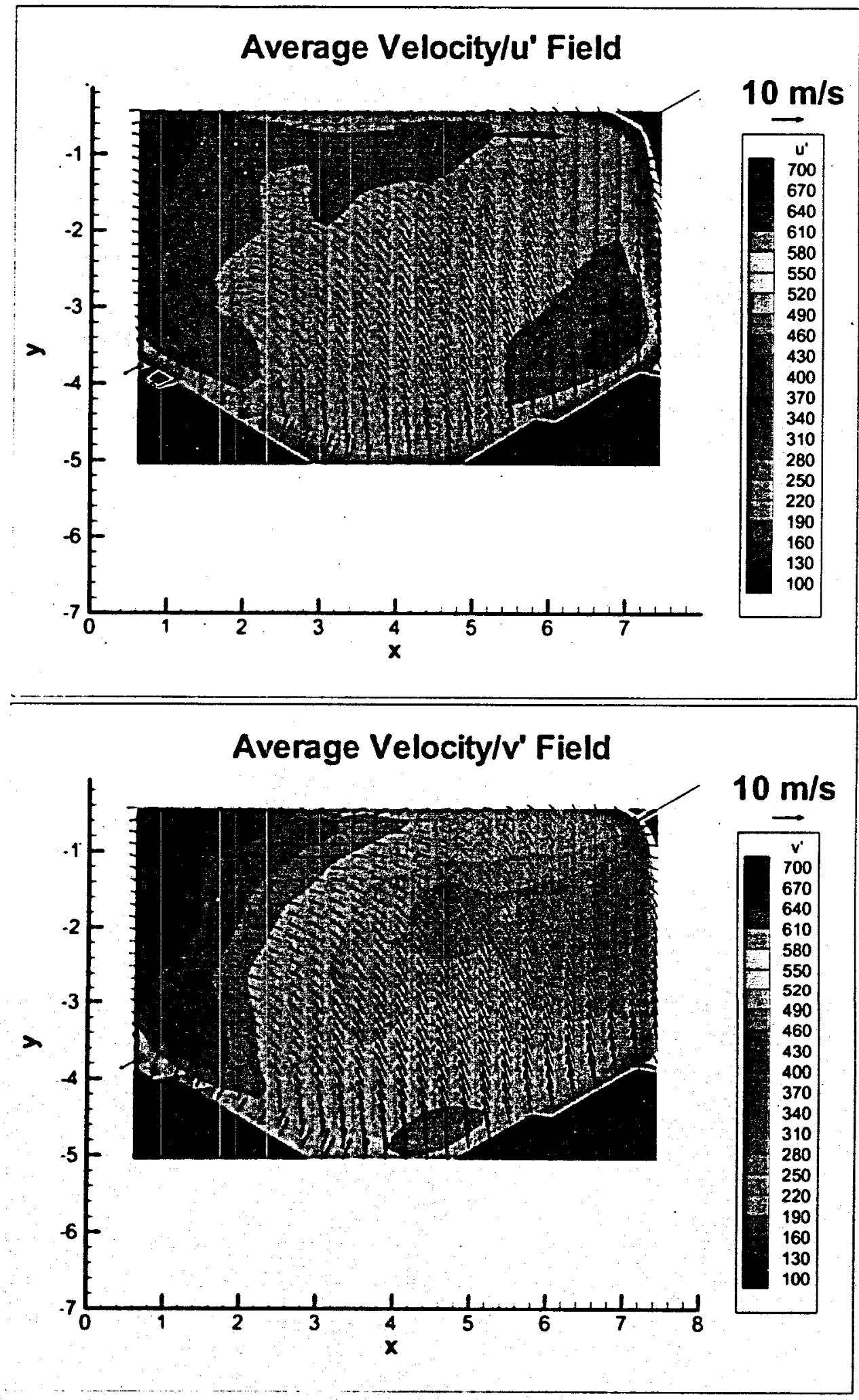

Figure 35: Average Velocity $\mathbf{u}^{\prime} / \mathrm{v}^{\prime}$ Fields for the crank angle of 270 at 1500 RPM. 0 in. $\mathrm{Hg}$ and excited at $2000 \mathrm{~Hz}$. 

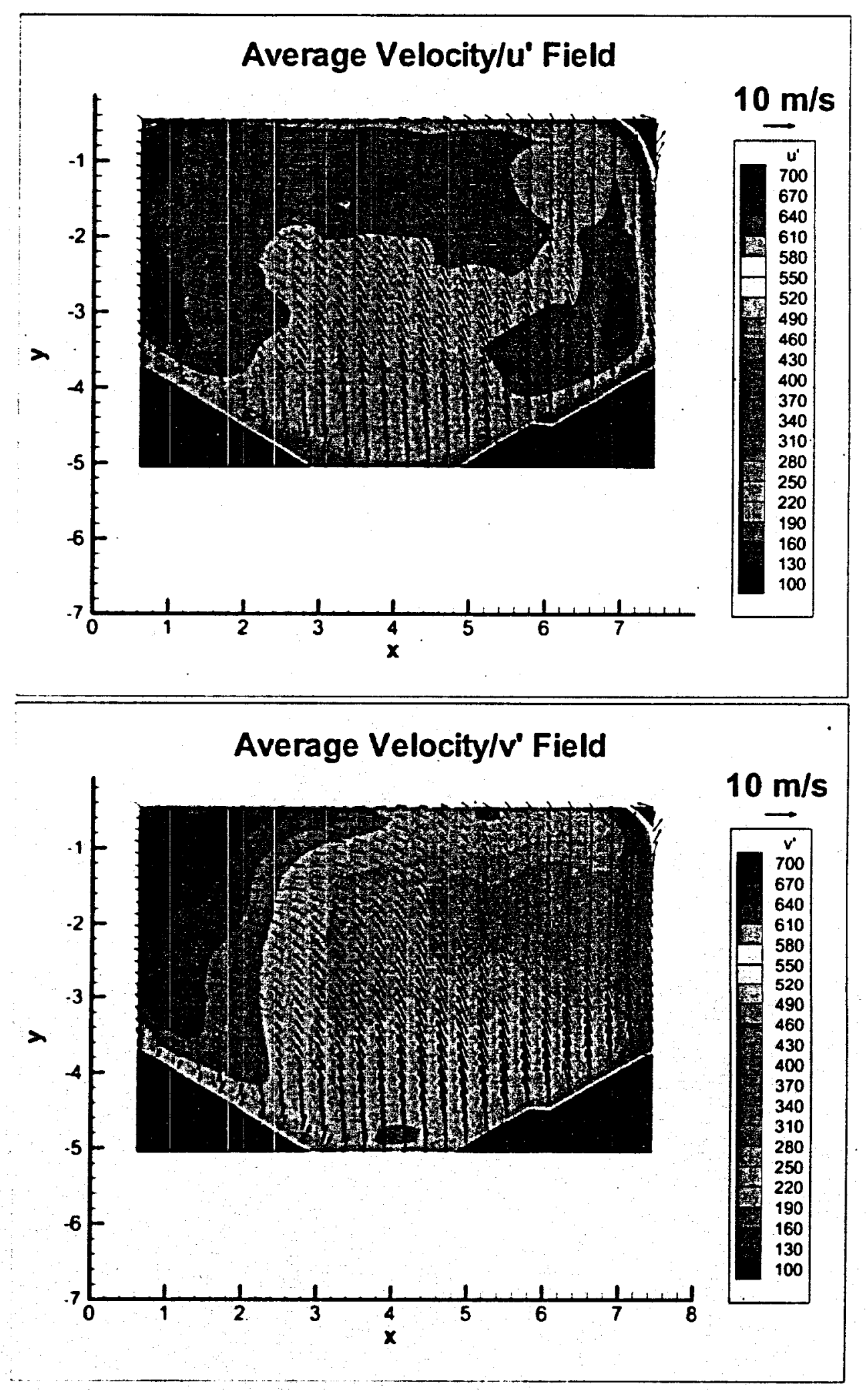

Figure 36. Average Velocity ' ${ }^{\prime} \cdot v^{\prime}$ Fields for the crank angle of 270 at 1500 RPM, 0 in. $\mathrm{Hg}$ and excited at $2100 \mathrm{~Hz}$. 

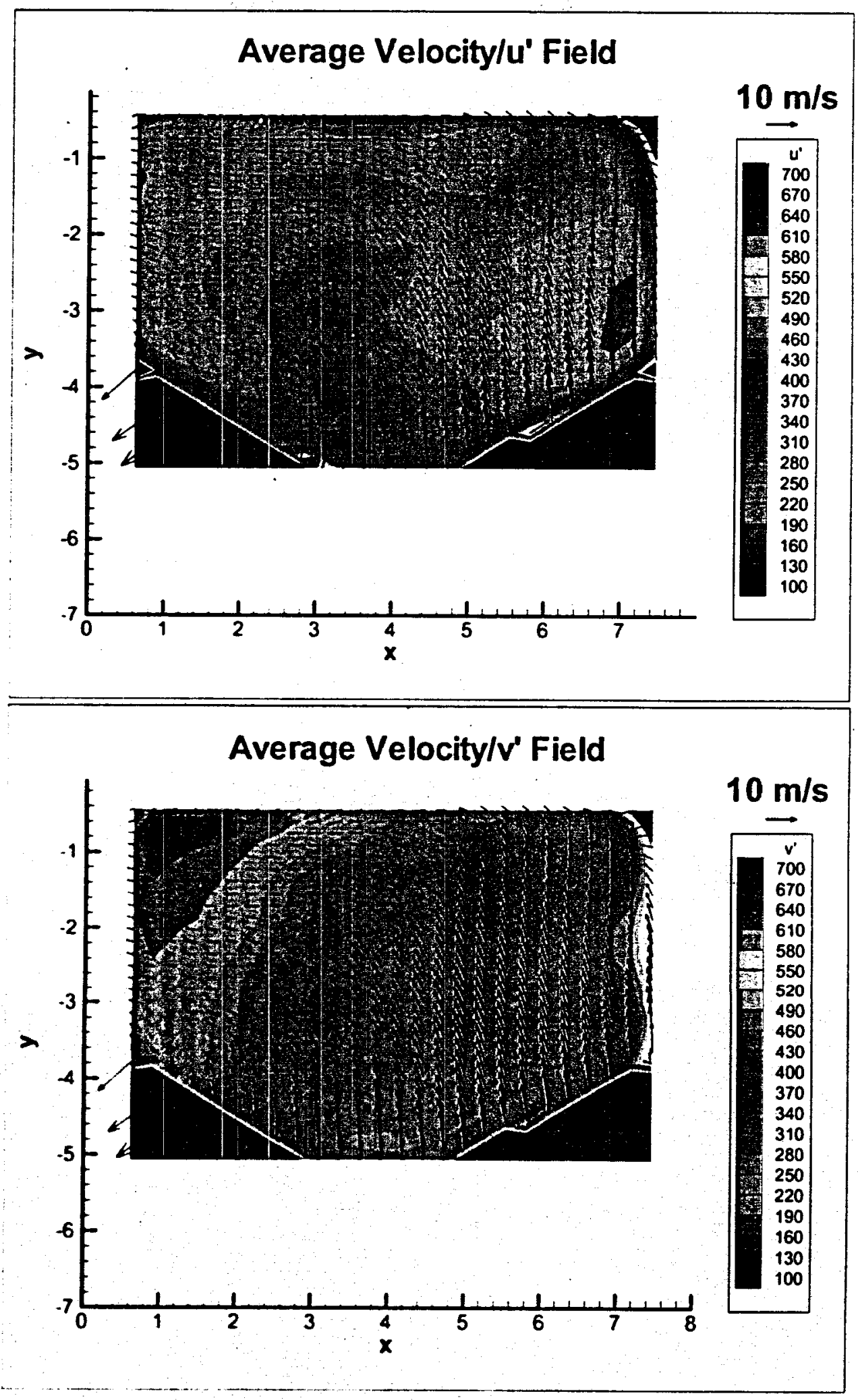

Figure 37: Average Velocity' $\mathbf{u}^{\prime} / \mathrm{v}^{\prime}$ Fields for the crank angle of 270 at 1500 $\mathrm{RPM}, 0$ in. $\mathrm{Hg}$ and excited at $2200 \mathrm{~Hz}$. 

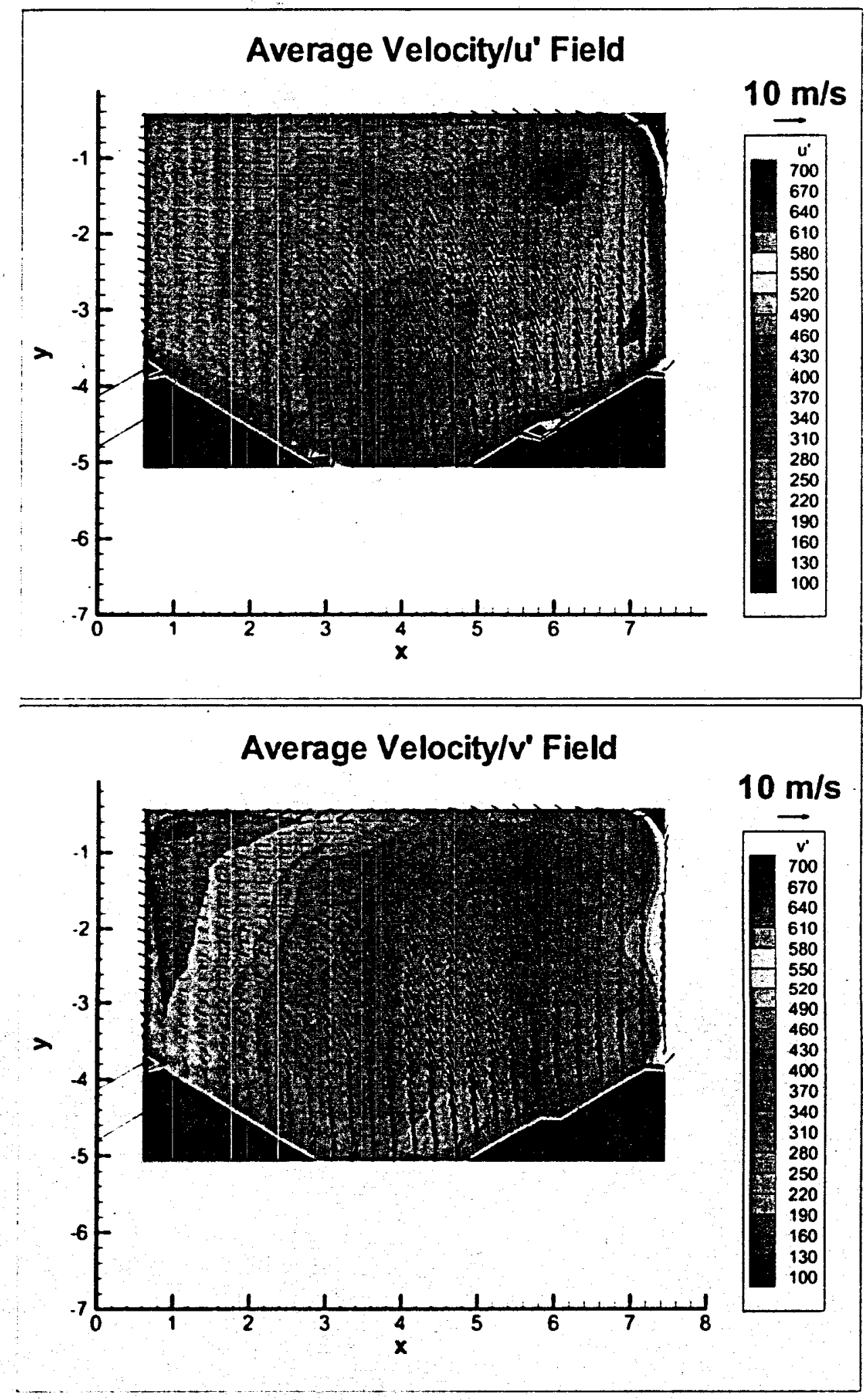

Figure 38: Average Velocity ${ }^{\prime} / \mathrm{v}^{*}$ Fields for the crank angle of 270 at 1500 RPM. 0 in. $\mathrm{Hg}$ and excited at $2300 \mathrm{~Hz}$. 

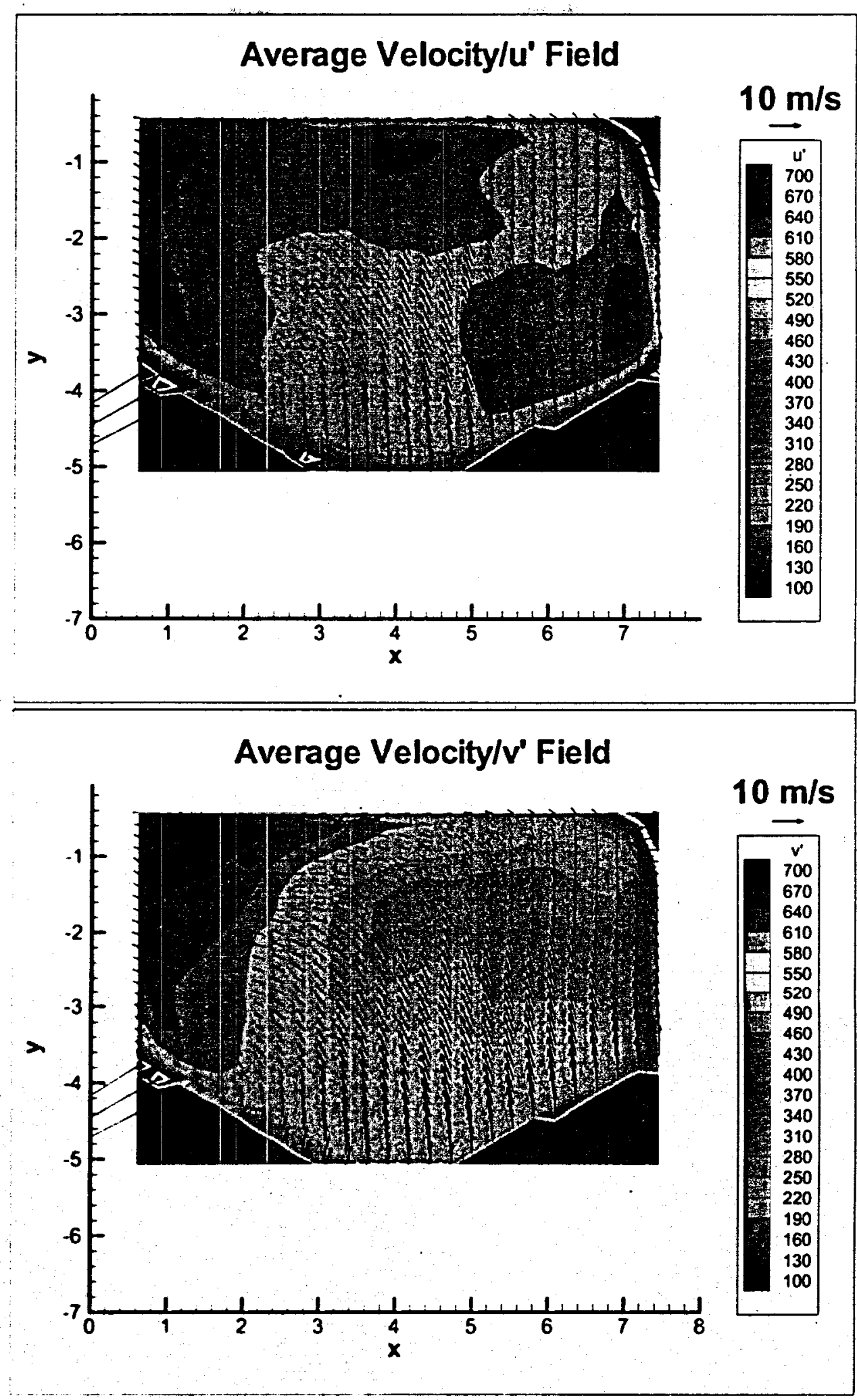

Figure 39: Average Velocity $/ \mathbf{u}^{\circ} / \mathrm{v}^{\prime}$ Fields for the crank angle of 270 at 1500 RPM, 0 in. $\mathrm{Hg}$ and excited at $2400 \mathrm{~Hz}$. 

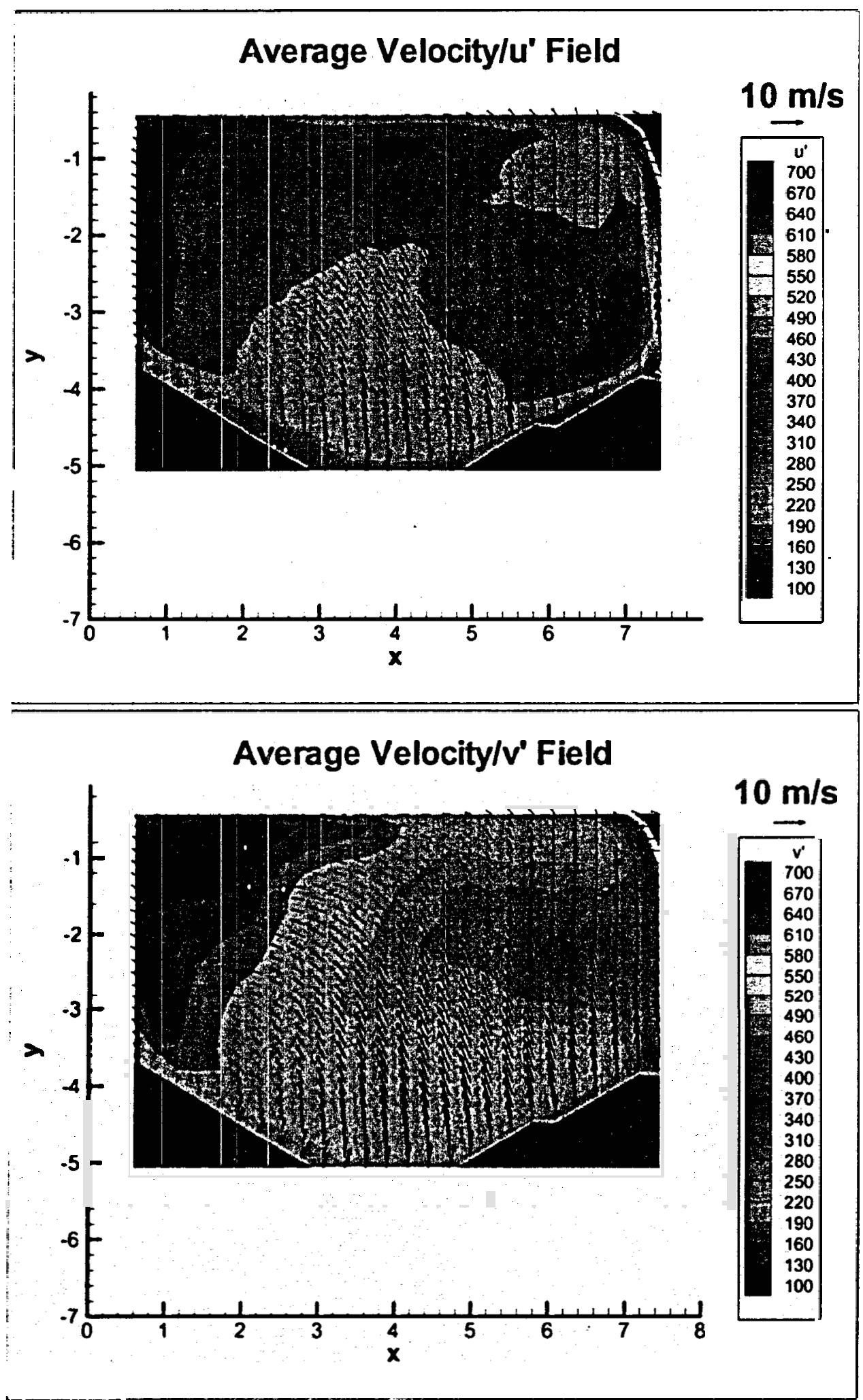

Figure 40: Average Velocity $\mathbf{u}^{\prime} / \mathrm{v}^{\prime}$ Fields for the crank angle of 270 a 1500 $\mathrm{RPM}, 0$ in. $\mathrm{Hg}$ and excited at $2500 \mathrm{~Hz}$. 


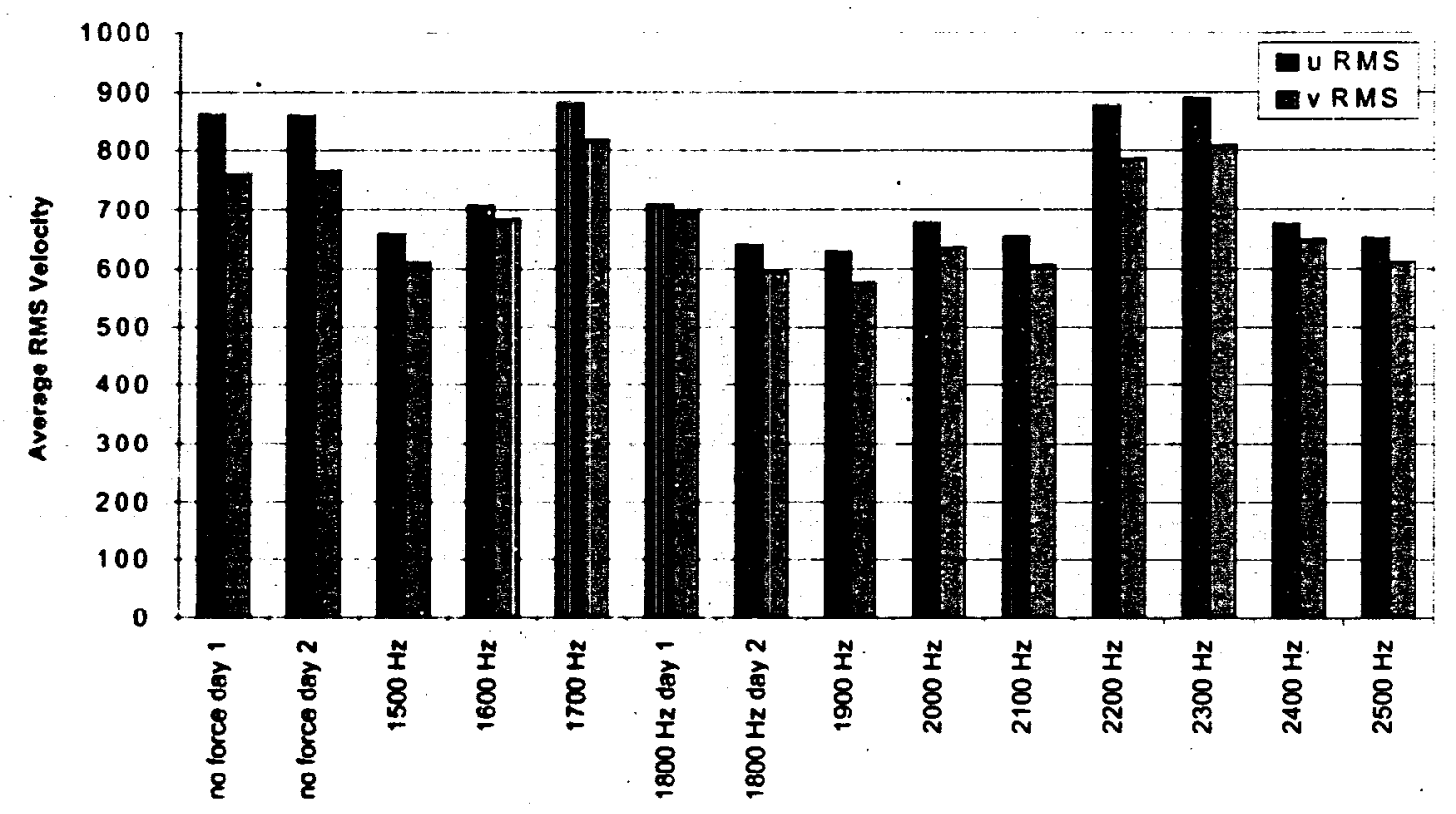

Figure 41: Average u and v RMS Velocities of Each Test Condition.

\subsection{Firing Rig}

The final results of testing on the single cylinder firing engine can be seen in Figure 42. Since measurements taken at wide open throttle showed little promise, it was decided to simply concentrate on the non forced condition and $1800 \mathrm{~Hz}$, the condition predicted to be the best. It appears that the active flow control produces very little difference in the average IMEP. In fact, there is more difference between the two non forced runs than between the between no force and $1800 \mathrm{~Hz}$. Furthermore, no evidence exists in the standard deviation plot in Figure 43, to suggest that the cycle-to-cycle variability of IMEP was improved. 


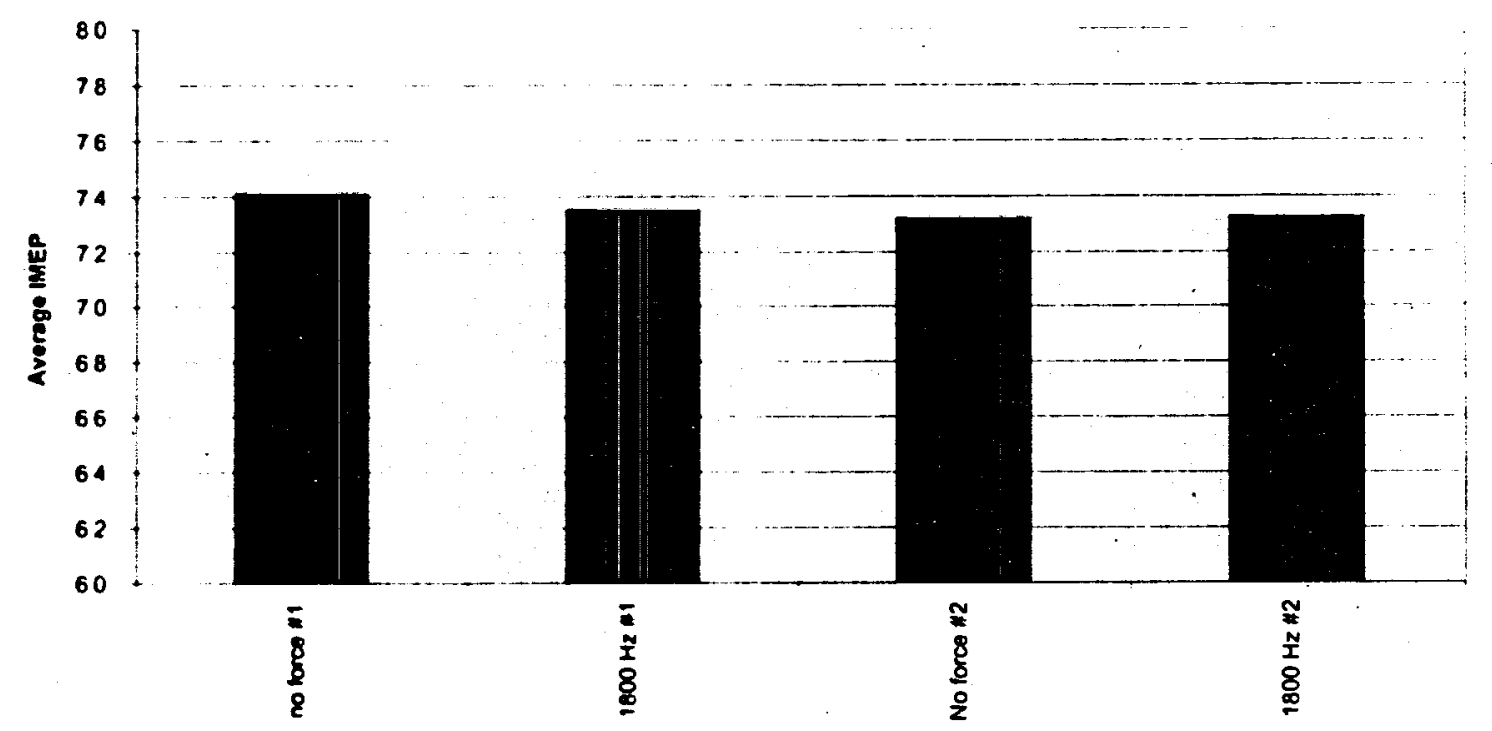

Figure 42: Average IMEP Calculated From Three Wavelengths of Cycles For the Firing Engine at $1500 \mathrm{RPM}$ and $14 \mathrm{in.} \mathrm{Hg.}$
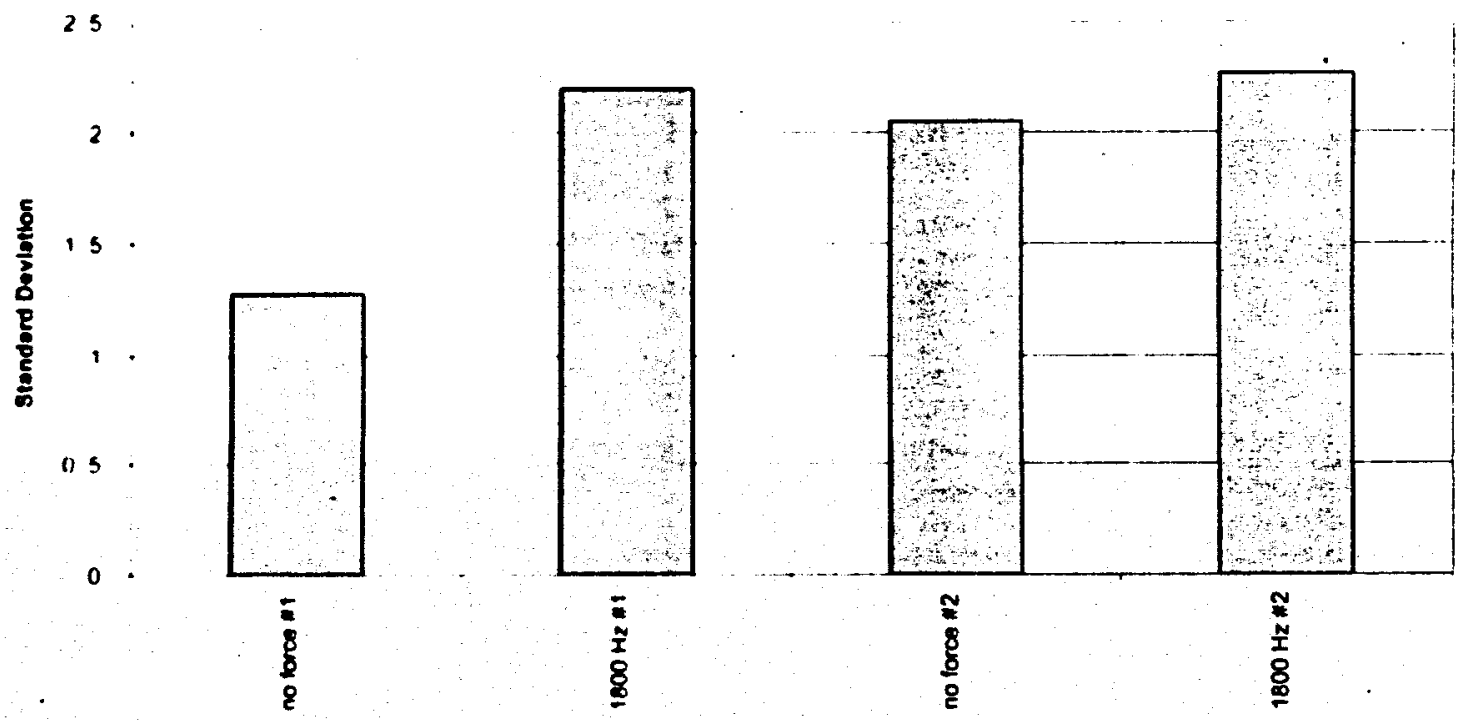

Figure 43: Standard Deviation Calculated From Three Wavelengths of Cycles For the Firing Engine at $1500 \mathrm{RPM}$ and 14 in. $\mathrm{Hg}$ 


\subsection{9L Ford}

The results of the experiments on the 1.9L 4 cylinder Ford engine can be seen in Figure 44 and Figure 45. It is evident that the active flow control has little effect on the IMEP of this engine. In fact, the difference between the no force condition and $1800 \mathrm{~Hz}$, the best case, is less than one percent. Likewise, the standard deviation, although relatively small, is essentially the same for each of the measured conditions.

To further investigate the small difference between the non forced case and the case of $1800 \mathrm{~Hz}$ excitation, a second test was run. This time, 2000 cycles worth of IMEP data would be stored for each set alternating between no force and the best case, $1800 \mathrm{~Hz}$. The results of this run can be seen in Figure 46 . From this plot we again see very little difference between conditions. In fact, the difference between two data sets of the same condition is just as large as the difference between conditions, implying the differences are due simply to experimental error.

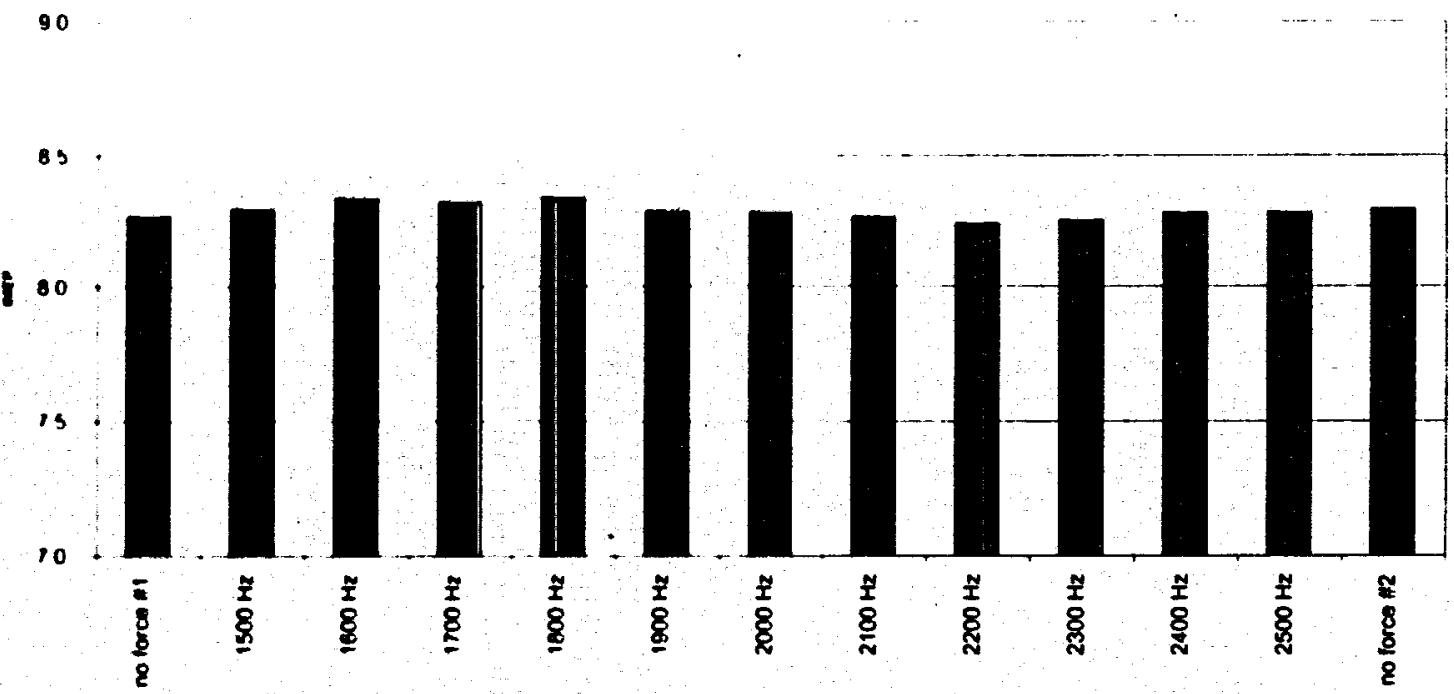

Figure 44: Average IMEP for the 1.9L 4 Cylinder Ford Engine at 1500 RPM and 14 in. $\mathrm{Hg}$. 


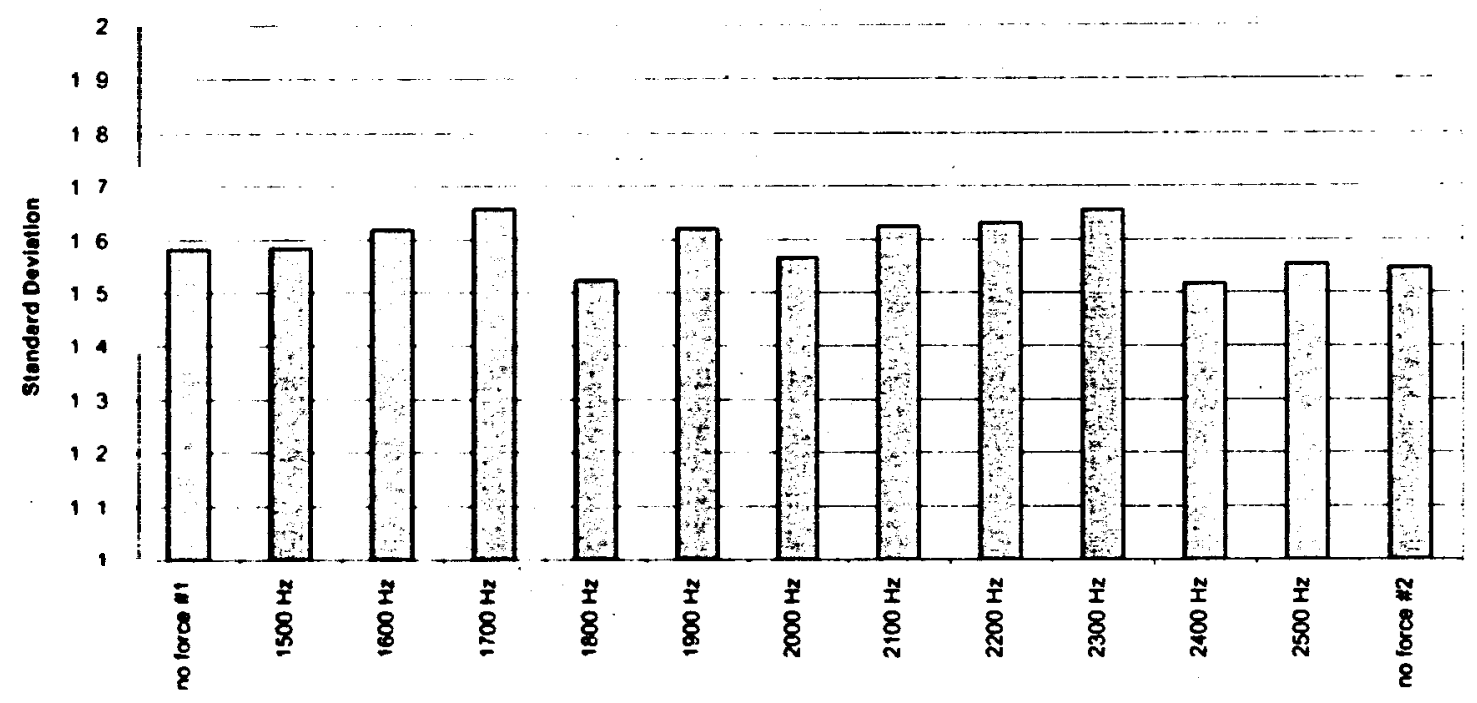

Figure 45: Standard Deviation of IMEP for the 1.9L 4 Cylinder Ford Engine at $1500 \mathrm{RPM}$ and $14 \mathrm{in.} \mathrm{Hg}$.

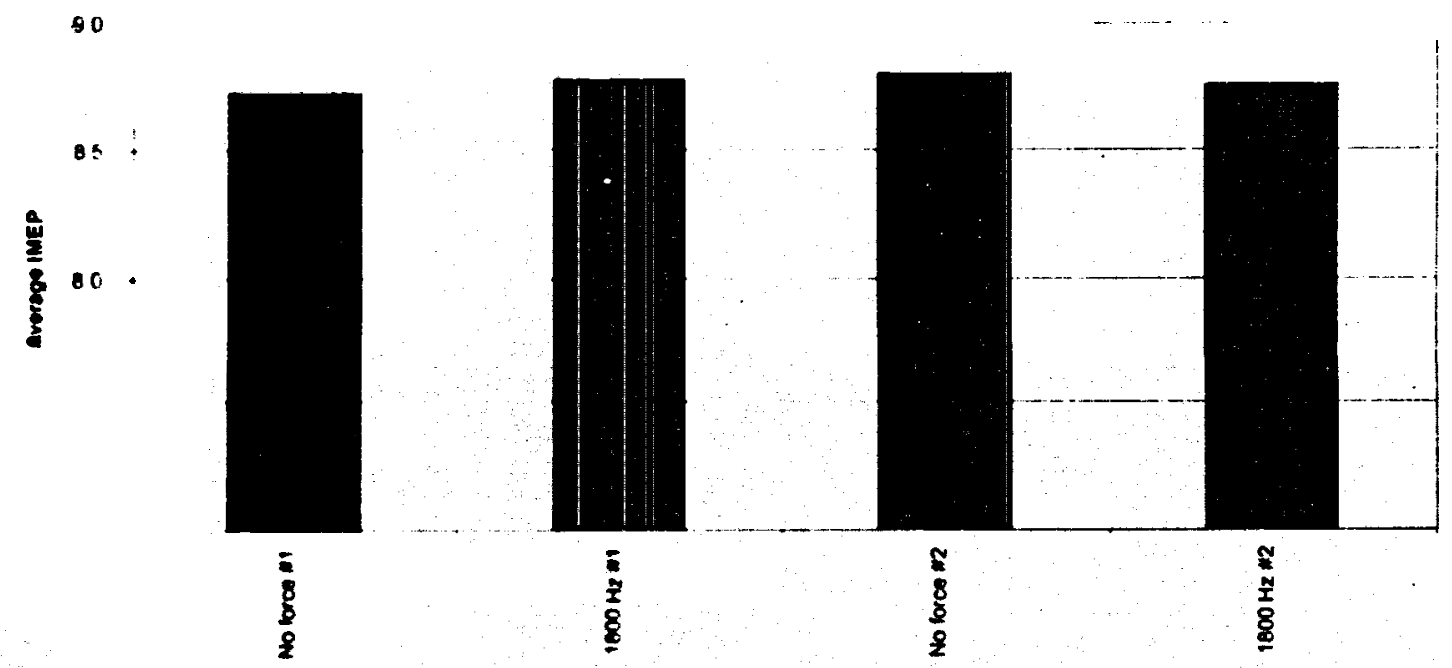

Figure 46: 2000 cycle Average IMEP for the 1.9L Ford Engine at 1500 RPM and 14 in. $\mathrm{Hg}$. 


\section{CHAPTER 5}

\section{Conclusions}

Two nearly identical engines have been designed and built to study the effects of active flow control on the in cylinder fluid motion, and in turn, the effect of the fluid motion on the performance of a running engine. Also, a third engine, a production 1.9L four cylinder Ford, was used to determine what effects the active flow control would have on an actual automotive engine. The main conclusions from the study are as follows:

1. The use of active flow control does affect the RMS velocities.

Reductions occur at many of the excitation frequencies, the maximum being approximately 25 percent at $1900 \mathrm{~Hz}$.

2. The average flow field in the tumble plane studied are not affected by the use of active flow control.

3. The combustion chamber geometry does not allow the generic firing engine to run properly at 1500 RPM and wide open throttle, making attempts to improve IMEP through active flow control useless.

4. Active flow control applied to the generic firing engine at 1500 RPM and 14.5 in. $\mathrm{Hg}$ showed no improvement in the average or standard deviation of IMEP.

5. When applied to the $1.9 \mathrm{~L} 4$ cylinder Ford engine, active flow control showed no evidence of improving performance.

Although the RMS of the velocities can be reduced through the use of active flow control, no positive effects are evident in the engine's performance. This suggest that engine performance cannot be significantly improved simply by lowering the rms of velocity. Therefore, there is no 


\section{. \\ reason to pursue further experiments with this type of active flow control}

device. 


\section{CHAPTER 6}

\section{Recommendations}

1. Before further investigation of this type of active flow control, a more robust and powerful excitation device should be developed, one possibility would be to use a linear motor to drive a diaphragm in the intake manifold.

2. Investigate the effect of introducing the extication through the valve itself similar to the water analog model study by Ambrose[1] rather than through the use of an upstream diaphram as in this study.

3. Future attempts to compare flow field data with running engine data should be done with a combustion chamber design more suitable for a SI gasoline engine than the flat head design used in this study. 
Appendices 


\section{Appendix A}

\section{Average Flowfields for Various Crank Angles}

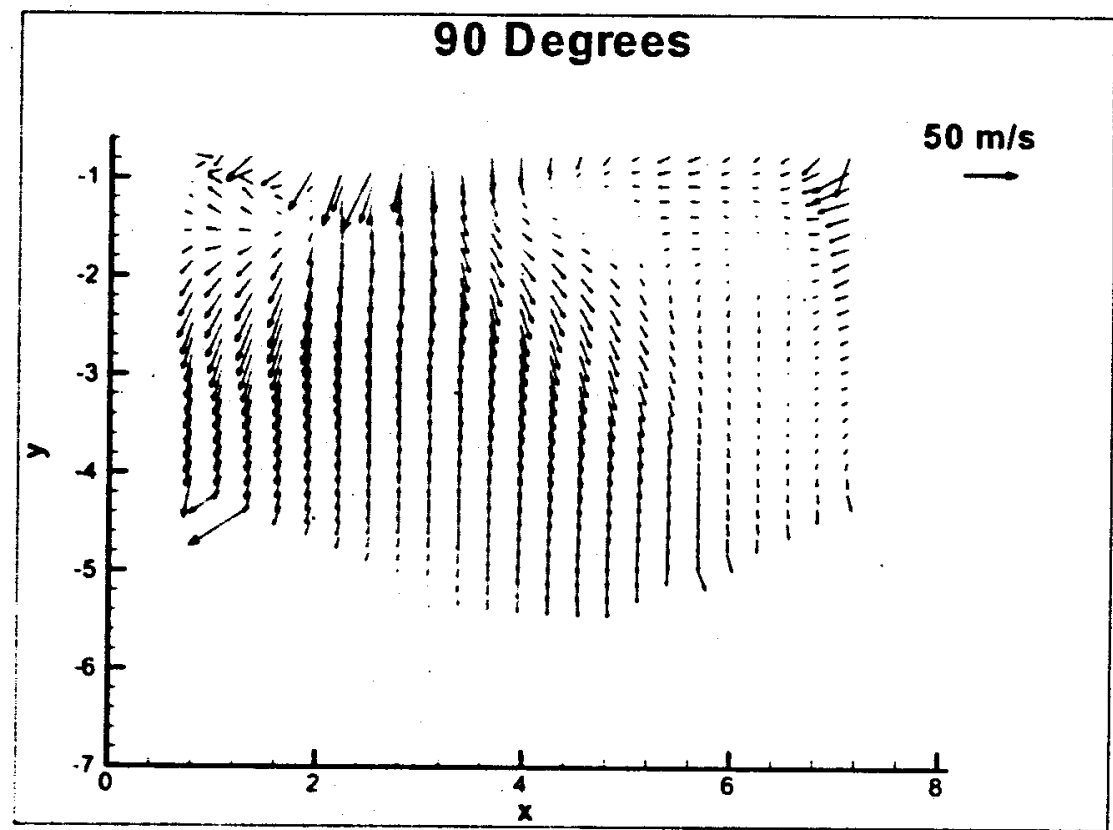

Figure 47: Average velocity field for the crank angle of 90 degrees, 1500 RPM, wide open throttle.

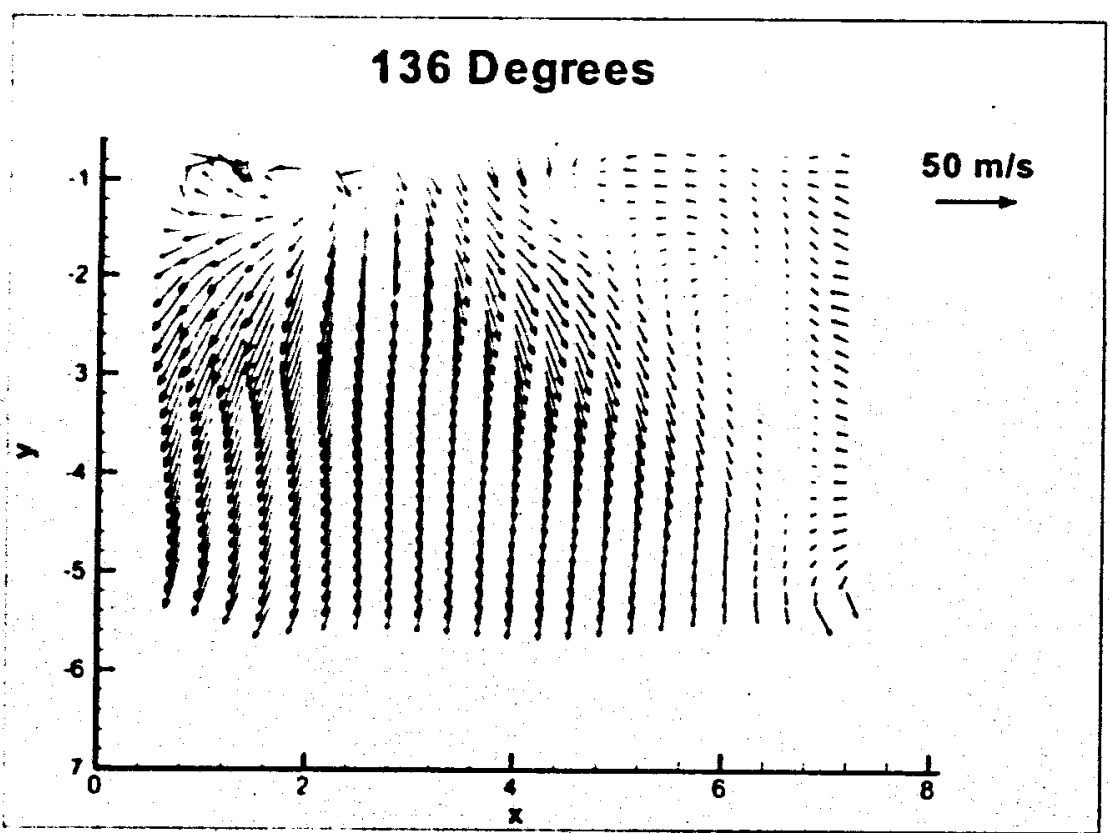

Figure 48: Average velocity field for the crank angle of 136 degrees, 1500 RPM, wide open throttle 


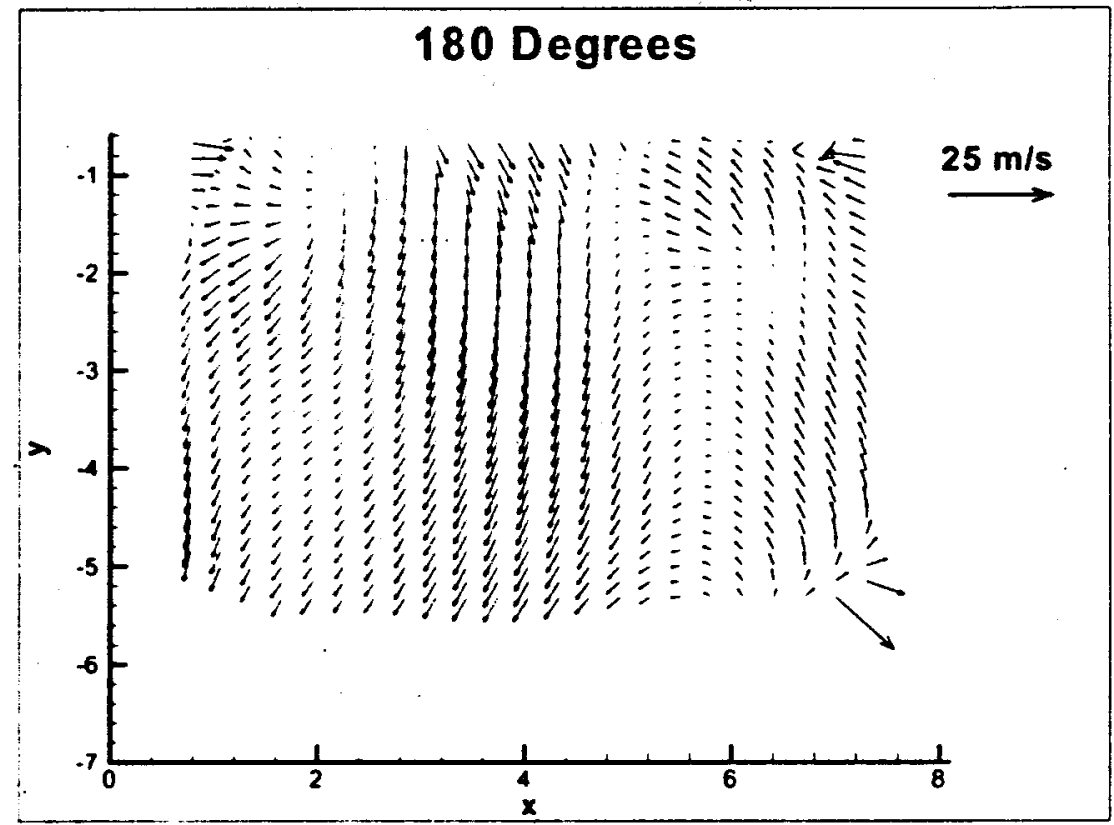

Figure 49: Average velocity field for the crank angle of 180 degrees, 1500 RPM, wide open throttle

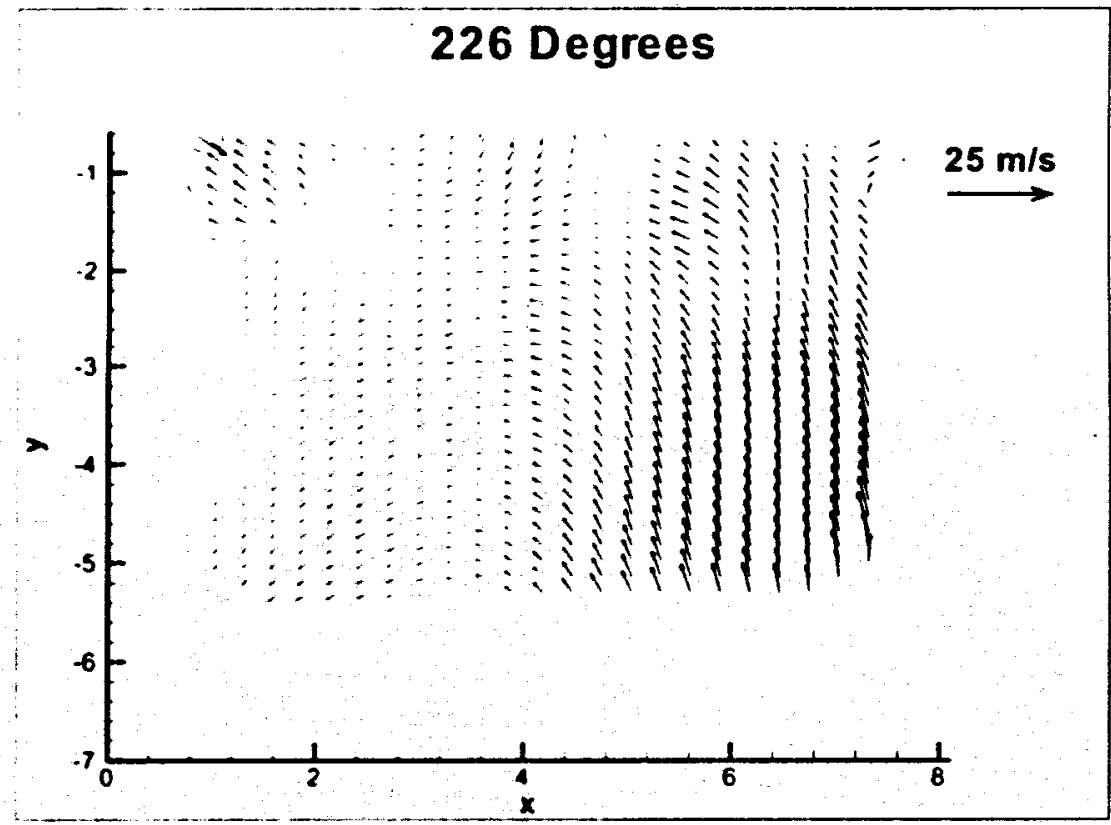

Figure 50: Average velocity field for the crank angle of 226 degrees, 1500 RPM, wide open throttle 


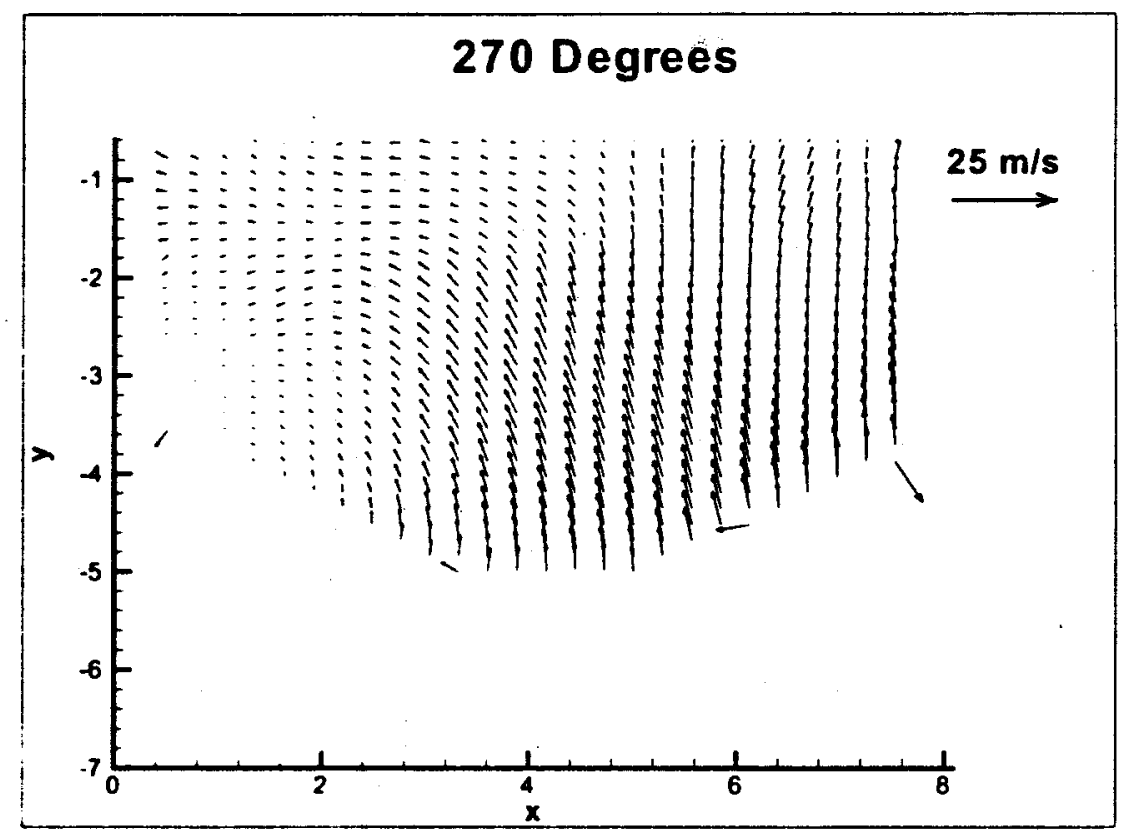

Figure 51: Average velocity field for the crank angle of 270 degrees, 1500 RPM, wide open throttle 


\section{Appendix B}

\section{Disassembly of Firing Rig}

Upon completion of the tests the single cylinder firing rig was disassembled and inspected. The combustion chamber was found to contain a surprisingly large amount of carbon deposits. Inspection of the piston would reveal that the heavy carbon was a result of the failure of the oil control ring as well as the lower compression ring. Also of note was the scoring of the cylinder walls and the piston skirt. Although the exact cause of the excessive wear is not known, there are two known possible causes. The first is that when the injectors were initially being calibrated, possibly too much fuel was injected when the engine was not firing. This could have washed the walls of oil, thus causing the piston to overheat. The second possibility is that the piston skirt may have protruded too far out of the bottom of the cylinder bore at BDC. The cylinder and head combination has been used for previous experiments at the Michigan State University Engine Research Laboratory; however, for this experiment the compression ratio was much lower, requiring a larger shim at the bottom of the cylinder. The difference in shim thickness was less than 1 centimeter, but this may have allowed the piston to extend far enough out of the bottom of the bore to rotate about the piston pin and place excessive force on the piston skirt/cylinder wall interface, thus overheating the piston. 


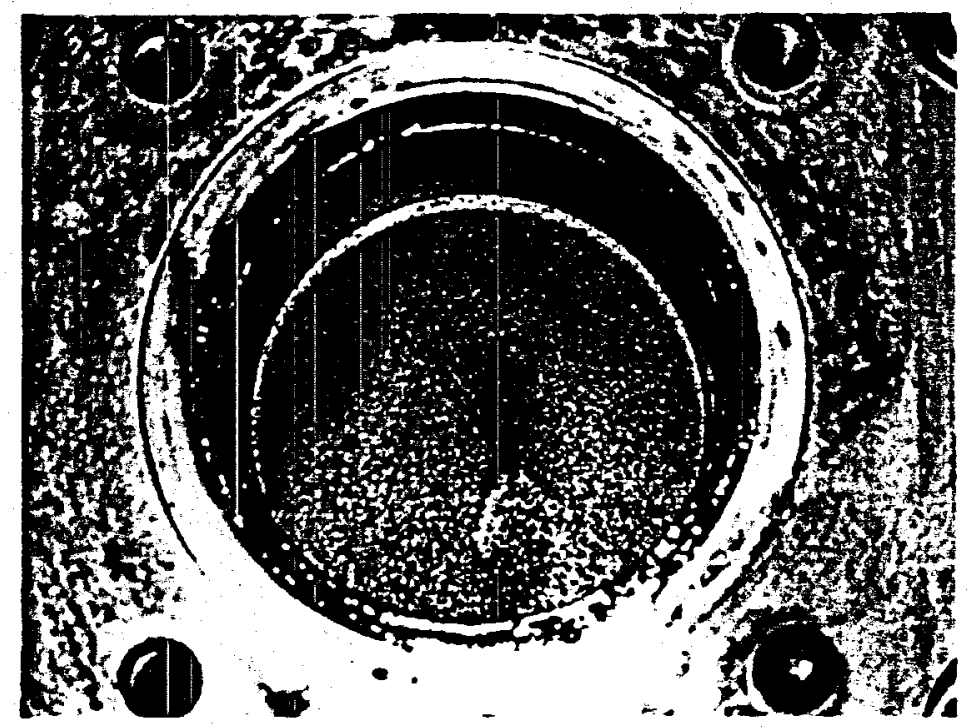

Figure 52: Single cylinder firing rig with head removed after testing.

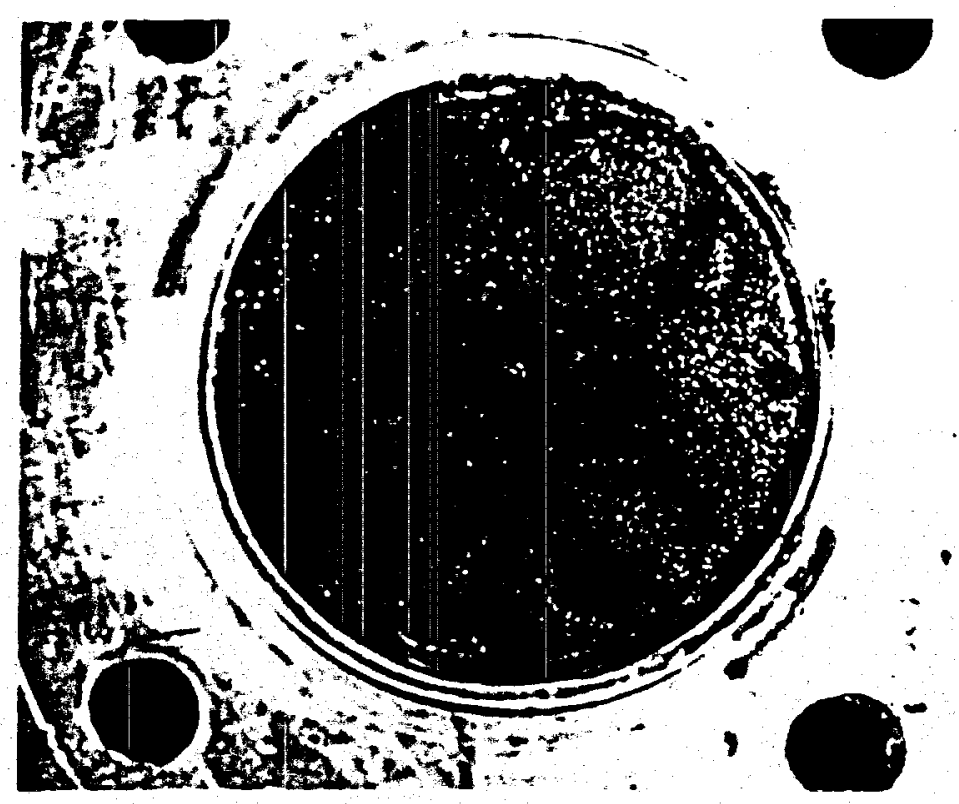

Figure 53: Cylinder head from single cylinder firing rig after testing. 



\section{Appendix C}

\section{Discussion of Indicated Mean Effective Pressure}

The performance for the firing engines in this study is measured in terms of Indicated Mean Effective Pressure (IMEP). IMEP relates to the work output per unit swept volume and is defined as:

$$
\text { IMEP }=\frac{\text { indicated work output per cylinder per mechanical cycle }}{: \text { swept volume per cylinder }}
$$

[13] This can also be seen graphically in the pressure verses volume plot in Figure 55. The graph contains two loops, the top which represents the work done on the piston by the combustion process and the bottom which represents the pumping work performed by the piston to draw fresh charge into and expel spent charge out of the cylinder. The area of the top loop (shaded in blue) is the IMEP. The area of the lower loop is known as the Pumping Mean Effective Pressure, and can be subtracted from the IMEP to get the net work done on the piston per cycle or net IMEP. In this study, however, all of the data is in terms of gross IMEP since the available equipment made for PMEP values of questionable accuracy. 


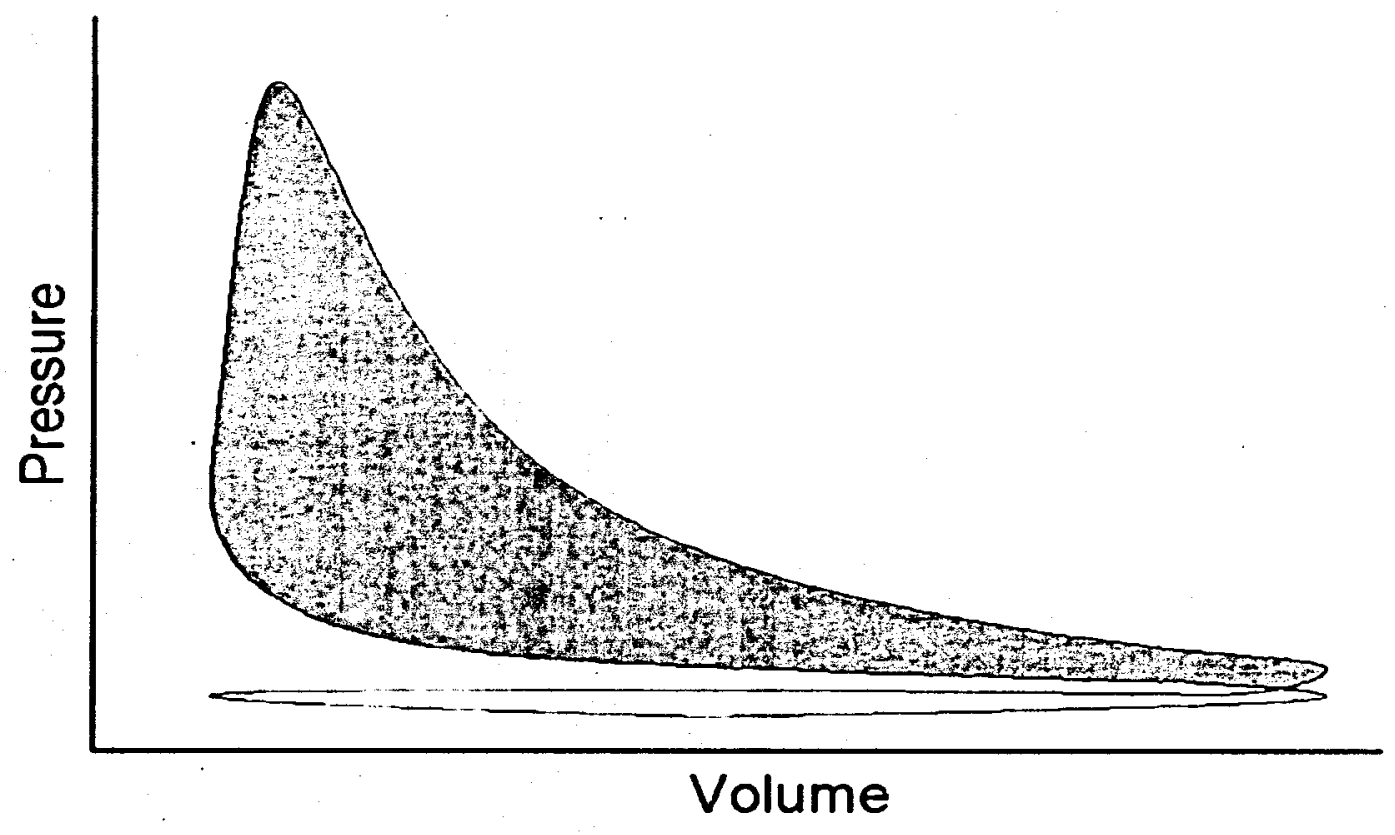

Figure 55: Typical Pressure vs. Volume diagram for a four cycle spark ignition engine. 


\section{References}




\section{References}

1. Ambrose, G, "A Study of the Effects of Exciting the Intake Flow in an Internal Combustion Engine Model." Master's Thesis, Michigan State University, 1997

2. Cohn, R. K., and Koochesfahani, M. M., "The Accuracy of Remapping Irregularly Spaced Velocity Data onto a Regular Grid and the computation of Vorticity." Experiments in Fluids, pp. S61-S69, 2000

3. Gendrich, C. P., and Koochesfahani, M. M., "A Spatial Correlation Technique for Estimating Velocity Fields Using Molecular Tagging Velocitrimity (MTV)." Experiments in Fluids, Vol. 22, pp. 67-77, 1996

4. Gendrich, C. P., and Koochesfahani, M. M., and Nocera, D. G., "Molecular Tagging Velocitrimity and Other Novel Applications of a New Phosphorence Supermolecule." Experiments in Fluids, Vol. 23, pp. 361-372, 1997

5. George, S., "Test Stand Design for a High Compression, Direct-Injection Spark-Ignition Methanol Fueled Engine and Results of Various Engine Configurations." Master's Thesis, Michigan State University, 2000

6. Goh, A. C. H., "Active Flow Control for Maximizing Performance of Spark-Ignited Stratified Charge Engines." Master's Thesis, Michigan State University, 2001

7. Hill, R. B., and Klewicki, J. C., "Data Reduction Methods for flow Tagging Velocity Measurements." Experiments in Fluids, Vol. 20, pp. 142-152, 1991

8. Hussain, A. K. M. F., and Zaman, K. M. B. Q., "The 'Preferred Mode' of the Axisymmetric Jet." Journal of Fluid Mechanics, Vol. 110, pp, 39-71, 1981 
9. Koochesfahani, M. M., and MacKinnon, C. G., "Influence of Forcing on the Composition of Mixed Fluid in a Two-Stream Shear Layer." Physics of Fluidus A, Vol. 3, pp. 1135-1142, 1991

10. Koochesfahani, M. M., and Stier, B., "Molecular Tagging in Gas Phase and its Application to Jet Flows." ASME Fluids Engineering Devision Summer Meeting, FEDSM'97, 1997

11. Stier, B. and Koochesfahani, M. M.. "Molecular Tagging Velocitrimity (MTV) measurements in Gas Phase Flows." Experiments in Fluids, 26 (4), pp. 297-304, 1999

12. Stier, B. and Koochesfahani, M. M., "Whole Field MTV Measurement in a Steady Flow Rig Model of an IC Engine." SAE Paper 980481, 1998

13. Stone, R., "Introduction to Internal Combustion Engines." Third Edition, SAE International, 1999

14. Zaman. K. M. B. Q.. and Hussain, A. K. M. F., "Vortex Pairing in a Circular Jet Under Controlled Excitation. Part 1. General Jet Response." Journal of Fluid Mechanics, Vol. 101, part 3, pp. 449-491, 1980 